University of Rhode Island

DigitalCommons@URI

Open Access Dissertations

1979

\title{
The Development of Imagination: The Relationship Between \\ College Students' Retrospective Reports of Parent-Child Interactions and Imaginal Activity in Everyday Life
}

Martin W. Ham

University of Rhode Island

Follow this and additional works at: https://digitalcommons.uri.edu/oa_diss

\section{Recommended Citation}

Ham, Martin W., "The Development of Imagination: The Relationship Between College Students' Retrospective Reports of Parent-Child Interactions and Imaginal Activity in Everyday Life" (1979). Open Access Dissertations. Paper 1040.

https://digitalcommons.uri.edu/oa_diss/1040

This Dissertation is brought to you for free and open access by DigitalCommons@URI. It has been accepted for inclusion in Open Access Dissertations by an authorized administrator of DigitalCommons@URI. For more information, please contact digitalcommons-group@uri.edu. 
THE DEVELOPMENT OF IMAGINATION:

THE RELATIONSHIP BETWEEN COLLEGE STUDENTS' RETROSPECTIVE REPORTS OF PARENT-CHILD INTERACTIONS AND

IMAGINAL ACTIVITY IN EVERYDAY LIFE

BY

MARTIN W. HAM

A DISSERTATION SUBMITTED IN PARTIAL FULFILIMENT OF THE REQUIREMENTS FOR THE DEGREE OF

DOCTOR OF PHILOSOPHY

IN

PSYCHOLOGY

UNIVERSITY OF RHODE ISIAND

1979 
ABSTRACT

The objectives were two-fold: 1) to determine the extent to which current models of parent-child interactions and imaginal activity are an artifact of the level of data analyzed, and 2) to determine to what extent and in what manner interactions with both parents are related to the imaginal activity of young adults. It was anticipated that the study would help illuminate the antecedent conditions that are associated with various patterns of imagining.

The subjects were 229 college students who participated in two group testing sessions. In the first session, subjects completed the 344-item Imaginal Processes Inventory developed by Singer and Antrobus (1970). During the second session, subjects were asked to retrospectively rate their parents' behavior toward them on Schaefer's Children's Report of Parental Behavior Inventory (1965a). Separate 192-item father and mother response forms were administered in counterbalanced order.

The items from both forms of the CR-PBI and from the IPI were separately analyzed using the MAP method of principal components analysis with varimax rotation. The results failed to support the present scoring systems for either inventory. Further, there were significant discrepancies between identified components and current models of both parent-child interactions and imaginal activity. With respect to parent-child interactions, for both the father and the mother, the majority of identified variance was accounted for by three components. In both sets, a bipolar component representing parental support was 
identified. Beyond this, however, there was little cross-identification between components. For the father, the other major components related to authoritative control and control through love withdrawal, whereas for the mother, they referred to authoritarian control and detached control. With regard to imaginal activity, three major components relating to the qualitative aspects of the imagining experience were identified. These included: the emotional tone of daydreaming, absorption in daydreaming, and prospective daydreaming.

Relationships between the imaginal variables and the parent variables developed from the principal components analyses were examined using Pearson correlations, as well as regression and canonical correlation to assess the multivariate relationships between the sets of data. Results indicated that 1) imaginal activity was related to control exerted by both parents within the context of emotional support, and 2) imaginal activity was more highly associated with the quality of interaction with the opposite-sex parent, particularly with regard to females. Overall, however, the results were not as promising as anticipated; relationships accounted for only a small proportion of the variance and predictive power was not substantially enhanced by the addition of variables to either the independent or dependent variable sets.

The results relating to both the structure of parent-child interactions and imaginal activity and the relationships between these domains are discussed in terms of correspondence to previous findings and implications for future research. 


\section{ACKNOWLEDGEMENTS}

This study would not have been possible without the unselfish support and assistance of many people. First, I want to thank the individuals who participated in this research, for without them, this study would not have been possible. I also thank the members of my committee for their interest and concern in the study as well as their expert knowledge and guidance throughout. I am particularly grateful to Wayne Velicer who, along with Bill Zwick, made the data analysis a reality.

I am also indebted to the many friends and colleagues who, through many years, have consistently supported this and other endeavors. A special debt of gratitude goes to Nick Spanos who has unselfishly given innumerable hours in discussing and encouraging my research interests and who has served as a constant source of inspiration for new ideas. I am also particularly grateful to my friends at wollaston II for their support, understanding and tolerance.

Last, but certainly not least, I want to express my appreciation to my parents and my wife. For my parents, I feel both love and gratitude. They have always offered encouragement, guidance, and inspiration. My wife, Marie, is one of the most giving and patient people in the world. Her love and encouragement has kept me from setting my sights too low. 
TABLE OF CONTENTS

Chapter

Page

ABSTRACT. . . . . . . . . . . . . . . . $i$

ACKNOWLEDGEMENTS. . . . . . . . . . . . . . . iii

LIST OF TABLES. . . . . . . . . . . . . . . . V v

LIST OF APPENDICES. . . . . . . . . . . . . . . vii

INTRODUCTION. . . . . . . . . . . . . . . . . 1

I THE DOMAIN OF IMAGINATION . . . . . . . . . . 5

II EMERGING TRENDS: PARENT-CHILD RELATIONS

AND HUMAN DEVELOPMENT . . . . . . . . . . . . . . 23

III OVERALL AIM OF THE RESEARCH . . . . . . . . . . . 41

IV METHODOLOGY . . . . . . . . . . . . . . . 43

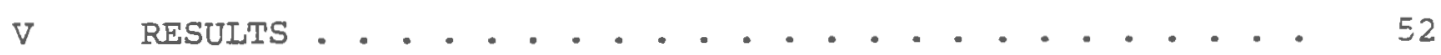

VI DISCUSSION. . . . . . . . . . . . . . . . 128

APPENDICES. . . . . . . . . . . . . . . 146

REFERENCES. . . . . . . . . . . . . . . 153 


\section{LIST OF TABLES}

Table

Page

I Subject and Family Background Characteristics. . . . . .

2 Items Loading $>.40$ on the Varimax Rotated Components of the Father Version of the CR-PBI . . . . . 56

3 Items Loading $>.40$ on the Varimax Rotated Components of the Mother Version of the CR-PBI . . . . . 70

4 Cross Classification of Items Between the Components of the CR-PBI (F.R.F.) and the Original Scales. . . . . . . . . . . . . . . . .

5 Cross Classification of Items Between the Components of the CR-PBI (M.R.F.) and the Original Scales. . . . . . . . . . . . . . . . . .

6 Cross Classification of Items Between the Father and Mother Components. . . . . . . . . . . 88

7 Intercorrelations of Father and Mother Variables . . . . .

8 Items Loading $>.40$ on the Varimax Rotated Components of the IPI (Items 1-172). . . . . . . . . . 92

9 Items Loading $>.40$ on the Varimax Rotated Components of the IPI (Items 173-344). . . . . . . . . 96

10 Items Loading $>.40$ on the Varimax Rotated Components of the Stage 1 Analysis . . . . . . . . . 103

11 Cross Classification of Items Between the Components of the IPI and the original scales. . . . . . 114

12 Summary of Parent-Child Interaction and Imaginal Activity Scales. . . . . . . . . . . . . 115 
13 Intercorrelations Among Parent Variables and Imaginal Variables (Male Subjects) . . . . . . . . 120

14 Intercorrelations Among Parent Variables and Imaginal Variables (Female Subjects) . . . . . . . . . 122 


\section{LIST OF APPENDICES}

Appendix

Page

A Scales and Sample Items of the Imaginal

Processes Inventory. . . . . . . . . . . . . . 147

B Scales and Sample Items of the Children's

Report of Parent Behavior Inventory. . . . . . . . 150

C Eigenvalues for the First Twenty-Five

Components from the Principal Components

Analyses of the CR-PBI and the IPI . . . . . . . 152 
INTRODUCTION

Cognitive activity subsumed urder the various terms of imagination, daydreaming, fantasy, and reverie comprises a major segment of waking life. While most likely to occur just prior to going to sleep (Singer, 1975), such activity is clearly not limited to this period of our lives and is seemingly interspersed amongst all other types of activity. Thus, as klinger notes, this aspect of cognitive functioning would seem to carry

- . important implications from the standpoint of behavioral science. The structure of so common an activity most probably carries profound significance for the organization of human behavior generally. Furthermore, in a species that has evolved through such extended molding by natural selection, so prominent an activity as (this) is likely to exercise important functions in the adaption of the organism (Klinger, 1971; pg. 4).

Despite the apparent significance of such cognitive activity, for more than a generation this aspect of human behavior has been considered to be more within the province of the artist, the poet, and the novelist than the behavioral scientist. In large part, this considered neglect has been a consequence of the disillusionment with the introspectionist 
research of Wundt and Titchener, and the behavioristic wave that swept over American psychology. So complete was the rejection of inner experience as a subject of scientific inquiry that not until 1966 was a book published in this country that devoted itself entirely to the examination of imaginative activity.

The years since the appearance of Singer's Daydreaming (1966) have, however, witnessed a renewed interest in cognitive functioning, in general, and in imagination, in particular. Somewhat ironically, one area where this trend can be most clearly seen is in the application of learning theory concepts to human social behavior. In the latest formulation of social learning theory, Bandura (1977) proposes that human behavior cannot be fully understood on the basis of antecedent inducements and response feedback influences alone. Rather, he contends that the effects of external influences on human functioning are mediated by cognitive factors. Specifically, cognitive factors determine, in part, which external events are attended to and retained, how the information they convey will be evaluated and organized for future use and, thus, what effect they will have in the future. Moreover, through cognitive operations, prospective actions may be evaluated in terms of the relative effort required, the potential risks and benefits involved, and the subjective probabilities of achieving the desired outcome.

Along similar lines, there has been a growing recognition, in recent years, of the role of cognitive activity in hypnosis. Such theorists as Barber (1972), J. R. Hilgard (1974), Sarbin and Coe (1972), Shor (1970), and Spanos (1973) have proposed that hypnotic behavior entails involvement in imaginings generated by and consistent with verbal 
suggestions. These formulations are supported by a growing body of experimental evidence (summarized in Barber \& Ham, 1974; Barber, Spanos \& Chaves, 1974) indicating that; a) successful hypnotic subjects tend to report a high level of imaginative activity in everyday life; b) suggestions are more likely to be experienced when they direct the subject to engage in imaginings that are consistent with the aims of the suggestion; c) highly suggestible subjects tend to report imaginings that are more elaborate and of longer duration than those of subjects rated medium or low in suggestibility; and d) the procedures most effective in increasing suggestibility consist of training subjects to become involved in suggestion-related imaginings.

Concurrent with the examination into the function of imagination in human behavior, there is a rapidly growing body of research focusing directly on delineating the nature and structure of imagination. While much has been accomplished, there are many obvious gaps in our knowledge. Perhaps the most glaring of these relates to the influence of environmental factors on the development of imagination. For the most part, developmental studies have been normative in nature, focusing on age trends in predisposition toward and content of imaginative activity (e.g., Giambra, 1974; Piaget, 1962; Singer, 1966). Moreover, with only a few exceptions, those studies which have attempted to examine environmental influences have suffered from such numerous methodological deficiencies as to make their findings of limited utility. In light of these considerations, this dissertation was designed to provide basic data on the relationship between imagination and a set of prominent 
factors in the developing child's environment; the behavior of the parents toward the child.

This dissertation is divided into eight chapters. The first delineates the domain of imagination by providing an overview of previous attempts to conceptualize and operationalize imagining, and the current focus of research on this topic. The second provides a detailed discussion of research relating parental-behavior characteristics to cognitive and personality development. The third involves a synthesis of the ideas formulated in the first two chapters in the form of testable hypotheses. The fourth chapter describes the methodology for the study. The fifth presents the results of the study, and the sixth discusses the implications of these results. 
THE DOMAIN OF IMAGINATION

In the present chapter, an attempt will be made to delineate the domain of imagination. In so doing, three issues will be considered; first, the theoretical conceptualization of imagination, second, the manner in which this concept has been operationalized, and finally, emerging trends in research on imagination.

\section{The Concept of Imagination}

While Klinger (1971) is quite accurate in noting that there are no generally accepted criteria for discerning the boundaries of imagination, there appears to be adequate consensus among investigators to formulate a working definition. Specifically, there would seem to be general agreement that imagination entails a shift in attention away from the immediate physical environment and, thus, encompasses all mental activity which is not evaluated by the individual in terms of its usefulness in achieving some extrinsic goal. This conceptualization of imagination has been most clearly explicated by schutz (1967) in his discussion "On Multiple Realities."

The natural attitude of daily life. According to Schutz, man's day-to-day interactions with his physical and social environment are guided by a set of assumptions relating to what is real and what is not. These assumptions, termed the natural attitude, serve as a frame of 
reference from which the individual integrates and interprets his experiences. Schutz has characterized the natural attitude in the following manner:

It is the world of physical things, including my body; it is the realm of my locomotions and bodily operations; it offers resistances which require effort to overcome; it places tasks before me, permits me to carry through my plans, and enables me to succeed or to fail in my attempt to attain my purposes. By my working acts I gear into the outer world, I change it; and these changes, although provoked by my working, can be experienced and tested both by myself and others, as occurrences within this world independently of my working acts in which they originated. I share this world and its objects with Others; with Others, I have ends and means in common; I work with them in manifold social acts and relationships, checking the others and checked by them (pp. 226-227). As is evident from this, the frame of reference of everyday life is viewed as possessing three primary characteristics. First, from the natural attitude, selective attention is directed toward the immediate physical and social environment; that is, toward objects and events which are either already within the individual's sphere of manipulation and perception or can be brought within it by his own actions. Second, the natural attitude is governed by a pragmatic motive in the sense that the world is seen as something to be altered by our actions or that alters our actions. It follows from this that all cognitive activity within 
this frame of reference is operational in nature. The intent of all thinking is to "gear into" the world through action and, as such, is continually guided by the consequences of action. Finally, the world of the natural attitude is viewed as being intersubjective. When operating within this frame of reference, the individual suspends doubt as to whether others' perceptions are the same. One additional property, not mentioned in the preceding quote, also figures prominently in Schutz's formulation. Specifically, cognitive activity and the resultant behavior is experienced as being volitional in nature; the individual defines himself as the causal agent that initiates and sustains these activities.

The attitude of imagining. While, according to schutz, the natural attitude of daily life is the "paramount reality," there are a number of other frames of reference from which the individual may operate. Alternative orientations include, play, religious experiences, scientific contemplation, dreaming, and imagining. Each is comprised of an internally consistent set of assumptions and a shift to one of these from the natural attitude implies a reorganization in what is attended to and the manner in which experiences are interpreted and defined.

With respect to the attitude of imagining, a shift to this orientation involves the suspension of the criteria of the natural attitude for determining reality. As a consequence, We have no longer to master the outer world and to overcome the resistence of its objects. We are free from the pragmatic motive which governs our natural attitude toward the world of daily life, free also from the bondage 
of 'interobjective' space . . . No longer are we confined within the limits of our actual, restorable, or attainable reach. What occurs in the outer world no longer imposes upon us issues between which we have to choose nor does it put a limit on our possible accomplishments (Schutz, 1967, pg. 234-5). In other words, when operating from the frame of reference of imagination, the individual is free of the constrictions of pragmatism and intersubjectivity which characterize the natural attitude. He is thus able to construe his experiences in a manner that would be considered impossible and unreal from the perspective of the natural attitude, and to do so without concern over detection from others.

Similar formulations of the attitude of imagining have been put forth by Shor (1959, 1962, 1970), Sarbin and Juhasz (1970), Singer (1966, 1975), and Klinger (1971). Parallels are perhaps most clearly apparent in Shor's concept of the "generalized reality orientation" and Sarbin and Juhasz' "hypothetical instantiation."

According to Shor (1959), our everyday activities are guided by a structured frame of reference. In all our waking life, this "generalized reality-orientation" is carried around in the background of our awareness and provides an implicit set of assumptions about the world which support, interpret and give meaning to all experience. However, under certain conditions such as involvement in mystical experiences, hypnosis, and imagination this orientation toward generalized reality fades into relatively nonfunctional unawareness. With this fading, ongoing experiences become isolated from their usual 
context. As a result of this, the individual becomes more receptive to internal sources of stimulation which could not have fit into the usual reality orientation. Moreover, without recourse to the logic, knowledge, and critical functions of the "generalized reality-orientation" these experiences may take on special meanings and reality.

A similar view toward the attitude of imagining has been expressed by Sarbin and Juhasz (1970). According to these investigators, a major activity of Man is making sense out of his sensations and experiences. This is accomplished through a process termed "instantiation"; that is, the categorization of inputs making contact with the cognitive system into instances of a general class. While this process is typically carried out at the literal level, the individual also has the ability to instantiate hypothetical occurrences. As a consequence of this, the individual is able to direct his attention away from the immediate environment and allow for stimulation at a distance, in terms of both space and time.

More specifically, Sarbin and Juhasz (1970) view the process of "hypothetical instantiation" or imagining as being characterized by two interrelated properties--time-binding and the semiotic function. The former refers to the process of inhibiting overt behavior while the individual places himself in a wide variety of more or less specific hypothetical situations. This allows him to rehearse future acts and to examine and manipulate the specifics of present or past actions. While this function bears some semblance to thinking and remembering, it differs in terms of both its greater degree of involvement and the fact that the hypothetical situations need bear no relationship to "reality." 
The semiotic function of imagining is closely related to time-binding and indicates the status of imagining as a signifier. Specifically, it relates to the imagining individual's ability to bridge the gap between the literal and figurative by imposing highly idiosyncratic, metaphoric codes on unpatterned inputs.

Although less thorough in their analyses, singer (1966, 1975), and Klinger (197I) attribute much the same properties to the concept of imagination. Singer (1966) has proposed that daydreaming "is used to mean a shift of attention away from an ongoing physical or mental task or from a perceptual response to external stimulation towards a response to some internal stimulus (p. 3)." Similarly, Klinger (1971), in his attempt to formulate a working definition of fantasy, makes particular note of both non-pragmatic and metaphorical properties.

Imagining and imaging. At this point in our discussion of the concept of imagination, it is important to draw a clear distinction between imagining and imaging. For several obvious reasons, these two concepts are frequently confused and the terms used interchangeably. First, in describing his imaginings the individual is more likely than not to use the visual idiom--"I saw it in my mind's eye" (Sarbin \& Coe, 1972). Moreover, as Spanos (1973) notes, imaginal activity is accompanied by a relative predominance of imagery, with productions spun primarily in terms of visual images.

Despite this overlap, there does not appear to be a functional relationship between the two processes. It is possible for individuals, who report a complete lack of imagery, to adopt the attitude of imagining (Shor, 1962, 1970). In addition, imagery can occur while the 
individual is operating from the framework of the natural attitude and is typically construed as "unreal" (Spanos, 1973). Thus, imagining should be taken to mean a frame of reference for integrating and interpreting experiences, and not the process of imagery.

Empirical evidence relating to the concept of imagination. The focus of this section has been on theoretical formulations of the process of imagining. As has been demonstrated, there appears to be a general concensus that imagining involves a shifting of attention away from the immediate external environment and the temporary development of an alternative frame of reference for organizing and defining experience. This alternate oxientation is generally characterized by the absence of such standards for evaluating experiences as pragmatism and intersubjectivity. In concluding this section, it would seem worthwhile to briefly consider a set of data which offers some preliminary support to this conceptualization.

With respect to the notion that imagining entails a shift in attention, a series of studies have been conducted by Singer and Antrobus assessing the interplay between internal and external stimulation (Antrobus, Antrobus \& Singer, 1964; Antrobus, Greenberg \& Singer, 1966; Singer \& Antrobus, 1964, 1967). The basic design was that of a visual signal detection experiment. The external environment was sharply restricted by seating the subject in a darkened room with limited opportunity for movement and feeding "white noise" through earphones. The subject's "inner" environment was controlled by setting up two alternating conditions--one in which inner activity was varied by requiring the subject to verbalize a continuous free association, and the 
other in which inner activity was limited to a narrow range by asking the subject to count out loud from one to nine continuously. Results indicated that: 1) the shift in attention to internal processes leads to a significant deterioration in detection of external stimuli; 2) the number of reports of task-irrelevant fantasies is reduced by increasing the complexity of the signal detection task; and 3) subjects who exhibit a greater predisposition to fantasy show more of a decrement in signal detection performance as the task proceeds. Taken together, these findings would seem to suggest that the process of imagining involves at least a partial shift in attention away from the external environment. With respect to the second notion (that the manner in which the individual construes his experiences is dependent on the frame of reference from which he is operating) a series of studies investigating the Perky phenomena (Segal, 1968, 1970, 1971; Segal \& Fusella, 1969; Segal \& Glicksman, 1967; Segal \& Gordon, 1969; Segal \& Nathan, 1964) appear to offer some preliminary support. In these studies, subjects were requested to imagine a variety of specific objects while, unbeknownst to them, the "imagined" objects were dimly projected on the blank screen before them. It was found that whether subjects attributed their "images" to external sources or to imagination was largely dependent on their expectancies. Thus, subjects were more likely to define experiences as arising from external stimulation when they were informed that stimuli might be flashed on the screen (Segal \& Fusella, 1969) or when they carried out the task while standing (a position associated with vigilance) (Segal \& Glicksman, 1967). On the other hand, subjects were more 
likely to construe their experiences as internally generated when they carried out the task while lying down.

\section{Methods of Assessing Imagination}

As suggested in the introduction, a primary cause for the rejection of imagining as a topic of scientific inquiry revolved around the issue of assessment; to paraphrase Watson, since inner experience is not observable, it cannot be legitimately studied. While it is still true that there are no adequate means of directly assessing imagining, this classic argument would appear to have more of the qualities of a "straw man" than a real obstacle. Other equally "unobservable" processes such as learning, memory, and attitudes are firmly established as comerstones of experimental psychology. This does not, however, release us from the obligation of assessing the adequacy of currently existing methods of measuring imagining.

In general, the wide range of approaches to operationalizing the concept of imagining fall into two broad categories--projective techniques and inventories. In the following sections, each will be considered in turn.

\section{Projective techniques. The use of projective techniques as} indices of an individual's imaginal capacity dates back to Rorschach's (1942) original abservation that individuals who produce a high frequency of human movement responses (M) to inkblots are, on the one hand, more controlled in their overt actions while, on the other, more given to attention to their own thoughts and imaginings. In the years since, the Rorschach $\mathrm{M}$ and its more recent adaptations (e.g., Barron's Movement Threshold Inkblots, Barron, 1955; Holtzman Inkblot Technique, 
Holtzman, 1968) have been the most popular projective measures of imaginative tendencies. Recently, however, the Thematic Apperception Test Transcendence Index (Weisskopf, 1950) has been achieving wider recognition and usage. Basically, this index is a measure of the extent to which the individual introduces characters, activities, and emotions not actually present on the stimulus card.

The numerous psychometric deficiencies of both the inkblot technique and the TAT are extensively documented (Anastasi, 1976) and carry serious implications for their use in any research work. Additional problems arise, however, when these techniques are applied to the study of imagining. Consideration of the procedures employed in both techniques raises serious question as to whether the "projected fantasies" which are obtained can be thought of as reasonable operationalizations of imagining (Klinger, 1971). Specifically, "projected fantasy" is defined as the overt response of the individual when presented with a standardized but ambiguous stimulus and is instructed by the examiner to communicate certain of his impressions of it. In sharp contrast to this, imagining has been conceptually defined as a covert process which does not involve a perceptual response to external stimulation or operant activity such as problem-solving in a task situation.

Perhaps more telling than this procedural issue is the fact that the relationship between "projected fantasy" and other indices of imagining is more of a generally accepted belief than a proven fact. Thus, a number of studies (Meltzoff, Singer \& Korchin, 1953; Singer, 1960; Singer, Meltzoff \& Goldman, 1952; Werner, 1945) have replicated 
Rorschach's initial observation of an inverse relationship between overt motility and the M response, and others (Singer \& Herman, 1954; Singer \& Opler, 1956) have demonstrated a relationship between the Transcendence Index and the M Response. However, as Singer (1966) points out, "The relationship of the $M$ response to imaginative behavior - . remains to be explored (pg. 85)." Similarly, Holt (1961) reports a number of substantive contrasts between TAT fantasy and other forms of imaginal activity, and concludes that they represent drastically different processes.

Inventories. In the past fifteen years, a large number of inventories designed to assess imaginal capacity have appeared in the literature (e.g., As, O'Hara \& Mungar, 1962; Lee-Teng, 1965; Shor, Orne \& O'Connell, 1962; Singer \& Antrobus, 1970; Tellegen \& Atkinson, 1974). In general, these instruments require the individual to indicate the extent to which he engages in a variety of everyday imaginative activities. Thus, the inventory developed by Tellegen and Atkinson (1974) is comprised of items such as: "While watching a movie, a T.V. show, or a play, I may become so involved that I forget about myself and my surroundings and experience the story as if it were real and as if I were taking part in it;" "I can sometimes recollect certain past experiences in my life with such clarity and vividness that it is like living them over again or almost so;" and "If I wish, I can imagine (or daydream) some things so vividly that they hold my attention in the same way a good movie or story does." Along similar lines, the "Imaginal Processes Inventory" (Singer \& Antrobus, 1970) includes such statements as: "I lose myself in active daydreaming many different times during 
the day;" "When a child, I would often create a great fantasy world for myself;" and "Sometimes my imagination keeps coming back to the same things over and over again, no matter how much I try to change the subject."

In terms of their psychometric characteristics, these inventories are generally more adequate than the projective techniques discussed previously. Most have demonstrated acceptable levels of reliability, either in terms of test-retest reliability or internal consistency. Moreover, individuals' scores have been found to consistently correlate with behaviors presumed to be associated with imaginal activity. For example, subjects who exhibit a greater predisposition to imaginal activity: 1) are most likely to define images flashed on a screen as products of their own imagination, (Fusella, 1972), 2) show more of a decrement in signal detection performance as the task proceeds (Singer \& Antrobus, 1964), and 3) tended to show greater dominance in the right hemisphere of their brain (the hemisphere that seems to be associated with more imaginative and intuitive forms of thinking) (Meskin \& singer, 1974). In addition, several investigations have found a consistent relationship between inventory ratings of imaginal capacity and hypnotic responsiveness (As, 1962; Lee-Teng, 1965; Tellegen \& Atkinson, 1974; Spanos \& McPeake, 1975 a \& b).

Inventory measures are not without their potential liabilities, however. As Klinger (1971) notes, since these methods require the recall of imaginings, they incur an irreducible minimum of distortion. Unfortunately, the evidence available to date is largely unsystematic and 
further investigation is required to clearly delineate the nature and extent of this problem.

Another fundamental limitation of inventory methods relates to their essentially unidimensional assessment of the process of imagining. Most measures define imagining only in terms of the individual's tendency to engage in such activity. The recent work of singer and Antrobus (1970, 1972) suggests, however, that more than frequency of imaginings must be taken into consideration when defining imaginal processes. Specifically, their results point to at least three independent modes of imaginal activity, each involving various content, structure, and affective components. The first, a MindwanderingDistractibe pattern, is characterized by fleeting, loosely connected fantasies usually involving anxieties and concerns. The second, a Guilty-Dysphoric daydreaming style, is characterized by ideational activity that is ethically toned and involves much self-doubt and selfcriticism. The third, a Positive-Vivid daydreaming style, is characterized by enjoyment of vivid and absorbing fantasies.

It should be noted in closing that while the above findings clearly point to the need to broaden the range of characteristics utilized in defining imaginal processes, the dimensions identified by Singer and Antrobus should not be considered conclusive. To date, all findings are based on factor analyses of scale scores from the Imaginal Processes Inventory. These scales vary widely in terms of internal consistency estimates of reliability. Additional and/or modified modes of imaginal behavior might be identified by more appropriate analyses of responses to individual inventory items. - 
Emerging Trends in Imagination Research

In recent years, an extensive body of empirical data on imagination has been accumulated. Some of this has already been considered in relation to the operationalization of the concept of imagining. Additional findings will be reviewed in later sections relating to the role of parental behaviors in the development of imagination. The purpose of the present section is to briefly consider research that appears to represent the primary focus of study in this area. In short, most investigations on imagining relate to two general questions - What is the normal course in the development of imagination from childhood through the adult years? and Are there differences in imagining as a function of background characteristics of the individual? The normative development of imagining. Drawing from his intensive naturalistic observations of the fantasy play of a rather limited number of children, Piaget (1945) presented the first overall picture of the developmental course of imaginal activity during the first decade of life. Specifically, Piaget concluded that fantasy-like activity was absent during the first year of life. Sometime between the ages of two and three years, however, symbolic play (which involves make-believe representation of absent objects) commences and exhibits a gradual growth in imaginativeness up to about the fifth year. In the years between five and twelve, symbolic play continues to increase in frequency while, at the same time, adhering more closely to reality; that is, the individual's growing awareness of reality intrudes more and more with symbolic constructions becoming less distorting and more nearly related to adopted work. 
Available quantitative data are generally in accord with Piaget's observations. Markey (1935), Pitcher and Prelinger (1963), Ames (1966) and Hurlock (1964), for example, found that self-initiated fantasy-like play, daydreaming, and the capacity for imaginative storytelling begins early in childhood between the second and fourth year. Similariy, data from diverse sources also support the suggestion of an increasing trend toward realism (Jersild, 1957; Jersild, Markey \& Jersild, 1933; Lehnman \& Witty, 1927; Smith, 1904; Yarrow, 1960). This is perhaps best exemplified in the findings of Jersild, Markey and Jersild indicating that from age five and twelve, prospective daydreams (e.g., regarding future occupation, marriage, etc.) and relatively realistic daydreams of accomplishments and prestige increased fourfold. In contrast, during the same period, daydreams of imaginary companions declined by more than fifty percent.

While trends in the development of imagining from birth through puberty have received rather extensive consideration, adolescent and adult imaginings were largely ignored until a series of investigations were conducted by Singer and his associates (Giambra, 1974; Singer \& Antrobus, 1963; Singer \& McCraven, 1961). Taken together, these data indicate a continued increase in the frequency of imagining through adolescence, with a peak between the ages of fourteen and seventeen years. As the individual enters adulthood, imaginal activity continues along with acceptance of it. However, following adolescence there is a sharp decline in both the frequency of and absorption in imaginings. Concurrent with this are several clear-cut shifts in the content and time orientation of imaginings. During adolescence, imaginings tend to 
be future-oriented with content typically being sexual, bizarre and improbable, achievement-oriented, hostile, and heroic. In addition, imaginings during this period also contain a rather high level of guilt and fear of failure. In the adult years, however, much of the prospective and negative quality has disappeared; replaced, instead, by generally pleasant imaginings that are oriented toward present concerns. Finally, as would be expected from our folk knowledge of aging, imaginings in later years tend to be characterized largely by an orientation toward the past.

Background characteristics and imagining. A wide range of background factors have been studied to determine their relationship to imagining. Somewhat surprisingly, few striking differences have been discerned along these dimensions. However, in some instances, the relationships seem intriguing and these will now be presented.

Sex. In a series of studies conducted by singer and his collaborators (Singer \& MCCraven, 1961, 1962; Singer \& Antrobus, 1963) no evidence emerged indicating that sex differences played a major role in determining either the frequency, structure or content of daydreaming. However, sex-role orientation does appear to make a difference for males in terms of the pattern of daydreaming. Men who are accepting of qualities in themselves that are traditionally defined as "feminine" tend to exhibit a higher frequency of daydreaming and to be more accepting of it. In contrast, men who possess a more traditional sex-role orientation tend to report fantasies which are more sexual, heroic and achievement-oriented in nature. 
Education and socioeconomic status. In the same studies, no evidence was found for a relationship between either education or socioeconomic status and daydreaming. This would seem to be contrary to the expectation that both factors would facilitate imaginal activity by providing a more varied stimulus environment. However, as Singer (1975) notes, this assumption may no longer be valid given the general availability of mass media.

Rural-urban background. The nature of the relationship between this factor and imaginal activity is as yet uncertain. In an initial investigation (Singer \& McCraven, 1961) clear-cut differences emerged along this dimension. Individuals from an urban background reported the highest frequency of daydreaming, those from a suburban background the lowest, while those from rural areas fell between these two groups. However, a more recent study (Segal \& Singer, 1974) failed to replicate this finding.

Sociocultural background. Perhaps the clearest differences in imaginal activity are among the American subcultural groups. In studies conducted by Singer and McCraven (1961, 1962) six cultural groups were found to cluster into two groups of three on the basis of daydreaming frequency. Italian, Negro and Jewish groups all reported a relatively high level of daydreaming while Irish, Anglo-Saxon, and German groups scored much lower on the daydream frequency scale. Moreover, groups in the first cluster were reported to exhibit greater "variety and richness" in daydreaming patterns. Singer (1975) has interpreted these results in terms of group social mobility: 
To some extent daydreaming represents one medium through which a person may explore his environment . . without committing himself to action . . Persons seeking advancement in social status are ever on the outlook for avenues of fulfillment. For a social group that has attained a relatively stable or secure status, the future may be less intriguing or demanding of imaginary exploration (pp. 61-2). In addition to the background characteristics just presented, one other factor, intelligence, has received ample consideration (Sarason, 1944; Singer \& Antrobus, 1963; Singer \& McCraven, 1961, 1962). To date, no data have been reported suggesting an association between level of intelligence and either the frequency or pattern of imaginal activity. This is particularly striking given the fact that sarason's sample included moderately retarded children and adults. 
EMERGING TRENDS: PARENT-CHILD RELATIONS AND HUMAN DEVELOPMENT

As was seen in the preceding chapter, the primary focus of imagination research has been normative. Only a limited number of investigations have attempted to determine the influence of environmental factors on the development of imagination. Moreover, of these, only a small proportion have focused directly on the role of parent-child relations. This problem is further compounded by the fact that most of these studies suffer from a variety of methodological limiations and are, thus, of limited utility in generating testable hypotheses. In light of these considerations, it would appear that the most productive course of action would be to search for emerging trends in research focusing on the role of parent-child relations in the development of other areas of cognitive activity. Following this, developmental research in imagination could be assessed to determine whether it lends support to these findings. From this process, the hypotheses to be tested in this investigation will be developed.

The Role of the Father

The child's relation to his mother... is without doubt in ordinary circumstances, by far his most important relationship during these years . . (w) hile 
continual reference will be made to the mother-child relation, little will be said of the father-child relation; his value as the economic and emotional support of the mother will be assumed (Bowlby, 195I, p. 13)

This general orientation toward the father--that he is of minimal importance in early child development and only serves the functions of "breadwinner" and occasional mother-substitute--has been accepted almost without question by most developmental theorists, whatever their orientation (Bijou \& Baer, 1961; Bowlby, 1951, 1973; Freud, e.g., 1940; Gewirtz, 1972; Kohlberg, 1966; Maccoby \& Masters, 1970; Mowrer, 1950; Parsons, 1958; Sears, 1957; Winnicott, 1956). For the most part, this view has been based on the dual assumptions of: 1) availability, and 2) need satisfaction; that is, the mother spends the most time with the child, interacts with him most, and, as the primary caretaker, has strong reward value due to her association with need satisfaction (Lamb, $1975 \mathrm{a}, 1976$ b). Recently, however, these assumptions have come under serious attack and the general hypothesis appears no longer to be tenable.

Differential availability. The assumption that mothers are highly available to their children while fathers are relatively uninterested and uninvolved is based on findings such as those reported by Rebelsky and Hanks (1971). In this oft-cited investigation, it was indicated that fathers averaged less than forty seconds of verbal interactions per day with their infants. Actually, however, there is no clear consensus on the relative amounts of time mothers and fathers spend interacting 
with their infants. Data from several sources suggest that the extent of paternal interaction may have been underestimated (Newson \& Newson, 1963, 1968; Parke \& O'Leary, 1976; Parke, O'Leary \& West, 1972; Pederson \& Robson, 1969). For example, Pederson and Robson (1969) found that fathers spent an average of 8 hours/week playing with their eight to nine month old infants. Along similar lines, Newson and Newson $(1963,1968)$ reported that over $50 \%$ of the fathers studied were highly participant in the care of their one- and four-year old children. In addition, the findings of at least one study (Clarke-Stewart, 1972) suggest that while mothers spend a large amount of time in close proximity to their infants, the extent of matemal interaction may have been overemphasized. Specifically, it was found that interactions with the mother characterized by play, object stimulation, and affectionate contact accounted for only about 5\% of the infant's waking day.

Of equal importance to these findings is another set of data clearly suggesting that the amount of time spent interacting with the child is a poor indicator of attachment to either parent. Pederson and Robson (1969), for example, found no association between the amount of time fathers spend interacting with their child and the extent of the infant's attachment to the father. Similarly, schaffer and Emerson (1964) found a negligible correlation between the degree of attachment of the child to the mother and the amount of time she spent with the child. Most recently, Fein and Clarke-Stewart (1973) reported that amount of time either parent spent in close proximity to the infant was a poor index of the quality of their relationship with it. 
Need satisfaction. A number of recent studies provide consistent support for the notion that fathers are less active than mothers in the caretaking role (Parke, O'Leary \& West, 1972; Parke \& O'Leary, 1976; Parke \& Sawin, 1976). However, the assumption that this is a critical factor in determining infant attachment and is the basis for the mother's "natural" preeminence as a socializing agent does not necessarily follow. Beginning with Harlow's work with infant monkeys (Harlow, 1961; Harlow \& Zimmerman, 1959), investigators have been unable to find any consistent association between attachment behavior, and caretaking and physical gratification (Ainsworth, 1963; Schaffer \& Emerson, 1964; Sears, Maccoby \& Levin, 1957; Sears, et al., 1953).

Thus, neither the assumption of differential availability nor of the role of need satisfaction in determining dependency behavior has received clear-cut empirical support. Likewise, additional evidence is contrary to the overall hypothesis that the father's role in child development is nominal, serving only the functions of "breadwinner" and "mother-substitute." In particular, it has been demonstrated that;

1) there are qualitative differences in fathers' and mothers' interactions with the infant, 2) infants do not clearly show stronger attachment to the mother, and 3) the quality of the father-child relationship has a profound impact on development. Each of these points will be considered in turn.

\section{Role differentiation. A series of observational studies suggest} that important differences exist in the nature of mother-child and father-child interaction. In a preliminary investigation conducted by Biller (1974 c) it was reported that fathers were more likely than mothers to encourage their infant's exploratory behavior and to support their 
efforts to solve cognitive and motoric challenges. These findings were supported and extended by Lamb's (1975 c, 1976 a) observations. Specifically, Lamb demonstrated that physical-contact interaction between mother and infant usually revolved around caretaking and control activities. In contrast, fathers most often held their infants for the purpose of playing with them. Role differentiation was further evidenced in the types of play activity each parent engaged in with the child; mothers tended to engage in play that was more conventional and toymediated while fathers' play was more physical and idiosyncratic.

Further evidence that parents assume different roles in relation to their children is derived from two nonobservational studies (Meltzer, 1935; Fagot, 1974). In these, the reports of the child and the parents, themselves, suggested that the mother is perceived as serving primarily a caretaking function, while the father is viewed as being more active in activities classified as play.

Attachment behavior. A wide range of infant behaviors have been employed to assess attachment. These include separation protest, proximity seeking, and a variety of behaviors directed toward the parent such as smiling, vocalizing, looking, laughing, reaching to, touching and seeking to be held. Despite this diversity, findings have been highly consistent in suggesting an absence of any long-standing differences in the infant's preference for the mother or the father. With only a single exception (Cohen \& Campos, 1974), it has been demonstrated that, by the age of 18 months to two years, infants display equal attachment to both parents (Ban \& Lewis, 1971; Kotelchuck, 1972, 1973; Kotelchuck, et al, 1975; Lamb, 1975 b, 1976 a; Lewis \& Weinraub, 1974; Lewis, Weinraub \& 
Ban, 1972; Ross, et al., 1975; Schaffer \& Emerson, 1964; Spelke, et al., 1973). Moreover, in two of these studies (Lamb, 1975 b, 1976 a) it was indicated that the strength of attachment behavior to the father was at least equal to that toward the mother by the time the infant reached the age of seven to eight months.

The father-child relationship. Perhaps most damaging to the notion of maternal preeminence is the growing body of data relating to the influence of the father-child relationship on cognitive, personal, and social development. With respect to cognitive functioning, for example, both the extent of paternal involvement and the quality of the interaction has been found to have a significant impact. Thus, Kimball (1952) studied a group of underachieving preparatory school boys with superior intelligence. Her findings indicated that, in comparison with others from the school population, these boys had poorer relationships with their fathers. A large number of the fathers were characterized as either being home infrequently, or as using excessive discipline as a means of controlling their sons. Moreover, the boys typically expressed feelings of paternal rejection and hostility. Similarly, Radin (1972), in a study of four-year old boys, found a highly significant positive relationship between both the overall level of father-son interaction and patermal nurturance, and measures of intellectual functioning. In contrast, these same measures were found to be negatively associated with paternal restrictiveness. Other evidence consistent with the notion that the character of father-son interaction has a significant effect on cognitive development comes from studies demonstrating that: 1) fathers of underachieving boys appear insecure in their masculinity and view themselves 
as failures (Grunebaum, et al., 1962); 2) academic achievement in lowerclass black elementary school boys is positively associated with patemal interest and encouragement (Katz, 1967; Soloman, 1969); 3) father absence, especially in early childhood, is related to poor school grades, lower functioning on intelligence and aptitude tests, and deficient academic performance in general (Blanchard \& Biller, 1971; Deutsch \& Brown, 1964; Dyl \& Biller, 1973; Lessing, et al., 1970; Santrock, 1972); 4) fathers of field independent boys tend to be perceived as more involved and nurturant (Dyl \& Witkin, 1965; Beder, 1957); 5) boys whose fathers are neglecting or passive are more likely to adopt a global versus an analytic conceptual style (Witkin, 1960); and 6) moderately active paternal participation is associated with flexible thinking in young boys (Busse, 1969).

While the father has been shown to be an important force in cognitive functioning, his influence is not limited to this aspect of development alone. As would be expected, the extent of paternal involvement is a critical factor in male sex-role development. Boys who experience patemal deprivation during the first four to five years have been found to have less masculine self-concepts and more sex-role conflicts (Biller, 1968, 1969 b, 1974 a; Biller \& Bahm, 1971), and to be less assertively aggressive and independent in their relations with peers (Hetherington, 1966; Stolz, et al., 1954). However, as with cognitive functioning, more than the level of father-son interaction must be considered. Studies have indicated that while interaction with a masculine, interested, and nurturant father who encourages his son to be independent and assertive facilitates masculine development, interaction 
with a father who is either punitive and rejecting, or passive and ineffectual can lead to inadequate sex-role functioning (Bandura \& Walters, 1959; Biller, 1969 a; 1971, 1974 b; Bronson, 1959; Mussen, 1961).

Other aspects of personal and social adjustment which have been found to be associated with the adequacy of the father-son relationship include: self-confidence and self-esteem (Coopersmith, 1967; Mussen, et al., 1963; Sears, 1970); social competence (Slater, 1962); achievement motivation (MCClelland, 1961; Veroff, et al., 1960); impulse control (Becker, et al., 1952, 1962); ability to form lasting heterosexual relationships (Andrews \& Cristenson, 1951); and delinquency (Glueck \& Glueck, 1950; Goode, 1961). In addition, several studies have demonstrated a link between psychopathology in both children and adults, and father absence and paternal inadequacy (Alkire, 1969; Anderson, 1969; Biller \& Davids, 1973; Johnson \& Meadow, 1966; Mishler \& Waxler, 1968; Kayton \& Biller, 1972; Piety, 1967).

In addition to being a highly critical force in his son's development, the father also plays an important role in his daughter's socialization. For example, Hetherington (1972) studied two groups of teenage girls who had become father-absent as a result of either divorce or death. She found that both groups exhibited marked difficulties in relating to men and male peers. The daughters of divorcees were typically overly aggressive and forward toward men, whereas, the daughters of widows were generally quite shy and timid in their interactions. Likewise, Biller and Zung (1972) found sex role conflict and anxiety to be associated with maternal dominance and patemal involvement, while Block (1971) indicated that the highest proportion of well-adjusted 
females came from homes where both parents were positively involved. In brief, the evidence summarized in the preceding sections clearly points to the significant influence of the father on his offspring's development. This emphasis on the father is by no means intended to minimize the role of the mother. As will be seen in the next section, clearly definable patterns of both parents' behavior have been found to effect development.

Dimensions of Parental Behavior

During the past forty years considerable research has been conducted in an attempt to systematically classify parental behavior. In this work a variety of information-gathering techniques have been employed including direct observation of parental behavior, interviewing of parents, and children's reports on their perceptions of parents behavior.

In general, most early studies of parental behavior were relatively consistent in isolating two major bipolar dimensions labeled Acceptance versus Rejection, and Firm Control versus Lax Control (Roe, 1957; Schaefer, 1959, 1961; Schaefer, Bell \& Bayley, 1959; Slater, 1962; Symonds, 1939). The first of these clearly related to degree of parental nurturance with behaviors characterized by affection and warmth contrasted with coldness and rejection. In comparison, the second dimension of parent-child interaction referred to permissiveness and control in different aspects of the child's life; that is, lax discipline and encouragement of independent thinking was contrasted with many restrictions and strict enforcement of demands in such areas as sex play, table manners, orderliness, noise, obedience, and aggression toward siblings, peers and parents. 
While investigations of a somewhat more recent origin have tended to confirm the dimensions summarized above, they have also clearly suggested that a two-dimensional model with axes for nurturance and control does not cover the entire domain of parent-child interactions. Thus, factor analyses of parent-behavior ratings (Lorr \& Jenkins, 1953; Becker, 1964), and of children's perceptions of their parents' childrearing behaviors (Roe \& Siegelman, 1963; Siegelman, 1965; Schaefer, $1965 \mathrm{a}, \mathrm{b})$ have isolated a third parent-behavior dimension. This dimension, labeled "Psychological Control," is unipolar and refers to, "covert, psychological methods of controlling the child's activities and behaviors that would not permit the child to develop as an individual apart from the parent ...(Schaefer, 1965b, p. 555)." The revised, three-dimensional model has been shown to be highly stable over a wide range of populations: American children in grades four through eight (Burger \& Armentrout, 1971; Armentrout \& Burger, 1972a), American and Canadian college students (Armentrout \& Burger, 1972b; Cross, 1969; Schludermann \& Schludermann, 1970), Walloon high school students (Renson, Schaefer \& Levy, 1968), and Hutterite adolescents (Schludermann \& Schludermann, 1971).

In large part, research assessing the relationship between child development and patterns of both parents' behavior have focused on each dimension in isolation. Thus, as was noted in the preceding section, paternal acceptance, involvement, and acceptance of individuation (behaviors constituting the positive pole of the Acceptance versus Rejection dimension) have been found to be associated with academic achievement, field independence and masculine development in sons, while 
rejection and hostility have been shown to relate to a global cognitive style and inadequate intellectual and sex-role functioning. Likewise, studies assessing both the mother and father have demonstrated scholastic achievement to be related to variations in parental behavior along both the dimensions of Acceptance versus Rejection (Andersland, 1968; Cooper \& Lewis, 1962) and Psychological Control (Cross \& Allen, 1969; Lynn, 1974; Teahan, 1963). Parental acceptance, positive involvement and encouragement of independence have also been found to be associated with such varied aspects of development as creativity (Datta \& Parloff, 1967; Mackinnon, 1962), ideational flexibility and fantasy (Weisberg \& Springer, 1961), vocational choice (Roe, 1957; Green \& Parker, 1965), and guilt (Moulton, et al., 1966). With respect to the dimension relating to degree and consistency of discipline exercised by the parents, investigations conducted by Becker (1964), Sanford (1943), Schaefer (1965 a) and Symonds (1939) have indicated that excessive restrictiveness is related to a dulling of intellective striving and delinquent behavior, whereas excessive permissiveness is associated with anxious emotionality, an inability to sustain attention and low social feelings.

While findings such as these are of significant import, a careful analysis by Becker (1964) points to the need to investigate the manner in which one dimension moderates the affects of another. This point was clearly demonstrated in his consideration of the differential developmental effects of restrictiveness vs. permissiveness exhibited in either a hostile or warm context. According to Becker, permissive parental behavior in a hostile context tends to maximize aggressive, poorly controlled behavior 
while in a warm context the child is typically less hostile and more independent, friendly, creative, and moderately persistent. Along similar lines, hostile restrictiveness facilitates self-aggression, social withdrawal and internal conflict whereas, restrictiveness coupled with warmth fosters dependency, extremes in persistence, fantasy hostility and low levels of creativity.

Clearly, further research on the interaction of parental-behavior dimensions is called for. In addition, further analysis of the dimensions defining parent-child interactions would also appear to be warranted. While findings tend to be highly consistent, they are, for the most part, based on factor analyses of scales exhibiting widely varying reliabilities. Two studies (Ellis, Thomas \& Rollins, 1976; Margolies \& Weintraub, 1977) suggest that factor analyses of individual items of Schaefer's "Children's Report of Parental Behavior Inventory" (1965b) might yield a revised structure. In the first, Ellis, Thomas, and Rollins (1976) obtained results arguing against the unidimensionality of the parental support dimension. Specifically, factor analysis of selected support and control items from the CR-PBI yielded four orthogonal dimensions: Rejection-Control; Companionship; Physical Affect; Withdrawal. In the second, Margolies and Weintraub (1977) factor analyzed a revised, 56-item CR-PBI. Analyses tended to yield factor structures similar to those previously reported. However, the factor representing Firm Control versus Lax Control had a considerably smaller proportion of expected items that loaded properly than did the other two factors and in three of six analyses a fourth (unidentified) factor appeared. 


\section{Sex Differences}

Thus far, discussion in this chapter has focused on data relating to the role of both parents in the cognitive and social development of their offspring. While it is clear that the behaviors of the father and the mother have a significant impact on both sons and daughters, it is necessary at this point to qualify this statement. One of the most pronounced themes emerging from recent developmental investigations is that the child tends to be most sensitive to the behaviors of the same-sex parent. With regard to cognitive functioning, the work of Radin is of particular importance (Radin, 1972, 1973, 1974, 1976; Radin \& Epstein, $1975 \mathrm{a}$ and b). In this series of studies, cognitive competence of four-year old children was measured on a variety of intelligence tests (e.g., the Stanford-Binet Intelligence Scale, the Peabody Picture Vocabulary Test, standardized Piagetian tasks) and parents' verbal and nonverbal behavior was assessed during an interview at home in which only a single parent and the child were present. Results consistently indicated that paternal nurturance was associated with intellectual ability in young boys while restrictiveness was linked to a lack of such competence. No such relationship between paternal behavior and girl's intellectual functioning was evidenced, however. Rather, cognitive competence in preschool girls was found to be linked to maternal warmth. On the basis of this evidence, Radin (1976) concluded that same-sex parents and children tend to be particularly sensitive to one another's behaviors and, as a result, respond to one another in a far more differentiated manner. 
Support for Radin's findings is derived from a variety of sources. Both correlational (Jordan, et al., 1975; Mutimer, Laughlin \& Powell, 1966) and longitudinal (Honzik, 1967) studies have indicated that intellectual competence in boys (girls) is most closely associated with warmth and acceptance in the father-son (mother-daughter) relationship. Further, evidence on father-absence suggests that while both boys and girls are influenced, paternal deprivation has a somewhat more negative effect on the cognitive abilities of boys (e.g., Landy, et al., 1969; Lessing, et al., 1970; Santrock, 1972). Similar results have been obtained in investigations of cognitive style. Harrington, Block and Block (1975) found three-year old boy's intolerance of ambiguity to be related to paternal hostility, rejection and impatience; girl's performance, on the other hand, was most clearly affected by their mother's behavior. Likewise, seder (1957) reported that fathers of field-independent boys spent little time with their sons, and the time they did spend with them was characterized by relatively passive activities such a T.V. watching. Also, boys who exhibited a global, as opposed to analytic, cognitive style typically had fathers who employed more punishment and physical aggression. Neither of these relationships held for girls. Finally, a close father-child relationship in which the father is both dominant and democratic is associated with high achievement motivation in boys, in particular (Norman, 1966; Werts, 1966). Boys, in turn, are less susceptible than girls to pressure to achieve exerted by their mothers (Kagan \& Freeman, 1963).

To sunmarize briefly, there are a number of relatively clear themes emerging from developmental research. These included: 1) the father's 
role in child development is equal in importance to that of the mother; 2) the domain of parental behavior may be conceptualized along clearly definable dimensions which are the same for both parents; 3) in general, parental acceptance and consistent though not excessive control is associated with adequate cognitive functioning (assessed in terms of intellectual competence, academic achievement and cognitive style) and personal adjustment; and 4) the child is relatively more sensitive to the behaviors of the same-sex parent.

Taken together, these findings would seem to suggest that the father, as well as the mother, should play an important role in the development of imaginal behavior. In particular, two studies indirectly point to the contribution of the father in such development. First, Singer and McCraven (1962) reported that while sex is not a factor in imaginal activity, sex-role orientation does appear to make a difference for males in terms of the pattern of daydreaming. Studies have consistently demonstrated the importance of the father-son relationship in sex-role development (Biller, 1971). Second, Lamb (1976a) found that father's interactions with infants tended to be characterized by play activities of an idiosyncratic nature. While the relationship between play and imagination has yet to be clearly defined, the development of one has been shown to closely parallel that of the other (Ham, 1975). In the next section, the extent to which these findings are supported by studies directly assessing the relationship between parental behavior and the development of imagining will be considered. 
Research on the Development of Imagining

Several studies have focused directly on the relationship between parental behavior and the development of imagining (Bene, 1975; Hilgard, 1974; Shatin, 1953; Singer, 1961; Singer \& McCraven, 1961; Singer \& Opler, 1956; Singer \& Schonbar, 1960; Singer \& Sugerman, 1955). As has been noted in previous sections, these investigations as a whole are subject to a number of serious limitations. It is important to consider these limitations before turning to the results and their relationship to the trends summarized above.

Limitations. Briefly, these studies may be criticized in terms of the subjects employed and/or the techniques utilized to assess both imaginal activity and parental behavior. With respect to the former, the majority of studies (Bene, 1975; Shatin, 1953; Singer \& Opler, 1956; Singer \& Sugerman, 1955) have employed subjects drawn from psychopathological populations and it is difficult to ascertain the extent to which observed relationships are a function of the unique characteristics of these samples. Moreover, with only three exceptions (Hilgard, 1974; Singer, 1961; Singer \& McCraven, 1961), studies have failed to use samples composed of both males and females. As a consequence, little data are available on the interaction between sex of parent and sex of child.

With regard to the measurement of parental behavior and imaginal activity in the offspring, several criticisms may be raised. In none of these studies was parental behavior or the perception of such behavior directly assessed. Instead, the quality of the parent-child relationship 
was measured through the use of such indirect techniques as responses to parental-type TAT figures, perceived similarity to parents, expressed preference for one parent over the other, and membership in a particular ethnic group (Irish vs. Italian). The reliability of such measures and their relationship to more direct measures of parental behavior is left unreported. Similar difficulties arise with respect to the assessment of imaginal activity. Most studies (Bene, 1975; Shatin, 1953; Singer \& Opler, 1956; Singer \& Sugerman, 1955) employed projective techniques-either Rorschach human movement response or the Transcendence Index--to assess such behavior. The limitations of these measures in terms of reliability and validity have already been addressed (see Chapter I). Moreover, in two additional studies (Hilgard, 1974; Singer, 1961), imaginal activity was measured in terms of responses to open-ended interview questions. Singer (1961), for example, categorized subjects as either high or low in "fantasy predisposition" on the basis of the number of positive responses to four questions: "What is your favorite game?"; "When you play by yourself, what games do you play?"; "Do you have pictures in your head?"; and "Do you have a make-believe playmate?" Reliabilities were not reported for either technique. Only two studies (Singer \& McCraven, 1961; Singer \& Schonbar, 1960) utilized inventories which possessed an acceptable level of reliability. In both instances, however, only frequency of imagining was assessed.

Findings. Within the constraints outlined above, results regarding the relationship between parental behavior and imagining provide partial support for the general themes emerging from developmental research. specifically, these findings may be summarized in the following manner: 
1) Although Singer (1961) suggests that fantasy predisposition is a function of the mother-child interaction, there is no clear-cut support for this contention. Rather, studies have shown that "high fantasy" subjects show a preference for one parent over the other but the sex of this parent has varied from study to ștudy.

2) A positive relationship with a relatively benign and nurturant parental figure appears to be associated with a tendency toward imaginal activity.

3) Parental intrusiveness and overprotectiveness appears to inhibit the development of imaginal skills for lack of the opportunity to practice.

4) Extent of parent discipline appears to be positively associated with imaginal activity. However, it is unclear as to whether this is a direct effect or whether discipline, which typically involves periods of isolation, facilitates such activity by providing greater opportunity for practice. 
OVERALL AIM OF THE RESEARCH

The overall aim of the present research is two-fold. The first is to obtain correlational evidence relating to the following questions: 1) To what extent can the a priori scales of the Children's Report of Parental Behavior Inventory (Schaefer, 1965a) and the Imaginal Processes Inventory (Singer \& Antrobus, 1970) be supported? 2) To what extent are the models for parent-child interactions and imaginal activity artifacts of the level of data analyzed?

As was discussed in Chapters I and II, previous analyses of the CR-PBI and IPI have been highly consistent. However, as was also noted, the overwhelming majority of these have evidenced a common weakness: scale scores rather than responses to individual items have been employed as the data base. This is viewed as problematic in that a) estimated reliabilities of inventory scales vary widely, with several falling below acceptable limits, and b) factor analyses suggest high intercorrelations amongst several inventory scales. Further, where actual item responses from the CR-PBI have been analyzed, a somewhat altered factor structure has been reported. On the basis of this, it is hypothesized that analyses carried out at the item level will:

1) Fail to support the present scoring system of both the CR-PBI and IPI. 
2) Yield a more complex structure for both parent-child interactions and imaginal activity than has previously been reported.

The second aim of the present investigation is to utilize the results from the preceding analyses to explore the relationships between imaginal activity and parent-child interactions. More specifically, the purpose is to obtain correlational evidence relating to the following question: How do identified dimensions of imaginal activity relate to the child's perceptions of interactions with both the mother and the father? In this regard, the following hypotheses were formulated:

3) The frequency of imaginal activity reported by subjects is related to the perceived quality of interactions with both the mother and the father.

4) The quality of imaginal activity reported by subjects (i.e., its content and structure) is related to the perceived quality interactions with both the mother and the father.

5) Both the frequency and quality of imaginal activity are most strongly related to the perceived quality of interactions with the same-sex parent. 
METHODOLOGY

\section{Subjects}

Two hundred seventy-one Ss from general psychology classes at three colleges (Stonehill College, University of Rhode Island, Rhode Island Junior College) volunteered (for credit) to participate in a "doctoral dissertation considering the relationship between cognitive activity and childhood experiences." Of this original number, 19 Ss were dropped from the sample because they failed to complete the testing. An additional 23 Ss were also dropped because family background questions revealed that they had been raised in a singleparent home. The final sample, therefore, consisted of 229 Ss. (The demographics on this sample are presented in the Results chapter.)

\section{Procedure}

All Ss were tested in two sessions conducted by the experimenter. Testing groups ranged in size from 38 to $75 \underline{\mathrm{Ss}}$

In the first testing session, $\underline{S}$ sere administered a standardized set of instructions emphasizing 1) the general characteristics of the inventory, 2) the importance of responding to all items honestly, and 3) the steps taken to protect confidentiality. Following this, the Imaginal Processes Inventory (IPI) devised by Singer and Antrobus (1970) was administered. Within one week thereafter, Ss participated in the 
second testing session. During this session, Ss were required to respond to a series of family background questions and to complete the Children's Report of Parental Behavior Inventory (CR-PBI; Schaefer, 1965a). The CR-PBI consists of separate, but virtually identical mother and father forms administered in counterbalanced order. Prior to administration of the $C R-P B I, \underline{S}$ were instructed to respond to items in terms of how they viewed their parents' behavior when they were 16 years of age.

Debriefing of Ss were conducted in the following manner: 1) At the conclusion of the second testing session, $\underline{S}$ were invited to meet with the experimenter to discuss the rationale of the study and to raise any questions. 2) A summary of the study and its findings was made available to $\underline{S}$ s through their course instructors upon completion of data analysis. This summary also informed $\underline{S}$ as to how the experimenter could be contacted if further information was desired.

Assessment of Variables

Imaginal Processes Inventory (IPI). The IPI is a self-report inventory designed to sample a large range of daydreaming and imaginal activity. In its current form, this instrument consists of 344 items responded to on a 5-point scale and includes 28 subscales (See Appendix Table A). Twenty-one subscales assess either content or structure of imaginal processes while 7 represent measures of curiosity and patterns of attention. Factor analytic studies (Fusella, 1972; Segal \& Singer, 1974; Singer \& Antrobus, 1970, 1972; Starker, 1974) have typically demonstrated that the IPI subscales represent three independent modes of 
imaginal behavior: Anxious-Distractibility in Daydreaming; GuiltyNegatively Toned Emotional Daydreams; and Positive-Vivid Daydreaming. However, all factor analyses have been based on the twenty-eight scale scores rather than using the 344 inventory items as input.

Overall, the reported internal consistency estimates of reliability of the IPI are mixed. Both Singer and Antrobus (1972) and Giambra (1974) report a mean scale reliability in the low 80 's. However, scale reliabilities are widely varied (from .39 for Auditory Images in Daydreams to .91 for Heroic Daydreams) and approximately one-third are below . 80 .

The relationship between IPI subscales and factors, and other behavioral manifestations of imaginal activity has been assessed in a number of studies. Starker (1974) reported that subjects who had especially high and low scores on the three IPI patterns of daydreaming exhibited highly similar styles of imaginal activity in their night dreams. Singer and Antrobus (1967) found that subjects who received high scores on IPI scales representing the Positive-Vivid Daydreaming dimension reported more extraneous thoughts during a signal detection task. These subjects also tended to show more decrement in performance as the task proceeded. Along similar lines, Fusella (1972) demonstrated that high scores on Positive Daydreaming scales were more likely to misconstrue dimly projected pictures as being products of their own imagination. Finally, Meskin and Singer (1974) found that subjects who consistently shifted their eyes to the left when responding to reflective questions (and who are, thus, presumed to have greater dominance in the brain hemisphere associated with more imaginative and intuitive forms of 
thinking) tended to score higher on Positive Daydreaming scales, such as Visual Images in Daydreaming, Future-Oriented Daydreams, Positive Reactions to Daydreams, etc.

Children's Report of Parental Behavior Inventory (CR-PBI). The revised version of the CR-PBI was developed from item and factor analyses (Schaefer, 1965 b) of the initial version (Schaefer, 1965 a). In its current form, the CR-PBI consists of 18 scales, 6 of which are based on 16 items and 12 of which are based on 8 items (See Appendix Table B) for a total of 192 items. The items are descriptions of concrete, specific, easily abservable parent behaviors. The subject indicates whether each item is like, somewhat like, or not like his parent's behavior on separate but identical forms for. mother and father. These responses are scored 3, 2, and 1, respectively, and summed to yield individual scale scores.

Internal consistency estimates of reliability for the earlier version of the CR-PBI have been computed with the Kuder-Richardson Formula 20 (Schaefer, 1965 a). Scale reliabilities were found to range from .38 to .94 ; the median scale reliability was .76 . Unfortunately, no data are available on the internal consistency reliability of the revised version. However, it is possible to estimate scale reliabilities from reported communalities or factor loadings (Thurstone, 1947). Employing the factor loadings reported by Cross (1969), whose sample most closely approximates that of the present investigation, the lower bound of scale reliabilities may be estimated to range from .44 to .90, with a median scale reliability of .74 . 
Research on both forms of the CR-PBI have focused primarily on assessing factor structure (Cross, 1969; Renson, Schaefer \& Levy, 1968; Schaefer, $1965 \mathrm{a}$ and b; Schludermann \& Schludermann, 1970). In these studies, diverse subject populations have been utilized, including children and adults, delinquents and nondelinquents, and different national groups. The factor structure for males' and females' reports of maternal and paternal behavior have been highly consistent; three dimensions (labelled Acceptance vs. Rejection, Lax Control vs. Firm Control, and Psychological control) account for the major amount of the common variance of the parent-behavior scales. Moreover, one study (Schludermann \& Schludermann, 1970) calculated the within-group similarity of CR-PBI factors and indicated that the factors were relatively independent of one another. However, as with studies of the factor structure of the IPI, all analyses have employed scale scores rather than inventory items as input.

In addition, Schaefer and Bayley (1967) compared ratings based on interviews with mothers of adolescents with adults' retrospective reports of maternal behavior. Eleven of the 12 correlations of adult behavior scales (Acceptance of Individuation, Acceptance, Positive Involvement, Hostile Involvement, Rejection, Hostile detachment) with the adolescent dimensions of Autonomy vs. Control, and Love vs. Hostility were significant, seven beyond the .0I level and 4 beyond the .05 Ievel. More importantly, the absolute size of the correlations was relatively high for sets of data gathered by different methods from different persons by different investigators at different times (range .35 to $.63 ; \bar{x}=.51$ ). 
Finally, scales of the CR-PBI have been shown to discriminate between groups of normal and delinquent boys (Schaefer, 1965 a), between normal and neuropsychiatric males, and among psychodiagnostic categories (Vogel, et al., 1964).

\section{Data Analysis}

Analysis of the data gathered in the present investigation was carried out in three parts. The purpose of the first two was to extend previous research on the structure of parent-child relations and imaginal activity as represented by the CR-PBI and IPI, respectively. As discussed previously, while findings have been highly consistent with respect to the factor structure of these two inventories, all investigations evidence a common weakness; scale scores rather than item responses have been employed as the data base. This was viewed as problematic in that 1) estimated reliabilities of CR-PBI and IPI scales vary widely with several falling below acceptable limits, and 2) factor analyses performed on both the CR-PBI and IPI suggest high intercorrelations amongst several inventory scales. In line with these considerations, Parts I and II consisted of separate principal component analyses of CR-PBI and IPI items. At this point, it should be noted that while the sample size of 229 Ss only slightly exceeded the total number of items in each analysis ( 172 to 198), this was considered sufficient to establish stable correlations.

Part III of the data analysis constituted a test of the hypotheses outlined in the preceding chapter. Specifically, results from the above analyses were utilized to generate scale scores which, in turn, were 
utilized to determine the relationship between dimensions of imaginal activity and parent-child relations.

The specific elements of each of these parts of the data analysis will now be considered in the following sections.

Part I. Identification of dimensions of parent-child interactions. Ss' responses to the mother and father versions of the CR-PBI were analyzed separately. The two forms could have been analyzed together in that $\underline{S}$ s rated their parents on the same questions. However, separate analyses permitted the evaluation of interparent variation.

For each version of the CR-PBI, a principal components analysis was performed on the $192 \times 192$ matrices of item intercorrelations. Velicer's (1976) Minimum Average Partial (MAP) correlation procedure was utilized to determine the number of components to extract. This procedure is based on the concept of partialing out components until the average squared partial correlation reached a minimum. A varimax rotation was performed on the resulting component pattern.

Following the above analyses, scale scores were calculated for all components containing 5 or more items with loadings at or above .40 . Only those items meeting this criteria were included in the unweighted summation. Further, for negatively weighted items, Ss' responses were reversed before summation (i.e., a rating of "3" was entered as a "1" and vice versa). The use of the .40 level for item component loadings rather than the conventional minimum value of .30 was based on two considerations: 1) the loadings of the initial items on each component were generally quite high; typically within the range of .70 to .90, 
2) since scale rather than component scores were calculated, this higher minimum value would serve to raise scale reliabilities.

Part II. Identification of dimensions of imaginal activity. Due to limitations in available computer programs, $\underline{S}^{\prime}$ responses to the 344 items of the IPI could not be analyzed as a single set. Therefore, IPI items were divided in half to form two sets. For each resulting 172 x 172 matrix of item intercorrelations, a principal components analysis was performed using the MAP procedure with a varimax rotation of the component pattern.

The above analyses were followed by a third principal components analysis of a 198 x 198 matrix of item intercorrelations. Items forming this matrix consisted of a) five marker items for each component identified in the previous analyses, and b) items which failed to load on any identified component at a level of . 40 or above. Again, the MAP procedure with a varimax rotation was employed.

Following the above analyses, unweighted scale scores were calculated for all components from the third analysis with five or more items loading at the .40 level or above. The procedure employed in calculating scale scores for the CR-PBI was again followed. In addition, a daydreaming frequency score was also calculated for each $\underline{s}$ to allow for the testing of hypotheses regarding general tendency toward imaginal activity. This scale was identical to the IPI scale of the same name. Part III. Identification of relationships between parent-child interaction and imaginal activity. In order to test for differential relations of parental behavior to imaginal activity as a function of both 
the sex of the parent and the sex of the offspring, all analyses were carried out on the following four data groupings: males' reports of their fathers' behavior, females' of fathers', males' of mothers', and females' of mothers'.

Pearson correlations. Basic zero order correlations were performed for all pairings of independent and dependent variables for males and females separately.

Stepwise multiple regression. A forward stepwise multiple regression analysis of each of the imaginal activity variables on the parent-child interaction variables was performed using the SAS76 program (Barr, et al., 1976). Mother and father variables were formed into separate predictor sets. The stepwise procedure was selected because of the fact that while the multiple correlation increases as variables are added, the increase may not be statistically significant. The significance of the incremental $R^{2}$ was tested by the following formula:

$$
\frac{R^{2}(\text { Larger })-R^{2}(\text { Smaller })}{\left(1-R^{2}(\text { Larger })\right) /(N-k-1)}
$$


RESULTS

\section{Demographic Data}

The final sample of this investigation consisted of 229 Ss, 91 males and 138 females. Data pertaining to subject and family background characteristics of this sample are sumarized in Table 1 . As indicated, Ss ranged in age from 16 to 48 years. However, nearly all (96\%) Ss were 25 years-of-age or below with a median age of approximately 19 years. Consistent with this, nearly two-thirds of the sample were college freshmen while another $27 \%$ were sophomores. In addition, nearly all Ss were white (96\%) and Catholic (81\%).

With regard to family background characteristics, $\underline{S}$ in the final sample had an average of three siblings, who were evenly divided between brothers and sisters. Moreover, nearly one-half of the $\underline{S}$ were about evenly divided between being the oldest and the youngest in the family, with only $1 \%$ being the only child. Finally, Ss' fathers tended to attain a somewhat higher level of education than their mothers. Specifically, the median level for fathers was "some college", whereas the median for mothers was "completed high school." In line with these educational levels, fathers tended to be employed in occupations other than skilled and unskilled labor. By comparison, Ss predominantly characterized their mothers' occupations as either "housewife" (37\%) or "laborer" (unskilled 17\%, skilled 20\%). 
TABLE 1

SUBJECT AND FAMILY BACKGROUND CHARACTERISTICS

\begin{tabular}{|c|c|c|c|}
\hline CHARACTERISTIC & RANGE & MEDIAN & PERCENTAGES \\
\hline AGE & $16-48$ & 19.07 & - \\
\hline CLASS & - & - & $\begin{aligned} \text { Fr. }-63 \% & \text { Jr. }-7 \% \\
\text { Soph. }-27 \% & \text { Sr. }-3 \%\end{aligned}$ \\
\hline RACIAL/ETHNIC GROUP & - & - & $\begin{array}{cc}\text { White }-95 \% & \text { Hisp. - .5\% } \\
\text { Black }-2 \% & \text { Am. Ind. }-0 \% \\
\text { Oriental - .5\% } & \text { Other }-1 \%\end{array}$ \\
\hline RELIGION & - & - & $\begin{array}{lr}\text { Prot. }-12 \% & \text { Jew }-3 \% \\
\text { Cath. }-81 \% & \text { Other }-4 \%\end{array}$ \\
\hline TOTAL \# SIBLINGS & $0-10$ & 3.02 & - \\
\hline \# BROTHERS & $0-7$ & 1.65 & - \\
\hline \# SISTERS & $0-6$ & 1.55 & - \\
\hline POSITION & - & - & $\begin{array}{l}\text { Only Child }-1 \% \\
\text { First }-26 \%\end{array} \quad$ Middle $-49 \%$ \\
\hline FATHER'S EDUCATION* & $1-8$ & 5.19 & - \\
\hline MOTHER'S EDUCATION* & $1-8$ & .4 .59 & - \\
\hline
\end{tabular}

*Parental education was scaled as follows: 1 = some grade school; 2 = completed grade school; 3 = some high school; 4 = completed high school; 5 = some college; 6 = completed college; 7 = some graduate work; 8 = completed doctorate 


\section{Principal Component Analysis of the CR-PBI}

\section{Father Response Form}

A principal components analysis was performed on the $192 \times 192$ matrix of intercorrelations among items from the father response form of the CR-PBI. The MAP method was employed to determine the number of components to retain. A varimax rotation was performed on the resulting component pattern.

This analysis of father response form items resulted in 16 components which together accounted for $66.7 \%$ of the total variance. Correlations among items were generally rather low with an average squared interitem correlation of .126 . Items with a loading of .40 or higher on at least one component were considered. These items were listed by component in order of the absolute size of their loadings and are presented in Table 2. As can be seen; only the first five components are represented. These components together accounted for $53.7 \%$ of the total variance (Eigenvalues for the first 25 components appear in Appendix C). The remaining eleven components were not considered because they were poorly defined; that is, they contained fewer than five items loading at or above the .40 level. Each of the five components represented in Table 2 will be briefly considered in turn.

Authoritative control. The first father component was labeled authoritative control because of its close correspondence to a parenting dimension previously identified by Baumrind (1968). Specifically, this component was very broadly defined with at least four items from 12 of the original $18 \mathrm{CR}-\mathrm{PBI}$ scales. Ninety-two of the total of 192 items had a loading of : 40 or higher on this component. The content of the 
highest loading items clearly related to control; that is, they suggested an individual who is directive and who exerts both direct and psychological forms of control when the child misbehaves. Items representative of this aspect of the component are "Wants to control whatever I do," "Asks other people what I do away from home," and "Almost always punishes me in some way when I misbehave." Additional items loading on this component further suggested a parent who, while not generally supportive or involved, is capable of being expressive and flexible with the child, encourages give and take, shares with the child the reasoning behind rules, and doesn't burden the child with numerous restrictions (i.e., acknowledges the child's rights in certain areas such as dress, use of free time, and the spending of personal funds).

\section{Control through love withdrawal. Iike the first component, this} component was broadly based, consisting of 87 items drawn largely from six CR-PBI scales. This component also appeared to represent a dimension of parental control. The content of positively loaded items largely related to directing or restricting the child in accordance with set standards of conduct (e.g., "Keeps reminding me about things I am not allowed to do," "Sticks to a rule instead of allowing a lot of exceptions"). Negatively loaded items, on the other hand, frequently referred to acceptance of the child as an individual and autonomy (e.g., "Tries to understand how I see things"). In contrast to the first component, the style of control appeared to be generally psychological with particular emphasis on withdrawal of affection. This was suggested in several ways. First, items which referred to rejection and detachment consistently 
TABIE 2

ITEMS LOADING $>.40$ ON THE VARIMAX ROTATED COMPONENTS OF THE FATHER VERSION OF THE CR-PBI

\begin{tabular}{lll}
\hline Loading & Item \\
Number Item & CR-PBI Scale \\
\hline
\end{tabular}

Component 1. Authoritative control

$.942 \quad 119$ Complains that I get on his nerves Hd

$.926 \quad 135$ Doesn't get me things unless I ask over and over again Rej

$.925 \quad 139$ Wants to control whatever I do HC

$.922 \quad 118$ Says that someday I'll be sorry that I wasn't better as a child Anx

$.914 \quad 114$ Says if I love him, I'd do what he wants me to do $\mathrm{Cg}$

$.914 \quad$ Doesn't work with me Rej

$.912 \quad 126$ Asks other people what I do away from home Int

$.906 \quad 104$ only keeps rules when it suits him Id

$.903 \quad 103 \quad$ Is unhappy that I'm not better than I am
in school

$.897 \quad 108$ Will avoid looking at me when I've disappointed him

$.894 \quad 142$ Thinks that any misbehavior is very serious and will have future consequences Anx

$.887 \quad 107$ Almost never goes on Sunday drives or picnics with me

.885130 Does not insist I obey if I complain or protest 
Table 2:Continued

Item

Loading Number Item

CR-PBI scale

Component 1. Continued

$.869 \quad 115$ Gets cross and nervous when I'm noisy around the house

Hc

$.869 \quad 116$ Seldom insists that I do anything

$\mathrm{Ne}$

.869148 Sees to it that I keep my clothes neat, clean, and in order

C

$.864 \quad 124$ Insists that I must do exactly as I am told

C

$.859 \quad 110$ Usually makes me the center of his

attention at home

Pos

$.859 \quad 112$ Almost always punishes me in some way when I am bad

E

$.809 \quad 128$ Frequently changes the rules I am

supposed to follow

Id

$.790 \quad 102$ Wants to know with whom I've been when

I've been out

Int

$.786 \quad 144$ Allows me to spend my money in any way I like

Ea

.784101 Often has long talks with me about the causes and reasons for things

$.781 \quad 106$ Lets me stay up late if I keep asking

Ld

$.778 \quad 122$ Enjoys staying at home with me more

than going out with friends

Cc

$.763 \quad 146$ Makes his whole life center about his children

Cc

$.757 \quad 120$ Lets me dress in any way I please

Ea

$-.753 \quad 81$ Makes me feel free when I'm with him

AI 
Table 2:Continued

\begin{tabular}{lll}
\hline Loading & $\begin{array}{l}\text { Item } \\
\text { Number }\end{array}$ & Item \\
\hline
\end{tabular}

Component 1 . Continued

$-.739 \quad 145$ Often speaks of the good things I do A

$.738 \quad 105$ Really wants me to tell him just how I feel about things

AI

.732121 Comforts me when I'm afraid

A

$.732 \quad 133$ Cheers me up when I'm sad A

$.717 \quad 141$ Makes me feel at ease when I'm with him AI

$.716 \quad 109$ Enjoys working with me in the house or yard

$.714 \quad 125$ Encourages me to read

$\mathrm{Pi}$

$.706 \quad 131$ Hardly notices when I'm good at home or at school

$\mathrm{Hd}$

$\begin{array}{lll}.703 & 113 & \text { often praises me }\end{array}$

$.699 \quad 137$ Tells me where to find out more about

things I want to know

$\mathrm{Pi}$

-.679 74 Often gives up something to get something for me

$\mathrm{Cc}$

-.666 24 Allows me to go out as often as I please Ea

-.666 79 Keeps after me about finishing my work Hc

$.623 \quad 134$ Does not approve of my spending a lot of time away from home

$-.622 \quad 132$ If I take someone else's side in an argument, is cold and distant to me $\mathrm{W}$

$-.620 \quad 147$ Doesn't seem to know what I need or want Rej

$-.609 \quad 13$ Seems to see my good points more than my faults 
Table 2:Continued

\begin{tabular}{lll}
\hline Loading & $\begin{array}{l}\text { Item } \\
\text { Number }\end{array}$ Item & CR-PBI Scale \\
\hline
\end{tabular}

Component 1. Continued

$-.606 \quad 1$ Makes me feel better after talking over my worries with him A

$\begin{array}{llll}-.595 & 10 & \text { Is easy with me Ld }\end{array}$

$.595 \quad 152$ Insists I follow a rule one day and then forgets about it the next Id

-.570 97 Enjoys doing things with me A

$-.565 \quad 143$ Is always finding fault with me Hd

-.55728 Believes in having a lot of rules and sticking to them

$\mathrm{Ne}$

-.552 55 Doesn't forget quickly the things I do wrong

$\mathrm{HC}$

$.551 \quad 127$ Loses his temper with me when I don't help around the house

Hc

$-.544$

37 Understands my problems and my worries

A

-.535 36 Sometimes when he disapproves, doesn't say anything but is cold and distant for a while

$-.513 \quad 67$ Tells me how to spend my free time

HC

$-.507$

26 Is always thinking of things that will please me

$\mathrm{Cc}$

$-.503 \quad 86$ Becomes very involved in my life Pos

$.498 \quad 150$ Questions me in detail about what my

friends and I discuss

Int

-.497 93 Asks me what I think about how we should do things 
Table 2:Continued

\begin{tabular}{lll}
\hline & Item & \\
Loading & Number Item & CR-PBI Scale \\
\hline
\end{tabular}

Component 1. Continued

$\begin{array}{lll}-.495 & 29 & \text { Tells me how much he loves me } \\ -.486 & 34 & \text { Lets me off easy when I do something }\end{array}$ wrong

$\mathrm{Pi}$

Id

-.479 52 Believes all my bad behavior should be punished in some way

C

-.47457 Wants me to tell him about it if I don't like the way he treats me

-.4656 Wants to know exactly where I am and what I am doing

Int

-.464 41 Likes to talk about what he has read with me

Pi

-.46396 Lets me go places I please without asking

$\mathrm{Ea}$

$-.457$

2 Likes to talk to me and be with me much of the time

-.457 61 Enjoys going on drives, trips or visits with me

33 Allows me to tell him if I think my ideas are better than his

$.447 \quad 166 \quad$ Says that sooner or later we always pay for bad behavior

-.44739 Forgets to help me when I need it

$.443 \quad 138$ Tells me of all the things he has done for me 
Table 2:Continued

\begin{tabular}{lll}
\hline Loading & $\begin{array}{l}\text { Item } \\
\text { Number }\end{array}$ & Item \\
\hline
\end{tabular}

Component 1 . Continued

-.415 92 Doesn't check up to see whether I have done what he told me Ne

-.41121 Enjoys it when I bring friends to my home AI

-.40946 If I break a promise, doesn't trust me again for a long time

Anx

Component 2. Control through love withdrawal

$.850 \quad 27 \quad$ Says I'm a big problem

Rej

.83032 Punishes me for doing something one day, but ignores it the next

.82530 Is always checking on what I've been doing at school or at play

Int

.82542 Thinks I'm not grateful when I don't obey Cg

$.821 \quad 53$ Hugs and kisses me often Pi

.82156 Sometimes allows me to do things that he says are wrong

$.813 \quad 72$ Gives me as much freedom as I want Ea

.80959 Thinks I am just someone to "put up with" Hd

$.806 \quad 68$ Doesn't insist that I do my homework Ne

$.794 \quad 63$ Forgets to get me things I need Rej

$.784 \quad 31$ Keeps reminding me about things I am not allowed to do

$.782 \quad 35$ Almost never brings me a surprise or present 
Table 2:Continued

\begin{tabular}{lll}
\hline Loading & $\begin{array}{l}\text { Item } \\
\text { Number }\end{array}$ & Item \\
\hline
\end{tabular}

Component 2. Continued

.77840 Sticks to a rule instead of allowing a lot of exceptions

.77751 Sometimes wishes he didn't have any children

.76947 Doesn't seem to think of me very often

Hd

.76846 If I break a promise, doesn't trust me again for a long time

Anx

$.768 \quad 70$ Says some day I'll be punished for my bad behavior

Anx

.76244 Doesn't pay much attention to my misbehavior

$\mathrm{Ne}$

.76138 Seems to regret that I am growing up and spending more time away from home

39 Forgets to help me when I need it

45 Likes me to choose my own way of doing things

$.746 \quad 52$ Believes that all my bad behavior should be punished in some way

34 Lets me off easy when I do something wrong

43 Tells me exactly how to do my work

$.723 \quad 36$ Sometimes when he disapproves, doesn't say anything but is cold and distant for a while

.72150 Gives me a lot of care and attention Cc 
Table 2: Continued

\begin{tabular}{lll}
\hline Loading & $\begin{array}{l}\text { Item } \\
\text { Number }\end{array}$ Item & CR-PBI Scale \\
\hline
\end{tabular}

Component 2. Continued

.70841 Likes to talk about what he has read with me

Pi

.70761 Enjoys going on drives, trips or visits with me

A

$.701 \quad 33$ Allows me to tell him if I think my ideas are better than his

.66428 Believes in having a lot of rules and sticking to them

C

-.608 $58 \quad$ Can't say no to anything I want Id

$.602 \quad 37 \quad$ Understands my problems and my worries A

$.600 \quad 74$ Often gives up something to get something

for me

Cc

$-.583 \quad 73$ Smiles at me very often

A

$-.567 \quad 129$ Allows me to have friends at my home often

AI

$-.560$

5 Says I'm very good natured

$\mathrm{P} \dot{1}$

$-.560$

113 Often praises me

Pi

$.552 \quad 163$ Is always trying to change me Hc

$-.551 \quad 133$ Cheers me up when I am sad

A

-.546 71 Doesn't seem to enjoy doing things with me

-.546 121 Comforts me when I'm afraid

A

$-.545 \quad 141$ Makes me feel at ease when I'm with him

-.543 137 Tells me where to find out more about

things I want to know 
Table 2: Continued

\begin{tabular}{lll}
\hline Loading & $\begin{array}{l}\text { Item } \\
\text { Number }\end{array}$ & Item \\
\hline
\end{tabular}

Component 2. Continued

$.536 \quad 155$ Often makes fun of me Hd

-.532 69 Lets me help to decide how to do things we're working on

.515191 Is never interested in meeting or talking with my friends Hd

.50960 Speaks to me in a cold, matter-of-fact voice when I offend him

W

$.506 \quad 54$ Asks me to tell everything that happens when I am away from home Int

.50583 Doesn't show me that he loves me Hd

$.504 \quad 57$ Wants me to tell him about it if I don't like the way he treats me

-.491 9 Doesn't mind if I kid him about things

$-.481 \quad 105$ Really wants me to tell him just how I feel about things

AI

$-.481 \quad 161$ Hugged or kissed me goodnight when I was small

$.479 \quad 176$ Changes his mind to make things easier for himself

-.473 117 Tries to understand how I see things AI

-.467 120 Lets me dress in any way I please Ea

-.459 109 Enjoys working with me in the house or yard 
Table 2:Continued

\begin{tabular}{lll}
\hline Ltem & & \\
Number Item & CR-PBI Scale
\end{tabular}

Component 2. Continued

$-.451 \quad 101$ Often has long talks with me about the causes and reasons for things

$\mathrm{Pi}$

-.448 144 Allows me to spend my money in any way

I like

Ea

$.439 \quad 84$ Is less friendly with me if I don't see things his way

W

$.437 \quad 64$ Gives hard punishments E

$-.436 \quad 106$ Lets me stay up late if I keep asking Id

$.435 \quad 187$ Doesn't let me decide things for myself Hc

.42499 Gets cross and angry about little things I do

Rej

$-.420 \quad 157$ Has a good time at home with me

A

-.414 122 Enjoys staying at home with me more

than going out with friends Cc

$.408 \quad 179$ Often seems glad to get away from me for a while Hd

$.404 \quad 75$ Is always getting after me Rej

$.403 \quad 102$ Wants to know with whom I've been when

I've been out Int

Component 3. Support

-.674 171 Tells me to quit "hanging around the house" and go somewhere Rej

$-.673 \quad 159$ Acts as though I'm in the way Rej

$.668 \quad 149$ Is happy to see me when I come from school or play 
Table 2:Continued

\begin{tabular}{lll}
\hline Loading & $\begin{array}{l}\text { Item } \\
\text { Number }\end{array}$ & Item \\
\hline
\end{tabular}

Component 3 . Continued

$.662 \quad 185 \quad$ Says I make him happy

$\mathrm{Pi}$

$.630 \quad 173$ Is very interested in what I am learning

at school

Pi

-.627 151 Doesn't give me any peace until I do

what he says

$\mathrm{HC}$

.620169 Seems proud of the things I do

A

AI

whenever possible

$.567 \quad 181$ Isn't interested in changing me, but

likes me as I am

A

$.566 \quad 177$ Lets me do things that other children

my own age do

.562189 Tries to be a friend rather than a boss

AI

.556

165

Is easy to talk to

AI

$-.518$

187

Doesn't let me decide things for myself

HC

.508161 Hugged or kissed me goodnight when I was small

Pi

$.507 \quad 157$ Has a good time at home with me

A

$-.500$

163

Is always trying to change me

$\mathrm{HC}$

$-.491$

183 Makes me feel I'm not loved

Rej

$-.456 \quad 160$ If I do the least little thing that I shouldn't, he punishes me

$E$

-.442 184 Has more rules than I can remember, so

is often punishing me

E

$.411 \quad 174$ Almost always wants to know who phoned me or wrote to me and what they said 
Table 2:Continued

\begin{tabular}{llll}
\hline Loading & Item & \\
Number Item & CR-PBI Scale
\end{tabular}

Component 4. Empathy

.72598 Makes me feel like the most important

person in his life CC

$.684 \quad 85$ Is able to make me feel better when I am upset

A

$.511 \quad 84$ Is less friendly with me if I don't see things his way $W$

$.500 \quad 89$ Always listens to my ideas and opinions Pi

$.429 \quad 82 \quad$ Excuses my bad conduct Ld

Component 5. Psychological autonomy

$.623 \quad 164$ Lets me get away without doing work I have been given to do Ne

$.568 \quad 178$ Can be talked into things easily Id

-.530 172 I have certain jobs to do and am not allowed to do anything until they are done

$\mathrm{C}$

$.507 \quad 154$ I can talk him out of an order, if I complain Ld

$.476 \quad 188$ Lets me get away with a lot of things Ne

$.421 \quad 190$ Will talk to me again and again about things that I do that are best 
loaded in a positive direction. Second, items which referred to patemal support, acceptance, and positive involvement loaded in both positive and negative directions. Finally, of the items relating to psychological control, those which dealt with withdrawal loaded in the highest number (e.g., "Sometimes when he disapproves, doesn't say anything but is cold and distant for a while").

Support. The third father component was labeled support and consisted of 20 items which loaded at or above .40. The pattern of item loadings was consistent with Schaefer's bipolar factor of acceptance vs. rejection. Specifically, positively loaded items clearly suggested a father who displays feelings of interest, support, and affection for the child, shares activities with the child, and is generally accepting of the child as (s)he is. Representative items are "Says I make him happy," "Tries to be a friend rather than a boss." In contrast, negatively loaded items referred to rejection and hostile control (e.g., "Acts as though I'm in the way," "Is always trying to change me"). Empathy. The fourth father component was less clearly defined in that it consisted of only five items and could not be matched with any of the original CR-PBI scales. The content of this component is reflected in the following item - "Is able to make me feel better when I am upset;" that is, parental support expressed in terms of comforting the child and making him/her feel important. However, items which referred to withdrawal of relations and lax discipline also loaded in a positive direction.

Psychological autonomy. The final father component was also rather poorly defined in that it consisted of only five items loading at.40 or 
higher. The content of the highest loading items alluded to parent-child interaction in which the child is allowed much freedom of activity through the father's laxness in enforcing rules (e.g., "Can be talked into things easily").

\section{Mother Response Form}

Analysis of the mother response form of the CR-PBI was the same as that for the father form. A principal components analysis was performed on the $192 \times 192$ matrix of item intercorrelations. The MAP method was employed to determine the number of components to retain, and a varimax rotation was performed on the resulting component pattern. This analysis resulted in 16 components which together accounted for $60.8 \%$ of the total variance. Correlations among items were generally quite low with an average squared interitem correlation of .089. As in the analysis of the father form, only those items which loaded at or above . 40 were considered. Table 3 presents these items listed by component in order of the absolute size of their loadings. As can be seen, only eight components, accounting for $51.3 \%$ of the total variance, appear in this table (Eigenvalues for the first 25 components appear in Appendix C). The remaining eight components were too poorly defined to be considered; that is, they consisted of fewer than five items with loading at or above the . 40 level.

Support. The first mother component was labeled support and consisted of 71 items with a loading of .40 or higher. These items were drawn almost entirely from six CR-PBI scales. As with the father component of the same name, this component represented parent-child interactions characterized by affection, security, and the sharing of 
TABIE 3 .

ITEMS LOADING $>.40$ ON THE VARIMAX ROTATED COMPONENTS

OF THE MOTHER VERSION OF THE CR-PBI

\section{Item}

Loading Number Item

CR-PBI Scale

Component 1. Support

-.88371 Doesn't seem to enjoy doing things with me

Hd

-.87270 Says some day I'll be punished for my bad behavior

Anx

$-.860$

72 Gives me as much freedom as I want

Ea

$-.858$

68 Doesn't insist that I do my homework

Ne

$-.857$

67 Tells me how to spend my free time

HC

$-.841$

69 Lets me help to decide how to do things we're working on

73 Smiles at me very often

A

$-.806$

74 Often gives up something to get something for me

$\mathrm{Cc}$

.72250 Gives me a lot of care and attention

Cc

.72161 Enjoys going on drives, trips, or visits with me

.69549 Enjoys talking things over with me

37 Understands my problems and my worries

A

.691

25 Almost always speaks to me with a warm and friendly voice

2 Likes to talk to me and be with me much of the time 
Table 3:Continued

\begin{tabular}{lll}
\hline Loading & $\begin{array}{l}\text { Item } \\
\text { Number }\end{array}$ Item & CR-PBI Scale \\
\hline
\end{tabular}

Component 1 . Continued

.67433 Allows me to tell her if I think my ideas are better than hers

AI

.6616 Wants to know exactly where I am and what I am doing

Int

.64729 Tells me how much she loves me

$\mathrm{Pi}$

$.645 \quad 54$ Asks me to tell everything that happens

when I'm away from home

Int

.636

9 Doesn't mind if I kid her about things

AI

.635

13 Seems to see my good points more than my faults

A

65 Believes in showing her love for me

$\mathrm{Pi}$

3 Isn't very patient with me

Rej

-.61751 Sometimes wishes she didn't have any children

Rej

$-.606$

23 Spends very little time with me

Hd

.606

26 Is always thinking of things that will

please me

Cc

$-.605$

47 Doesn't seem to think of me very often

Hd

$.598 \quad 145$ Often speaks of the good things I do

A

.595

21 Enjoys it when I bring friends to my home

41 Likes to talk about what she has read with me 
Table 3:Continued

\begin{tabular}{lll}
\hline Loading & $\begin{array}{l}\text { Item } \\
\text { Number Item }\end{array}$ & CR-PBI Scale \\
\hline
\end{tabular}

Component 1 . Continued

$.563 \quad 133$ Cheers me up when I an sad A

$.557 \quad 113$ Often praises me $\quad$ Pi

.55597 Enjoys doing things with me A

-.546 43 Tells me exactly how to do my work Hc

$-.543 \quad 83$ Doesn't show that she loves me Hd

$.543 \quad 121$ Comforts me when I'm afraid A

$.541 \quad 102$ Wants to know with whom I've been when I've been out

Int

$-.540 \quad 11$ Doesn't talk with me very much Hd

$.531 \quad 141$ Makes me feel at ease when I'm with her AI

$-.524 \quad 39$ Forgets to help me when I need it Rej

$.521 \quad 137$ Tells me where to find out more about

things I want to know Pi

$.518 \quad 125$ Encourages me to read Pi

$.516 \quad 89$ Always listens to my ideas and opinions Pi

-.514 15 Thinks my ideas are silly Rej

-.496191 Is never interested in meeting or

talking with my friends Hd

-.491 176 Changes her mind to make things easier

for herself Id

$.491 \quad 85$ Is able to make me feel better when I am upset

A

.490161 Hugged and kissed me goodnight when I was small 
Table 3:Continued

\begin{tabular}{ll}
\hline & Item \\
Loading Number Item & CR-PBI Scale \\
\hline
\end{tabular}

Component 1. Continued

-.483 59 Thinks I an just some to "put up with" Hd

.47957 Wants me to tell her if I don't like the way she treats me

.47781 Makes me feel free when I'm with her AI

$.475 \quad 117$ Tries to understand how I see things AI

$.474 \quad 45$ Iikes me to choose my own way to do things

$.465 \quad 157$ Has a good time at home with me A

$.462 \quad 53$ Hugs and kisses me often Pi

$.458 \quad 105$ Really wants me to tell her just how I feel about things

$.458 \quad 109$ Enjoys working with me in house or yard

$.453 \quad 149$ Is happy to see me when I come from school or play

.449129 Allows me to have friends at my home often

$.443 \quad 62$ Worries about me when I'm away Pos

$.442 \quad 14$ Doesn't let me go places because something might happen to me 
Table 3:Continued

\begin{tabular}{lll}
\hline Loading & $\begin{array}{l}\text { Item } \\
\text { Number }\end{array}$ & Item \\
\hline
\end{tabular}

Component 1. Continued

$-.419 \quad 183$ Makes me feel I'm not loved

Rej

-.417 7 Decides what friends I can go around with

HC

$.412 \quad 24$ Allows me to go out as often as I please Ea

.41036 Sometimes when she disapproves, doesn't say anything but is cold and distant for a while

$.403 \quad 106$ Lets me stay up late if I keep asking

$\mathrm{Ld}$

Component 2. Authoritarian control

$.760 \quad 123$ Doesn't work with me Rej

$.756 \quad 147$ Doesn't seem to know what I need or want Rej

$.755 \quad 159$ Act as though I'm in the way Rej

$.753 \quad 75$ Is always getting after me Rej

$.739 \quad 139$ Tells me of all the things she has done for me Hc

$.733 \quad 163$ Is always trying to change me Hc

$.732 \quad 87$ Almost always complains about what I do Rej

$.730 \quad$ Gets cross and angry about little things
I do

$.723 \quad 124$ Insists that I must do exactly as I'm told C

$.722 \quad 143$ Is always finding fault with me Hd

$.719 \quad 155$ Often makes fun of me Hd

$.719 \quad 187$ Doesn't let me decide things for myself Hc 
Table 3: Continued

\begin{tabular}{lll}
\hline Loading & Item \\
Number & Item & CR-PBI Scale \\
\hline
\end{tabular}

Component 2. Continued

$-.708 \quad 157$ Has a good time at home with me A

-.699 169 Seems proud of the things I do A

$.696 \quad 171$ Tells me to quit "hanging around the house" and go somewhere

Rej

$.693 \quad 76$ Sees to it that I'm on time coming home

from school or for meals

A

C

$.692 \quad 151$ Doesn't give me any peace until I do

what she says

HC

$.684 \quad 103$ Is unhappy that I'm not better in

school than I am

Hc

$.682 \quad 167$ Wishes I were a different kind of person

Hd

.681191 Is never interested in meeting or

talking with my friends

Hd

$.679 \quad 84$ Is less friendly with me if I don't see things her way

W

$.675 \quad 111$ often blows her top when I bother her Rej

$.663 \quad 135$ Doesn't get me things unless I ask over and over again

Rej

.662179 Often seems glad to get away from me for a while

Hd

.660160 If I do the least little thing that I shouldn't, punishes me

$\mathrm{E}$

$.640 \quad 183$ Makes me feel I'm not loved Rej

$.633 \quad 107$ Almost never goes on Sunday drives or picnics

$-.631 \quad 173$ Is very interested in what I am learning at school 
Table 3:Continued

\begin{tabular}{lll}
\hline Loading & $\begin{array}{l}\text { Item } \\
\text { Number Item }\end{array}$ & CR-PBI Scale \\
\hline
\end{tabular}

Component 2. Continued

$-.622 \quad 161$ Hugged and kissed me goodnight when I was small Pi

$.621 \quad 131$ Hardly notices when I am good at home or in school Hd

$.619 \quad 119$ Complains that I get on her nerves Hd

$-.616 \quad 85$ Is able to make me feel better when I am upset

A

$.607 \quad 83$ Doesn't show that she loves me Hd

$.604 \quad 100$ Believes in punishing me to correct

and improve my manners

C

$-.604 \quad 185$ Says I make her happy

$\mathrm{Pi}$

$.602 \quad 115$ Gets cross and nervous when I'm noisy around the house HC

.60095 Doesn't share many activities with me Hd

-.600 97 Enjoys doing things with me A

.59791 Would like to be able to tell me what to do all the time Hc

$.593 \quad 175$ Doesn't like the way I act at home Hc

$.582 \quad 79$ Keeps after me about finishing my work HC

-.580 149 Is happy to see me when I come from

school or play Pi

$-.567 \quad 181$ Isn't interested in changing me, but

likes me as I am A

$-.566 \quad 133$ Cheers me up when I am sad A

$.563 \quad 172$ I have certain jobs to do and am not

not allowed to do anything else until

they are done 
Table 3:Continued

\begin{tabular}{lll}
\hline Loading & $\begin{array}{l}\text { Item } \\
\text { Number Item }\end{array}$ CR-PBI Scale \\
\hline
\end{tabular}

Component 2. Continued

-.563 189 Tries to be a friend rather than a boss AI

$\begin{array}{llll}-.556 & \text { Tries to treat me as an equal Pi }\end{array}$

$-.555 \quad 89$ Always listens to my ideas and opinions Pi

$-.552 \quad 145$ Often speaks of the good things I do A

$.550 \quad 184$ Has more rules than I can remember, so

is often punishing me $E$

.540127 Loses her temper with me when I don't help around the house HC

$-.523 \quad 113$ Often praises me Pi

$-.522 \quad 165$ Is easy to talk to AI

$\begin{array}{lll}-.504 & 125 & \text { Encourages me to read }\end{array}$

$-.490 \quad 121$ Comforts me when I'm afraid A

$-.481 \quad 129$ Allows me to have friends at my home often AI

-.475 109 Enjoys working with me in the house or yard A

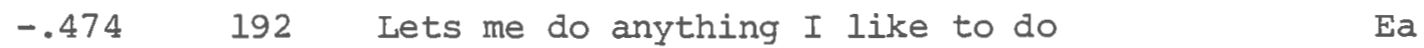

-.450 141 Makes me feel at ease when I'm with her AI

-.443 117 Tries to understand how I see things AI

.438148 Sees to it that I keep my clothes neat,
clean, and in order

-.435 164 Lets me get away without doing work I

have been given to do Ne

$.433 \quad 136$ Sees to it that I obey when she tells me something 
Table 3:Continued

\begin{tabular}{lll}
\hline Loading & $\begin{array}{l}\text { Item } \\
\text { Number Item }\end{array}$ CR-PBI Scale \\
\hline
\end{tabular}

Component 2. Continued

-.420101 Often has long talks with me about the causes and reasons for things

-.40593 Asks me what I think about how we should do things

$.404 \quad 108$ Will avoid looking at me when I've

disappointed her

W

Component 3. Control through guilt/intrusiveness

$.711 \quad 138$ Tells me of all the things she has done for me

$.699 \quad 114$ Says if I loved her, I'd do what she wants me to do

$.654 \quad 162$ Says if I really cared for her, I would not do things that cause her to worry

.57590 Tells me how much she has suffered for me

$.554 \quad 126$ Asks other people what I do away from home

$.462 \quad 102$ Wants to know with whom I've been when I've been out

$.436 \quad 174$ Almost always wants to know who phoned me or wrote to me and what they said

Int

Component 4. Control through guilt/restrictiveness

$.704 \quad 66$ Feels hurt by the things I do

.69842 Thinks I am not grateful when I don't obey

52 Believes that all my bad behavior should be punished 
Table 3: Continued

\begin{tabular}{lll}
\hline Loading & $\begin{array}{l}\text { Item } \\
\text { Number Item }\end{array}$ & CR-PBI Scale \\
\hline
\end{tabular}

Component 4. Continued

$.510 \quad 38$ Seems to regret that I am growing up and am spending more time away from home pos

$.503 \quad 18$ Feels hurt when I don't follow advice $\mathrm{Cg}$

$.500 \quad 62$ Worries about me when I'm away Pos

$.476 \quad 14$ Doesn't let me go places because

something might happen to me Pos

Component 5. Detached control

651 Decides what friends I can go around with

$\mathrm{HC}$

$.642 \quad 31$ Keeps reminding me about things I am not allowed to do

$\mathrm{HC}$

$.636 \quad 19$ Is always telling me how I should behave Hc

$.554 \quad 59$ Thinks I am just someone to "put up with" Hd

$.552 \quad 15$ Thinks my ideas are silly Rej

$.54320 \quad$ Usually doesn't find out about my misbehavior

.51639 Forgets to help me when I need it Rej

.50644 Doesn't pay much attention to my misbehavior

$\mathrm{Ne}$

$.499 \quad 23$ Spends very little time with me Hd

$.466 \quad 43$ Tells me exactly how to do my work HC

$.447 \quad 63$ Forgets to get me things I need Rej

-.437 21 Enjoys it when I bring friends to my home 
Table 3:Continued

\begin{tabular}{lll}
\hline Loading Number Item & CR-PBI Scale
\end{tabular}

Component 5. Continued

.42255 Doesn't forget quickly the things

I do wrong HC

$.412 \quad 57$ Doesn't seem to think of me very often Hd

Component 6. Psychological autonomy

$.602 \quad 96$ Lets me go places I please without asking

$\mathrm{Ea}$

$.589 \quad 144$ Allows me to spend my money in any way

I like

$\mathrm{Ea}$

$.574 \quad 192$ Lets me do anything I like to do

$\mathrm{Ea}$

$.561 \quad 168$ Lets me go out any evening I want

$\mathrm{Ea}$

$.484 \quad 188$ Lets me get away with a lot of things Ne

$.440 \quad 120$ Lets me dress in any way I please Ea

$.431 \quad 116$ Seldom insists that I do anything Ne

$.430 \quad 140$ Doesn't bother to enforce rules Ne

$.408 \quad 164$ Lets me get away without doing work I

had been given to do

Component 7. Control through withdrawal from a relationship

.68660 Speaks to me in a cold, matter-of-fact

voice when I offend her

$.657 \quad 12$ Will not talk to me when I displease her 
Table 3:Continued

\begin{tabular}{|c|c|c|c|}
\hline Loading & $\begin{array}{l}\text { Item } \\
\text { Number }\end{array}$ & Item & CR-PBI scale \\
\hline \multicolumn{2}{|c|}{ Component 7 . } & Continued & \\
\hline .558 & 40 & $\begin{array}{l}\text { Sticks to rules instead of allowing a } \\
\text { lot of exceptions }\end{array}$ & $\mathrm{E}$ \\
\hline .534 & 36 & $\begin{array}{l}\text { Sometimes when she disapproves, doesn't } \\
\text { say anything but is cold and distant for } \\
\text { a while }\end{array}$ & $\mathrm{W}$ \\
\hline \multicolumn{2}{|c|}{ Component 8 . } & Inconsistent discipline & \\
\hline .619 & 104 & Only keeps rules when it suits her & Id \\
\hline .564 & 128 & $\begin{array}{l}\text { Frequently changes the rules I am } \\
\text { supposed to follow }\end{array}$ & Id \\
\hline-.456 & 166 & $\begin{array}{l}\text { Says that sooner or later we always pay } \\
\text { for bad behavior }\end{array}$ & An $x$ \\
\hline .441 & 80 & $\begin{array}{l}\text { Depends upon her mood whether a rule is } \\
\text { enforced or not }\end{array}$ & Id \\
\hline .419 & 176 & $\begin{array}{l}\text { Changes her mind to make things easier } \\
\text { for herself }\end{array}$ & Id \\
\hline
\end{tabular}


ideas, interests and activities. The component generally contained positive loadings for items from the CR-PBI scales of acceptance, positive involvement, and acceptance of individuation. The following items are highly representative of these - "Understands my problems and my worries," "Believes in showing her love for me," "Makes me feel at ease when I'm with her." Negative loadings were on items drawn primarily from the scales of rejection and hostile detachment. Characteristic of these are the items "Sometimes wishes she didn't have any children," and "Spends very little time with me."

Authoritarian control. The second mother component was labeled authoritarian control due to its high degree of similarity to a parenting dimension previously reported by Baumrind (1968). This component was rather broadly based in that it consisted of 63 items drawn largely from seven CR-PBI scales. The content of loaded items clearly related to control. Specifically, the majority of positively loaded items referred to direction and regulation of the child's behavior in accordance with set standards of conduct but without reference to the style of control (i.e., direct or psychological). Positive loadings for other than control-related items were found for coldness and unresponsiveness toward the child, and the expression of annoyance and impatience when the child is disruptive or disobeys. The content of negatively loaded items referred to positive emotional involvement, acceptance of the child as an individual, and autonomy. In sum, the nature of this component is reflected in the following items: "Doesn't seem to know what I need or want," "Is always trying to change me," 
"Doesn't show me that she loves me," "Has more rules than I can remember, so is often punishing me."

Control through guilt/intrusiveness and guilt/restrictiveness.

The third and fourth mother components were not very clearly defined in that they contained only six and seven items, respectively. Both appeared to represent a specific style of psychological control control through instilling guilt (e.g., "Tells me how much she has suffered for me"). These two components could only be differentiated by the fact that additional items in the former suggested a parent who actively seeks out information on the child's behavior outside the home, whereas, those in the latter suggested a parent who expresses concern and may take direct measures to restrict the child's activities. This distinction is illustrated by the following two items: "Asks other people what I do away from home," "Doesn't let me go places because something might happen to me." On the basis of this, the third and fourth mother components were labeled control through guilt/intrusiveness and control through guilt/restrictiveness, respectively.

Detached control. The fifth mother component consisted of 14 items and was labeled detached control. Items loading on this component were drawn primarily from the following three CR-PBI scales: hostile control, hostile detachment, and rejection. The content of items suggested parent-child interactions marked by control ("Is always telling me how I should behave"), fault-finding ("Thinks my ideas are silly"), detachment ("Spends very little time with me"), and either unawareness or unresponsiveness to the child's needs ("Forgets to help me when I need it"). 
Psychological autonomy. The sixth mother component contained six items, all of which were drawn from the CR-PBI scales labeled extreme autonomy and nonenforcement. This component seemed to represent a generally permissive style of parenting. The content of loaded items reflected a parent who makes few demands on the child, sets no clearly defined standards of conduct, and avoids the exercise of power.

Control through withdrawal from a relationship. The seventh mother component contained six items from two CR-PBI scales - control through withdrawal of relationship and enforcement. Examination of these items suggested some similarities to the love withdrawal component identified in the analysis of the father response form. However, in contrast to it, the items of this component did not directly indicate that love or support is present and then taken away. Rather they indicated only that the parent cuts off interaction with the child when she disapproves of the behavior (e.g., "Will not talk to me when I displease her"). For this reason, it was felt that this component would be best conceptualized as withdrawal from a relationship.

Inconsistent discipline. The final mother component consisted of five items, four of which came from the CR-PBI scale labeled inconsistent discipline. The content of items loading on this component represented a parent whose enforcement of rules is totally dependent upon her moods or whims (e.g., "Only keeps rules when it suits her"). 
TABLE 4

CROSS CLASSIFICATION OF ITEMS* BETWEEN THE

COMPONENTS OF THE CR-PBI (F.R.F.) AT THE ORIGINAL SCALES

\begin{tabular}{|c|c|c|c|c|c|c|}
\hline \multirow{2}{*}{$\begin{array}{l}\text { CR-PBI } \\
\text { Scales }\end{array}$} & \multicolumn{5}{|c|}{ Components } & \multirow[b]{2}{*}{ Possible } \\
\hline & 1 & 2 & 3 & 4 & 5 & \\
\hline A & 8 & 8 & 3 & 1 & 0 & 16 \\
\hline $\mathrm{Cc}$ & 5 & 3 & 0 & 1 & 0 & 8 \\
\hline Pos & 3 & 1 & 0 & 0 & 0 & 8 \\
\hline $\operatorname{Rej}$ & 5 & 7 & 3 & 0 & 0 & 16 \\
\hline $\mathrm{C}$ & 4 & 2 & 0 & 0 & 1 & 8 \\
\hline$E$ & 1 & 3 & 2 & 0 & 0 & 8 \\
\hline $\mathrm{P} i$ & 6 & 10 & 4 & 1 & 0 & 16 \\
\hline Int & 5 & 2 & 1 & 0 & 0 & 8 \\
\hline $\mathrm{Cg}$ & 2 & 1 & 0 & 0 & 0 & 8 \\
\hline HC & 7 & 6 & 3 & 0 & 0 & 16 \\
\hline Id & 3 & 3 & 0 & 0 & 0 & 8 \\
\hline $\mathrm{Ne}$ & 3 & 2 & 0 & 0 & 2 & 8 \\
\hline $\bar{A} I$ & 8 & 9 & 4 & 0 & 0 & 16 \\
\hline Ld & 4 & 3 & 0 & 1 & 2 & 8 \\
\hline Anx & 4 & 2 & 0 & 0 & 1 & 8 \\
\hline $\mathrm{Hd}$ & 6 & 8 & 0 & 0 & 0 & 16 \\
\hline W & 3 & 3 & 0 & 1 & 0 & 8 \\
\hline $\mathrm{Ea}$ & 4 & 3 & 0 & 0 & 0 & 8 \\
\hline
\end{tabular}

*Includes all items with loadings $>.40$ on any component. 
TABLE 5

CROSS CLASSIFICATION OF ITEMS* BETWEEN THE

COMPONENTS OF THE CR-PBI (M.R.F.) AT THE ORIGINAL SCALES

\begin{tabular}{|c|c|c|c|c|c|c|c|c|c|}
\hline \multirow{2}{*}{$\begin{array}{l}\text { CR-PBI } \\
\text { Scales }\end{array}$} & \multicolumn{8}{|c|}{ Components } & \multirow[b]{2}{*}{ Possible } \\
\hline & 1 & 2 & 3 & 4 & 5 & 6 & 7 & 8 & \\
\hline A & 13 & 9 & 0 & 0 & 0 & 0 & 0 & 0 & 16 \\
\hline $\mathrm{Cc}$ & 4 & 0 & 0 & 0 & 0 & 0 & 0 & 0 & 8 \\
\hline Pos & 2 & 0 & 0 & 3 & 0 & 0 & 0 & 0 & 8 \\
\hline $\operatorname{Rej}$ & 8 & 10 & 0 & 0 & 3 & 0 & 0 & 0 & 16 \\
\hline $\mathrm{C}$ & 0 & 5 & 0 & 1 & 0 & 0 & 0 & 0 & 8 \\
\hline $\mathrm{E}$ & 0 & 3 & 0 & 0 & 0 & 0 & 3 & 0 & 8 \\
\hline $\mathrm{Pi}$ & 12 & 9 & 0 & 0 & 0 & 0 & 0 & 0 & 16 \\
\hline Int & 3 & 0 & 3 & 0 & 0 & 0 & 0 & 0 & 8 \\
\hline $\mathrm{Cg}$ & 0 & 0 & 3 & 3 & 0 & 0 & 0 & 0 & 8 \\
\hline $\mathrm{HC}$ & 2 & 8 & 0 & 0 & 5 & 0 & 0 & 0 & 16 \\
\hline Id & 1 & 0 & 0 & 0 & 0 & 0 & 0 & 4 & 8 \\
\hline $\mathrm{Ne}$ & 1 & 1 & 0 & 0 & 2 & 4 & 0 & 0 & 8 \\
\hline$A I$ & 11 & 6 & 0 & 0 & 1 & 0 & 0 & 0 & 16 \\
\hline Ld & 2 & 0 & 0 & 0 & 0 & 0 & 0 & 0 & 8 \\
\hline Anx & 1 & 0 & 0 & 0 & 0 & 0 & 0 & 1 & 8 \\
\hline $\mathrm{Hd}$ & 8 & 9 & 0 & 0 & 3 & 0 & 0 & 0 & 16 \\
\hline$W$ & 1 & 2 & 0 & 0 & 0 & 0 & 3 & 0 & 8 \\
\hline $\mathrm{Ea}$ & 2 & 1 & 0 & 0 & 0 & 5 & 0 & 0 & 8 \\
\hline
\end{tabular}

*Includes all items with loadings $>.40$ on any component. 
Correspondence between father and mother components and CR-PBI scales

A cross classification of the items between the components identified in the preceding analyses and the eighteen original CR-PBI scales was developed. The cross classification for the father components appears in Table 4, and for the mother components in Table 5. In both tables, items that loaded on more than one component were counted in all cells in which they appeared.

Inspection of these tables indicated that there was no clearcut cross-identification between either the father or the mother components and the original CR-PBI scales. Only one of the total of 13 components drew more than $75 \%$ of its items from a single scale. This was the mother component labeled inconsistent discipline. The remaining components drew the majority of their items in approximately equal numbers from between two and eight scales.

Correspondence between father and mother components

For the most part, the father and the mother components identified in the preceding analyses were assigned different names. This was based on the belief that conceptual differences between most father and mother components outweighed their similarities. This conclusion received support from the cross classification of items between the components for each parent. As shown in Table 6, there was little correspondence between father and mother components. There was either little or no overlap between components, particularly when the direction of item loadings was considered, or a component for one parent was crossidentified with several components for the other. There were only two exceptions to this; the third and fifth father components each 
TABLE 6

CROSS CLASSIFICATION OF ITEMS* BETWEEN THE FATHER COMPONENTS AND THE MOTHER COMPONENTS ${ }^{+}$

\begin{tabular}{lcccccc}
\hline & \multicolumn{7}{c}{ Father Components } \\
& 1 & 2 & 3 & 4 & 5 \\
\hline & 1 & $34(15)$ & $49(17)$ & $5(5)$ & $2(2)$ & - \\
& 2 & $28(16)$ & $22(22)$ & $17(0)$ & $3(1)$ & $2(0)$ \\
Mother & 3 & $5(5)$ & $1(0)$ & $1(1)$ & - & - \\
Components & 4 & $1(0)$ & $3(3)$ & - & - & - \\
& 5 & $4(1)$ & $7(7)$ & - & - & - \\
& 6 & $5(4)$ & $2(0)$ & - & - & - \\
\hline
\end{tabular}

*Includes all items with loadings $>.40$ on any component

${ }^{+}$Number of shared items with loadings in the same direction are listed in parentheses next to the total number of shared items. 

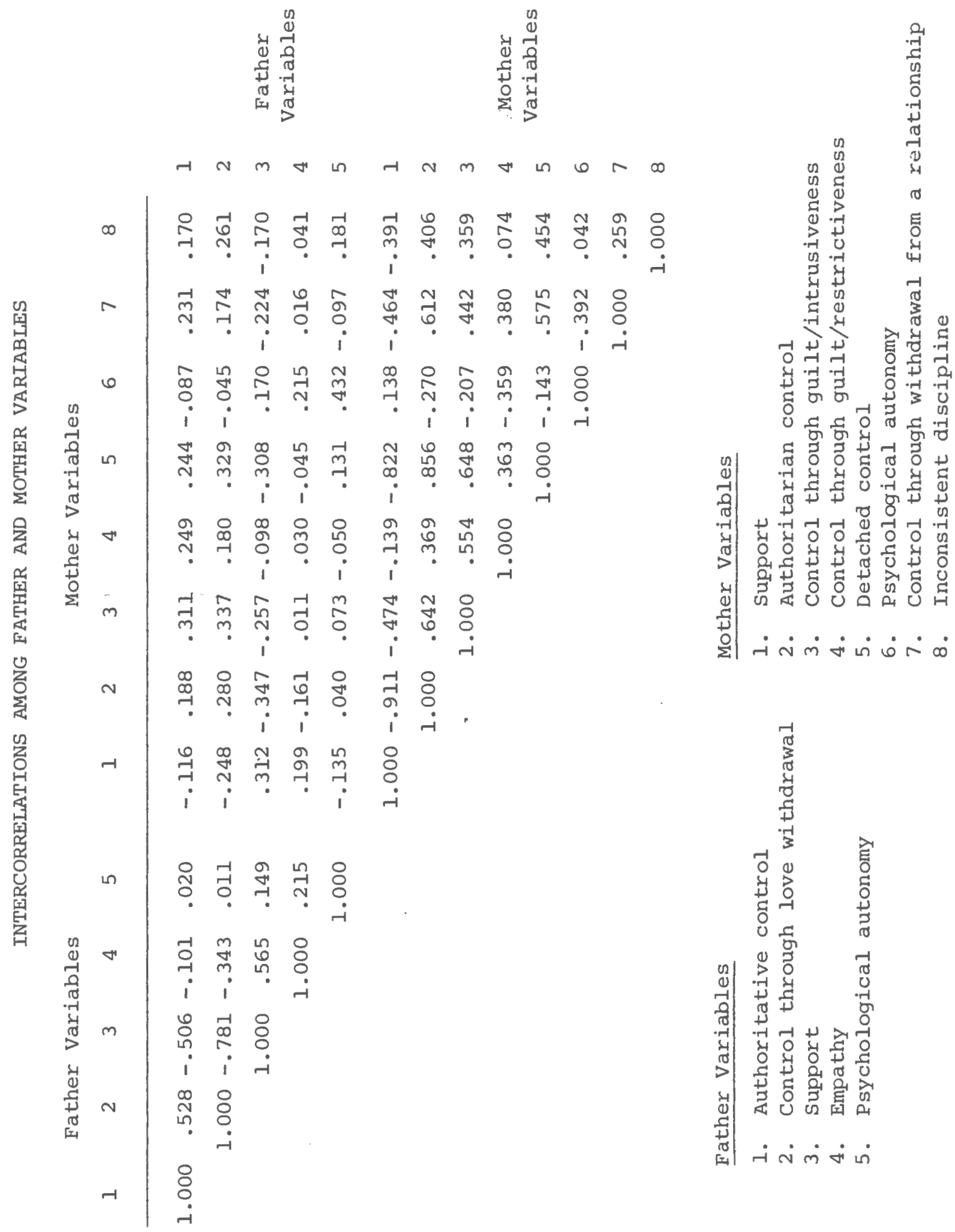
cross-identified with a single mother component, the first and sixth, respectively. In both instances the same label was applied to the father and mother components (i.e., support and psychological autonomy). Interrelations among father and mother components

Intercorrelation among alI the parent variables are presented in Table 7. Examination of this table indicated that the highest intercorrelations were among variables for the same parent. For example, the correlation between father control through love withdrawal and father support was -.78 , and mother support and mother authoritarian control was -.91. By comparison, correlations across parent variables were either a) exceedingly low, or b) distributed amongst variables at an approximately equivalent and moderate level. An example of the latter was the second father variable (control through love withdrawal) which correlated with four mother variables within a range of .26 to .34 . On the basis of this, it may be concluded that the child's perception of one parent along a particular interaction dimension was largely independent of his perception of the other parent along a particular dimension.

\section{Principal Components Analysis of the IPI}

As noted in the method chapter, due to the number of items contained in the IPI, it was necessary to carry out the analysis of these items in two stages. In the first stage, the IPI items were divided in half to form two sets. For each resulting 172 x 172 matrix of item intercorrelations, a principal components analysis was performed using the MAP method with a varimax rotation of the component pattern. In the second stage, a third principal components analysis of a $198 \times 198$ matrix of 
item intercorrelations was performed. The items used to form this matrix consisted of a) the five highest loading items (markers) for each component from stage 1 which contained five or more items with a loading of . 40 or above, and b) items which failed to load on any identified component at a level of .40 or higher. Again, the MAP method with a varimax rotation was performed.

\section{Stage 1 Analyses}

The first 172 items of the IPI were drawn from 24 of the original 28 scales. However, IPI scales labeled daydreaming frequency, night dreaming frequency, absorption in daydreaming, positive reactions in daydreaming, problem solving daydreams, bizarre improbable daydreams, mind wandering, achievement-oriented daydreams, hallucinatory-vividness of daydreams, curiosity:interpersonal, curiosity:impersonal, and boredom were the most highly represented.

The analysis of this set of items resulted in 22 components which together accounted for $65.7 \%$ of the total variance (Individual eigenvalues appear in Appendix C). The average squared interitem correlation was .077. Only items with a loading of .40 or higher on at least one component were considered. Further, only those components with five or more items above this cut-off point were considered. Table 8 presents the resulting seven components with items listed in order of the absolute size of their loadings.

Items 173-344 of the IPI were drawn from the following 16 IPI scales: acceptance of daydreaming, frightened reactions to daydreams, visual imagery in daydreams, auditory images in daydreams, presentoriented daydreams, future in daydreams, past in daydreams, fear of 
TABLE 8

ITEMS LOADING $>.40$ ON THE VARIMAX ROTATED

COMPONENTS OF THE IPI (ITEMS 1-172)

Item

Loading Number Item

IPI Scale

Component 1 .

.95849 At times it is hard to keep my mind from wandering

$\mathrm{MW}$

$.957 \quad 68 \quad$ I often relive happy or exciting

experiences in my daydreams

$.954 \quad 55$ Most things that are interesting to start

with lose their appeal after a while

B

.950

53 Sometimes a thrill goes up my spine as I reflect on a great moment of triumph or achievement

51 Maydreams are fairly realistic

Additional Items: $66,70,46,69,57,48,45,67,47,50$, $61,64,54,73,72,63,60,62,65,58$, $52,59,71,1,56,74,24,13,22,106$, $9,26,4,98,3,25,33,10,154,21,20$, $14,75,41,135,17,28,29,84,130,38$, $81,42,110,117,153,32,27,6,100$, $158,18,40,8,127,94,129,91,82,2$, $148,165,96$

Component 2 .

.660147 During a speech meeting, or lecture, I often "come to" realizing that I have not heard a worå the speaker was saying

$.658 \quad 146 \quad$ I often daydream about event that happened over a year ago

Abs 
Table 8:Continued

Item

Loading Number Item

IPI Scale

Component 2. Continued

.512118 In my daydreams, the voices of people in my family are criticizing me

$\mathrm{Hv}$

.449148 I often have the same daydream over and over again

Abs

Additional Items: 131, 108, 142

Component 3 .

$.840 \quad 15 \quad$ I recall my dreams fairly clearly (never once a night)

Ndf

$.829 \quad 11 \quad$ I recall my night dreams vividly (never once a night)

Ndf

.81619 I recall my dreams in some form (never once a night)

Ndf

.7697 I can recall a dream (never - once a night) Ndf

$.707 \quad 12 \quad$ I recall my night dreams in the form of (vague impressions - clearly with great detail)

Ndf

Additional Items: $8,16,23,4$

Component 4 .

$.763 \quad 87$ I like to read about the personal lives of persons of public prominence

Ci

$.738 \quad 85 \quad$ My thoughts seldom drift from the subject

before me

Mw

.732

95 I usually feel content and quite excited after a daydream

Pr 
Table 8:Continued

\begin{tabular}{lll}
\hline & $\begin{array}{l}\text { Item } \\
\text { Loading }\end{array}$ Number & \\
\hline
\end{tabular}

Component 4. Continued

.73093 In my fantasies, I receive an award before

a large audience

Ach

.70789 I often imagine myself as a different

person or living a very different life

than I am now

$\mathrm{Bi}$

Additional Items: $90,81,78,97,82,96$

Component 5 .

$.618 \quad 37$ The visual images in my daydreams are so

vivid I believe they are actually

happening

$\mathrm{HV}$

.60021 I recall interesting or elaborate areams (rarely - once a night)

Ndf

.5445 I recall or think over my daydreams

(infrequently - many different times during the day)

Df

$.490 \quad 17$ I lose myself in active daydreaming

(infrequently - many different times

during the day)

Df

$-.480 \quad 39$ I often think about the lives of famous persons

Additional Items: $9,38,32,35$

Component 6 .

$.627 \quad 77$ My daydreams often leave me with feelings

of sadness $\quad$ Pr

$.624 \quad 84$ I seldon get really interested or involved

in what I am doing 
Table 8:Continued

\begin{tabular}{ll}
\hline Item \\
Loading \\
Number Item
\end{tabular}

Component 6 . Continued

$.57892 \quad$ I am the kind of person whose thoughts often wander

MW

.52488 Sometimes my thoughts keep coming back to the same things over and over again, no matter how much I try to change the subject Abs

$.510 \quad 137$ The people in my daydreams are so true to life I often believe they are in the same room with me

Hv

Additional Items: $76,91,75,83,79,80,123$

Component 7 .

$.731 \quad 126$ Voices in my daydreams seem so distinct and clear that I'm almost tempted to answer them

Hv

$.524 \quad 111$ My fantasies sometimes surprise me by suggesting an answer to a problem which I could not work out

Ps

$.431 \quad 171$ In my fantasies I am resentful to a superior for reprimanding me without just cause

Hos

$.430 \quad 137$ People in my daydreams are so true to life I often believe they are in the same room with me

$.400 \quad 136$ In my daydreams I see myself as an expert whose opinion is sought by all 
TABLE 9

ITEMS LOADING $>.40$ ON THE VARIMAX ROTATED

COMPONENTS OF THE IPI (ITEMS 173-344)

Ionding

Number Item

IPI Scale

Component 1 .

$.772 \quad 286$ I feel guilty in a daydream because of my cheating in a game or contest

Glt

$.736203 \quad$ I daydream of volunteering as a subject for an important scientific experiment and winning fame for my bravery

Her

$.735240 \quad$ I daydream about taking advantage of someone less fortunate than I and feeling guilty about it afterward

Glt

.699214 I do not think about what the future will be like

Fut

.673259 My thoughts often come to me slowly

$\mathrm{Mr}$

Additional Items: $222,312,342,300,294,191,316,258$, $247,239,228,289,261,193,195,237$, $283,177,263,213,218,328,206,298$, $324,204,284,288,311,282,186,307$, $205,281,264,293,326,314,207$

Component 2 .

$.680302 \quad$ I get restless if I have nothing to do

NES

$.658 \quad 211$ While working intently at a job, my mind will wander to thoughts about sex

$\mathrm{Sx}$

$.622 \quad 174 \quad$ My thoughts are never on things far

removed from my present-day problems

Prs

.621216 There is always something going through my mind 
Table 9:Continued

Item

Loading Number Item

IPI Scale

Component 2. Continued

$.618200 \quad$ I am happiest when there is nothing I have to do and nowhere I have to go

NES

$\begin{array}{ll}\text { Additional Items: } & \begin{array}{l}212,323,291,182,268,271,280, \\ \end{array} \\ & \begin{array}{l}184,192,218,232,225,301,235,326,\end{array}\end{array}$

Component 3 .

.591335 I daydream about not living up to my parents expectations

Ff

.590249 The effect of a frightening daydream will

linger on for a long time

Fr

.449217 My daydreams have such an emotional effect

on me that I often react with fear

Fr

$.442 \quad 179$ I find myself imagining the unhappiness

I caused my family because of my failure

Ff

$.442 \quad 297$ In my daydreams I am always afraid of

being caught doing something wrong

Glt

Additional Items: 208

Component 4 .

$.631 \quad 173$ I can see the people or things in my

daydreams as if they are moving around

$\nabla i$

$.471 \quad 197$ I often "see" a large number of things or people in my fantasies

Vi

.467228 I sometimes seem able to hear the

characters in my fantasies talking to

one another

$\mathrm{Ai}$ 
Table 9:Continued

Item

Loading Number Item

IPI Scale

Component 4. Continued

.465303 I can hear conversations between myself and other people very clearly in my mind during a daydream

Ai

$.464^{\circ} \quad 185$ I sometimes have a very clear, lifelike picture of what I am imagining

Vi

Additional Items: 242, 252, 194

Component 5 .

.617277 In my idle thoughts, I fear not being able to meet the demands of my job

Ff

$.582 \quad 332$ I don't like to do dangerous or daring things

NES

$.544 \quad 336$ I feel uncomfortable when someone asks me

a personal question

Sr

.536265 I imagine myself not being able to finish

a job I am required to do

Ff

.521317 I imagine endangering myself in order to save my family

Her

Addional Items: $269,241,314$

Component 6 .

$-.627 \quad 175$ I never think at all about events or

scenes of my early childhood

Pst

.487221 Sometimes on my way to work, I imagine myself making love to an attractive person of the opposite sex

219 Even when I am listening to an interesting speaker, my mind wanders 
Table 9:Continued

Item

Loading Number Item

IPI Scale

Component 6 . Continued

$.454191 \quad$ I imagine myself preventing a plot to

kill a political candidate

Her

-.448 186 My present concerns are usually reflected

in my daydreams

Prs

Additional Items: 176

Component 7 .

$.708 \quad 272 \quad I$ never panic as a result of a daydream

Fr

-.694 329 In my daydreams, I show my anger towards

my enemies

Hos

$.646 \quad 331 \quad$ I seldom find myself daydreaming about my younger days

Pst

-.439 284 Some of my fantasies are so terrifying I

shake and shiver

Fr

$-.403$

330 I daydream more about my hopes for the

far future than about my hopes for the present time

Prs

Component 8 .

$.744 \quad 318$ I like to observe my own reactions to things and to other people

Sr

.725295 I am very much concerned with the present in my daydreams

Prs

.610285 In my daydreams I am more likely to

"relive" the past than to look ahead into the future

Pst

$.497307 \quad$ I imagine myself in situations far removed

from my day-to-day life 
Table 9:Continued

Item

Loading Number Item

IPI Scale

Component 8. Continued

$.439 \quad 340$ Details from my day-to-day life are more

clear and complete in my daydreams than

memories of the past

Prs

Component 9 .

.533250 I daydream about the first places in which

I lived, the scenery and the events of my youth

Pst

.507262 In my daydreams I feel guilty for having escaped punishment

$.474274 \quad$ I imagine myself running away from someone who is going to punish me

$.453240 \quad$ I daydream about taking advantage of someone less fortunate than I and feeling guilty about it afterward

.400339 When I an deeply engrossed in my work it is difficult for someone to catch my attention 
failure daydreams, hostile daydreams, sexual daydreams, heroic daydreams, guilt daydreams, mentation rate, distractibility, need for extemal stimulation, and self-revelation. Each of these scales received approximately equal representation.

Analysis of these items resulted in 18 components which together accounted for $51.3 \%$ of the total variance (Individual eigenvalues appear in Appendix c). Interitem correlations tended to be quite low with an average squared correlation of .026 . Again, only those components with a minimum of five items loading at or about. 40 were considered. The resulting nine components are presented in Table 9.

\section{Stage 2 Analysis}

A total of 198 items were included in this stage of the analysis. This set consisted of markers for each component identified in the previous analyses and those items which failed to load on any component at a level of . 40 or higher. The analysis of this reduced set of IPI items resulted in 20 components which accounted for $49.4 \%$ of the total variance. Interitem correlations were very low with an average squared correlation of .018. As in previous analyses, only those items which loaded at or above .40 were considered. Table 10 presents these items listed by component in order of the absolute size of their loadings. As can be seen, only nine components, accounting for $32.9 \%$ of the total variance, appear in this table (Eigenvalues for the first 25 components appear in Appendix C). The remaining 11 components were too poorly defined to be considered; that is, they consisted of fewer than five items with loadings at or above the .40 level. 
Emotional tone of daydreaming. The first component was bipolar and consisted of 22 items. The ten highest loading items were markers for the first components identified in each of the stage 1 analyses. Further, two additional items were markers for the second component in the analysis of items 173-344. Thus, this component represented a total of 154 items with at least one item from every IPI scale.

The content of items represented by this component generally related to the affective quality of imaginal activity. Specifically, positively loaded items suggested an individual with an active fantasy life and a generally positive approach to such activity. For this individual, daydreams consist of enjoyable experiences (e.g., achievement, sex) which serve to stimulate and arouse him/her. Moreover, while daydreams may be somewhat fantastic in nature, they are more typically fairly realistic and are used for anticipating the future and for problem solving.

The content of negatively loaded items suggested a strikingly different orientation toward imaginal activity. For this individual, daydreams take on a strongly negative, ethical tone. Specifically, the content of daydreams revolve around guilt, self-questioning, fears of not meeting others expectations, and hostility. The only potentially positive quality to these experiences is heroism. However, these fantasies tend to be characterized by danger and aggression. As would be expected from the above, the individual tends to view his imaginal activity as neither worthwhile nor interesting, and often reacts to it with fright. 
TABLE 10

ITEMS LOADING >.40 ON THE VARIMAX

ROTATED COMEONENTS OF THE IPI

Item

Loading Number Item

IPI Scale

Component 1. Emotional tone of daydreaming

.92251 My daydreams are fairly realisti

.91755 Most things that are interesting to start with lose their appeal after a while

B

.90749 At times it is hard for me to keep my mind from wandering

Mw

$.90453 \quad$ Sometimes a thrill goes up my spine as I reflect on a great moment of triumph or achievement

.90368 I often relive happy or exciting experiences in my daydreams

-.829286 I feel guilty in a daydream because of my cheating in a game or contest

-.791240 I daydream about taking advantage of someone less fortunate than I and feeling guilty about it afterward

-.760214 I do not think about what the future will be like

Fut

-.718203 I daydream of volunteering as a subject for an important scientific experiment and winning fame for my bravery

-.610259 My thoughts often come to me slowly

$\mathrm{Mr}$

$.489 \quad 199$ I imagine myself to be physically attractive to people of the opposite sex 
Table 10:Continued

Item

Loading Number Item

IPI Scale

Component 1. Continued

$.489296 \quad$ I sometimes daydream about people and places I was familiar with when I was younger

Pst

$-.488 \quad 80$ Some of the voices in my thoughts are threatening or frightening

Hv

.470190 I think about how "the world of the future" will look

Fut

-.461 114 The things that happen in my daydreams

are often extremely strange and unusual

$\mathrm{Bi}$

.425327 When I do hear voices in my thoughts,

they are not really very clear or

recognizable

$\mathrm{Ai}$

$.422 \quad 308$ I think more about "here-and-now" than

about yesterday

Pst

$.422 \quad 170$ When people speak in my daydreams, I

cannot really hear their voices

$\mathrm{Ai}$

.419216 There is always something going through

my mind

$\mathrm{Mr}$

$-.417 \quad 125 \quad$ I can get a fresh approach to an old

problem almost at once during what begins

as an idle daydream

PS

-.404 71 My daydreams often leave me with feelings

of sadness

Pr

$.401 \quad 211$ While working intently at a job, my mind

will wander to thoughts about sex

Sx

Component 2. Absorption in daydreaming

$.632 \quad 147$ During a speech, meeting, or lecture I often "come to" realizing that I have not heard a word the speaker was saying 
Table 10:Continued

Item

Loading Number Item

IPI Scale

Component 2. Continued

$.599 \quad 189 \quad$ A really original idea can sometimes develop from a really fantastic daydream

AcC

$.548 \quad 167$ I picture myself not receiving a promotion I long waited for

Ff

.545310 I do not think about my day-to-day affairs

$.538 \quad 180$ When alone, thoughts do not stop racing through my mind

Mr

$.525210 \quad$ I prefer to keep my personal thoughts and feelings to myself

223 Because daydreaming often takes me away from my work, I try to avoid it even when I have no specific task to complete

.508295 I am very much concerned with the present in my daydreams

Prs

.478299 My thoughts are of the future rather than of the past

Fut

.461318 I like to observe my own reactions to things and to other people

.431277 In my idle thoughts, I fear not being able to meet the demands of my job

.424332 I don't like to do dangerous or daring things

146 I often daydream about events that happened over a year ago

$.406 \quad 131$ My imagination often goes around and around in the same circle 
Table 10:Continued

\begin{tabular}{ll}
\hline Item \\
Loading \\
Number Item
\end{tabular}

Component 3. Guilt (parental) daydreams

$.555 \quad 335$ I daydream about not living up to my parents' expectations

Ff

.551297 In my daydreams I am always afraid of being caught doing something wrong

Glt

.531249 The effect of a frightening daydream will

linger on for a long time

Fr

$.483251 \quad$ I often imagine that someone else knows of the things I've done wrong and holds them against me

Glt

$.457 \quad 179$ I find myself imagining the unhappiness I caused.my family because of my failure

Ff

$.453 \quad 248$ I think about saving the life of a drug addict

Her

$.420 \quad 338$ I daydream of clashing with my parents

over trivial matters

HoS

Component 4. Worried-obsessive daydreams

.56392 I am the kind of person whose thoughts often wander

Mw

.56288 Sometimes my imagination keeps coming back to the same things over and over again, no

matter how much I try to change the subject

Abs

$.548 \quad 83 \quad$ I imagine solving all my problems in my daydreams

Ps

77 My daydreams often leave me with feelings

of sadness

Pr

$.464 \quad 109$ Sometimes a daydream will make me so upset

that I feel like crying

Abs 
Table 10:Continued

Item

Loading Number Item

IPI Scale

Component 4. Continued

$.438 \quad 151$ Some of my daydreams are so powerful that I just can't take my attention away from them

Abs

$.418 \quad 123$ I often wonder about the life of a person

I happen to see standing at a window of an apartment building

Ci

Component 5. Pleasant-controlled daydreams

$.591 \quad 124$ My daydreams often leave me with a warm, happy feeling

$\operatorname{Pr}$

$.565 \quad 166$ I picture myself as I will be several years from now

Fut

-.542 219 Even when I am listening to an interesting speaker, my mind wanders

$-.536 \quad 175$ I never think at all about events or scenes of my early childhood

Pst

$.476 \quad 140 \quad$ My fantasies usually provide me with pleasant thoughts

Pr

$-.455 \quad$ I76 I find that sitting home is a nice way to pass the time

NES

$.437 \quad 152$ I do not like to visit factories and manufacturing plants

$\mathrm{Cm}$

.405221 Sometimes on the way to work, I imagine myself making love to an attractive person of the opposite sex 
Component 6. Vividness of night dream recall

11 I recall my night dreams vividly (never once a night)

Ndf

.818

15 I recall my dreams fairly clearly (never once a night)

Ndf

$.793 \quad 19$ I recall my dreams in some form (never once a night)

Naf

.786

7 I can recall a dream (never - once a night)

Ndf

.707

12 I recall my night dreams in the form of (vague impressions - clearly with great detail)

Ndf

Component 7. Curiosity-achievement daydreams

.70993 In my fantasies, I receive an award before a large audience

Ach

$.706 \quad 87$ I like to read about the personal lives of persons of prominence

.70695 I usually feel content and quite excited after a daydream

$\operatorname{Pr}$

$.703 \quad 85$ My thoughts seldom drift from the subject before me

89 I often imagine myself as a different person or living a very different life than I am now

Component 8. Prospective daydreaming

$.658 \quad 200 \quad$ I am happiest when there is nothing I have to do and nowhere I have to go 
Table 10:Continued

Item

Loading Number Item

IPI Scale

Component 8. Continued

$.561 \quad 174$ My thoughts are never on things far removed

from my present day-to-day problems

Prs

.561211 While working intently at a job, my mind

will wander to thoughts about sex

Sx

$.462 \quad 178$ I am more likely to think about tomorrow

than wonder about yesterday

Fut

.460164 I enjoy arguing with someone who knows a lot

NES

$.447 \quad 111$ My fantasies sometimes surprise me by suggesting an answer to a problem which

I could not work out

Ps

.433

302 I get restless if I have nothing to do

NES

Component 9. Distractibility

$.617 \quad 181$ I will not allow myself to think of some things, knowing how upset I can become when I do

Fr

$.581 \quad 132$ I have difficulty in maintaining concentration for long periods of time

Mw

$.548 \quad 187 \quad$ My daydreams about love are so vivid, I actually feel they are occurring

$\mathrm{Sx}$

$-.462 \quad 160$ My attention is seldom diverted by what

others around me are doing

$\mathrm{D}$

$-.452 \quad 139$ I have often wondered how a bird is able to $f l y$

$\mathrm{Cm}$

.440155 In my daydreams, I fear meeting new

responsibilities in life

Ef 
Absorption in daydreaming. Fourteen items loaded on the second component in this analysis. Of these, four were markers for the second component in the analysis of items 1-172, and two for the fifth component in the analysis of items 173-344. This component, thus, represented a total of 21 items drawn from 13 IPI scales.

In contrast to the first component, the items loading on this component did not appear to refer to any specific daydream content. Less than one-third were content-related, and these were about evenly divided between those which were positive and negative in nature. Moreover, items did not suggest any particular time orientation in daydreaming (i.e., past, present, future). Rather, the content of items comprising this component related to the extent to which an individual is oriented towards and becomes absorbed in ideational activity. Specifically, it was characterized by an emphasis on involvement in such activity to a degree whereby daydreams are experienced as real occurrences and elicit some type of emotional reaction. A further quality of this involvement was that daydreaming is also experienced as being nonvolitional. This latter quality is evident in the following item: "During a speech, or lecture I often 'come to' realizing that I have not heard a word the speaker was saying."

Guilt (parental) daydreams. The third component consisted of seven items. This component bore some similarity to the first in that items reflected a negative affective quality in the content of daydreams. However, the content of this component was far more circumscribed. With only a single exception, items loading on this component referred to imaginal activity involving fears of clashing with parental figures, not 
fulfilling their expectations, or being caught in wrongdoing. Overall, the quality of this component is well summarized by the following item: "I find myself imagining the unhappiness I caused my family because of my failure."

Worried-obsessive daydreams. Seven items loaded on the fourth component. As with the preceding component and most of the remaining components in this analysis, this appeared to represent a rather limited dimension of ideational activity. The nature of this component is reflected in the following items: "Sometimes my imagination keeps coming back to the same things over and over again, no matter how much I try to change the subject," "My daydreams often leave me with feelings of sadness." In other words, this component referred to ideational activity characterized by obsessive worry.

Pleasant-controlled daydreams. This component consisted of five items and was not clearly defined. The items suggested imaginal activity of varied, but generally pleasant, content. Further, the pattern of item loadings suggested that a certain degree of control is exerted over such activity. Thus, one possible interpretation was that that component represented imaginal activity which the individual uses as a means of diversion during periods of inactivity.

Vividness of night dream recall. This component consisted of markers for the third component in the analysis of items 1-172. Thus, nine of the 12 items from the IPI scale labeled night dreaming frequency were represented by this component. Inspection of the content of both those items which loaded and failed to load on this component suggested, however, that it would be more appropriately termed vividness of night 
dream recall. Of the items loading on this component, two-thirds related to how clearly dreams are recalled (e.g., "I recall my night dreams vividly"). Consistent with this, the same proportion of unloaded scale items referred to the frequency of night dream occurrence.

Curiosity-achievement daydreams. Five items, which were markers for the fourth component in the analysis of items 1-172, loaded on the seventh component. It, thus, represented a total of 11 items. This component was not clearly defined. The content generally related to curiosity, both interpersonal and impersonal, and enjoyable fantasies of achievement. The following items are representative: "I like to read about the personal lives of persons of prominence," "I am interested in the kinds of highly skilled machine operations that can be successfully duplicated by completely automatic equipment," "In my fantasies, I receive an award before a large audience."

Prospective daydreaming. This component contained eight items, four of which were markers for a component identified in stage 1. (i.e., the second component in the analysis of items 173-344). A total of 25 items from 13 IPI scales were thus represented. The scales receiving the highest level of representation on this were those for need for external stimulation, future in daydreams, and sexual daydreams. Representative items include: "I get restless when I have nothing to do," "I find myself imagining what I will be doing a year from now," "My sexual daydreams are very vivid and clear in my mind," "Daydreaming is a common experience for great scientists and artists as well as for the average person." As these items would suggest, this component referred to imaginal activity which is both frequent and vivid, and while varied 
in content, is typically prospective in nature. Further, while this anticipation of the future may have practical significance, it is more typically employed as a means of self-distraction and self-stimulation. Distractibility. This is the final component presented in Table 10. It consisted of six items, the content of which largely referred to distractibility, and fears or concerns. The following two items are representative: "I have difficulty in maintaining concentration for long periods of time," "In my daydreams, I fear meeting new responsibilities in life."

\section{Correspondence Between Imaginal Activity Components and IPI Scales}

Table 11 shows the cross classification of items between components identified in the present analysis and the original IPI scales. Iisted for each component are all items with a loading of .40 or higher in the Stage 2 analysis, and items from stage 1 analysis represented by markers.

As indicated in this table, there was little correspondence between components and IPI scales. No component drew a preponderence of its items from any one scale. Moreover, items from 26 of the 28 IPI scales loaded on more than one component; the two exceptions were the scales labeled Daydreaming Frequency and Visual Imagery in Daydreams.

\section{Development of Parent-Child Interaction and Imaginal Activity Scales}

Due to the lack of correspondence between the components identified in the present study and the original scales of both the CR-PBI and IPI it was necessary to develop new scales prior to testing the hypotheses regarding relationships between parent-child interactions and imaginal 
TABLE 11

CROSS CLASSIFICATION OF ITEMS* BETWEEN THE

COMPONENTS OF THE IPI AND THE ORIGINAL SCALES

IPI

Scales

Components

\section{-}

Df

Naf

Abs

AcC

Pr

Fr

$\mathrm{Vi}$

Ai

Ps

Prs

Fut

Pst

$\mathrm{Bi}$

Mw

Ach

$\mathrm{Hv}$

Ff

Hos

Sx

Her

Glt

Ci

$\mathrm{Cm}$

B

$\mathrm{Mr}$

D

NES

Sr

12

456

$\begin{array}{lll}7 & 8 & 9\end{array}$

Possible

12

12

20

12

12

12

12

12

12

12

12

12

12

12

12

12

12

12

12

12

12

12

12

12

12

12

12

12

*Includes all items with loadings $>.40$ on any component. 
TABIE 12

SUMMARY OF PARENT-CHILD INTERACTION

AND IMAGINAL ACTIVITY SCAIES*

Father Scales

Authoritative Control $=1 r+2 r+6 r+10 r+13 r+21 r+24 r+26 r+28 r+29 r+33 r+34 r+36 r+$ $37 r+39 r+41 r+46 r+47 r+52 r+55 r+57 r+61 r+67 r+74 r+79 r+81 r+86 r+92 r+93 r+$ $95 r+96 r+97 r+101+102+103+104+105+106+107+108+109+110+111+112+113+$ $114+115+116+117+118+119+120+121+122+123+124+125+126+127+128+130+$ $131+132 r+133+134+135+137+138+139+140+141+142+143 r+144+145 r+146+$ $147 r+148+150+152+166+174$

Love Withdrawal $=5 r+9 r+16 r+27+28+29+30+31+32+33+34+35+36+37+38+39+40+41+$ $42+43+44+45+46+47+48+49+50+51+52+53+54+56+57+58 r+59+60+61+63+64+65+$ $67+68+69 r+70+71 r+72+73 r+74+75+83+84+87+99+101 r+102 r+105 r+106 r+109 r+$ $113 r+117 r+120 r+121 r+122 r+125 r+129 r+133 r+137 r+141 r+144 r+155+157 r+$ $161 r+163+175+176+179+187+191$

Support $=149+151 r+153+157+159 r+160 r+161+163 r+165+169+171 r+173+174+177+$ $181+183 r+184 r+185+187 r+189$

Empathy $=82+84+85+89+98$

$\underline{\text { Psychological Autonomy }}=154+164+172 r+178+188+190$

Mother scales

Support $=2+3 r+5+6+7 r+9+11 r+13+14+15 r+17+21+23 r+24+25+26+27 r+29+33+34+36+$ $37+39 r+41+43 r+45+47 r+49+50+51 r+53+54+57+59 r+61+62+63 r+65+67 r+68 r+$ $69 r+70 r+71 r+72 r+73 r+74 r+81+83 r+85+89+97+102+105+106+109+113+117+$ $121+125+129+133+137+141+145+149+155 r+157+159 r+161+176 r+183 r+191 r$

Authoritarian Control $=75+76+77 r+79+83+84+85 r+87+89 r+91+93 r+95+97 r+99+$ $100+101 r+103+107+108+109 r+111+113 r+115+117 r+119+121 r+123+124+125 r+$ $127+129 r+131+133 r+135+136+139+141 r+143+145 r+147+148+149 r+151+155+$ $157 r+159+160+161 r+163+164 r+165 r+167+169 r+171+172+173 r+175+179+181 r+$ $183+184+185 r+187+189 r+191+192 r$

Guilt/Intrusiveness $=90+102+114+126+138+162+174$ 
Table 12:Continued

Mother Scales - Continued

Guilt/Restrictiveness $=14+18+38+42+52+62+66$

$\underline{\text { Detached Control }}=7+15+19+20+21 r+23+31+39+43+44+47+55+59+63$

$\underline{\text { Psychological Autonomy }}=96+116+120+140+144+164+168+188+192$

Withdrawal from Relations $=12+16+36+40+60+64$

Inconsistent Discipline $=11+80+104+128+166 r+176$

Imaginal Activity Scales

Emotional Tone $=1+2+3+4+6+8+10+13+14+17+18+20+21+22+24+25+26+27+28+29+$ $30+32 r+33+38+40+41+42+45+46+47+48+49+50+51+52+53+54+55+56+57+58+59+$ $60+61+62+63+64+65+66+67+68+69+70+71+72+73+74+75 r+77 r+80 r+81 r+82+$ $84 r+91+94 r+96 r+98 r+100 r+106+110+114 r+116 r+117+125 r+127 r+129+130+$ $135+148+153 r+154+156 r+158+165+170+177 r+182+183+186+190+191 x+192+$ $193 r+195 r+199+203 r+204 r+205 r+206 r+207 r+211+212+213 r+214 r+216+218 r+$ $222 r+224+225+228 r+232+233+235 r+237 r+239 r+240 r+247 r+258 r+259 r+261 r+$ $263 r+264 r+268+271+280+281+282+283+284 r+286 r+288+289 r+291+293 r+294 r+$ $296+298 r+300 r+301+307 r+308+311+312 r+314+316 r+323+324 r+326+327+382 r+$ $342 r$

Absorption $=108+131+142+146+147+148+163+167+180+189+210+223+241+269+277+$ $295+299+310+314+318+332$

Guilt Daydreams $=179+248+249+251+297+335+338$

Worried-Obsessive Daydreams $=77+83+88+92+109+123+151$

$\underline{\text { Pleasant-Controlled Daydreams }}=124+140+152+166+175 r+176 r+219 r+221+304$

Night Dream Recall $=4+7+8+11+12+15+16+19+23$

Curiosity-Achievement Daydreams $=78+81+82+85+87+89+90+93+95+96+97$

$\underline{\text { Prospective Daydreaming }}=111+126+164+174+178+182+183+192+211+2181+224+$ $225+232+233+235 r+268+271+280+291+301+302+323+326$ 
Table 12:Continued

Imaginal Activity Scales - Continued

$\underline{\text { Distractibility }}=132+139 r+155+160 r+181+187$

$\underline{\text { Daydream Frequency }}=1+2+3+5+6+9+10+14+17+18+20+24$

*An " $r$ " following an item number indicates that the $S$ 's response to that item was reversed prior to addition. For CR-PBI items, reversal was done by subtracting the response value from 4 (i.e., $4-x$ ); for IPI, by subtraction from 6 (i.e., $6-x$ ). 
activity. With regard to the components for the father and mother response forms of the CR-PBI, this process was relatively straightforward - for each component listed in Tables 2 and 3, all items with a loading of . 40 or higher were included in the unweighted summation; if an item loaded positively on a component, the $\underline{S}$ 's response was added directly; if an item loaded negatively on a component, the $\underline{S}$ 's response was reversed before being added. In developing imaginal activity scales for each component listed in Table 10, the same general procedure was followed. However, each scale was the unweighted sum of the items loading at .40 or above, and the items from stage 1 analyses represented by markers. Again, the sign of the item loading determined whether the S's response was added directly or reversed prior to summation. In addition to the above, a daydream frequency score was calculated for each $\underline{S}$ using items from the original IPI scale. A summary of all scales is presented in Table 12 .

\section{Analysis of Relationships Between Imaginal}

Variables and Parent Variables

\section{Pearson Correlations}

Zero order correlations between imaginal activity variables and parent-child interaction variables are presented separately for male and female $\underline{S}$ s in Tables 13 and 14. The initial examination of these matrices indicated that the correlations were generally quite low; no relationship accounted for more than $8 \%$ of the variance and only a small proportion of the correlations achieved statistical significance. Examination of both father and mother variables by sex of $\underline{s}$ indicated that correlations were of approximately equal magnitude. There was a 
slight tendency, however, for the mother variables to be correlated more highly than father variables in the male sample, and for the reverse in the female sample.

Inspection of correlations which achieved significance indicated that, for both fathers and mothers, parent variables referring to control were most consistently related to imaginal variables. There were, however, a limited number of significant correlations between variables relating to support and psychological autonomy, and imaginal variables. In contrast to correlations involving control variables, these tended to be negative. Thus, in general, it would appear that a controlling and somewhat distancing parenting style was associated with imaginal activity.

\section{Stepwise Multiple Regression}

Each of the ten imaginal variables was analyzed using forward stepwise multiple regression techniques. In order to test for differential effects of parental behavior on imaginal activity as a function of the sex of parent, as well as the sex of the child, separate analyses were performed for the following five groups: males' reports of their fathers' behavior, females' of fathers', males' of mothers', and females' of mothers'. Due to the large number of analyses this entailed, only those stepwise regressions resulting in significant relationships (p .05) will be considered.

Absorption in daydreaming. For absorption, there was only one significant correlation with any of the dependent variables. Specifically, the regression of absorption on females' reports of patemal behavior was 


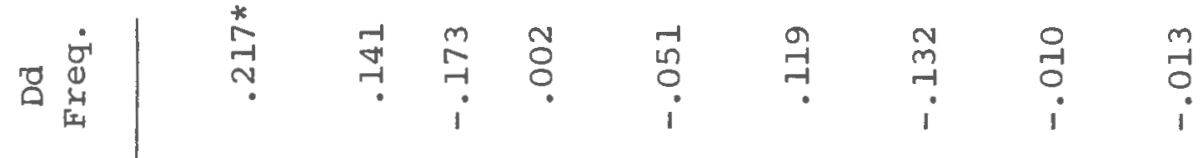

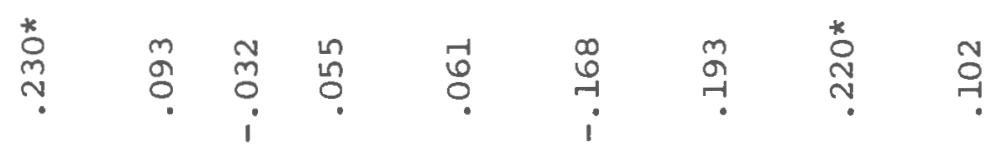

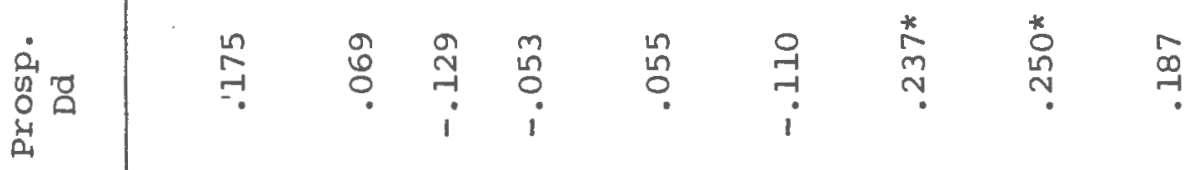

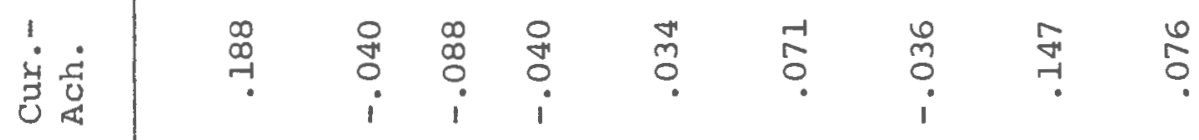

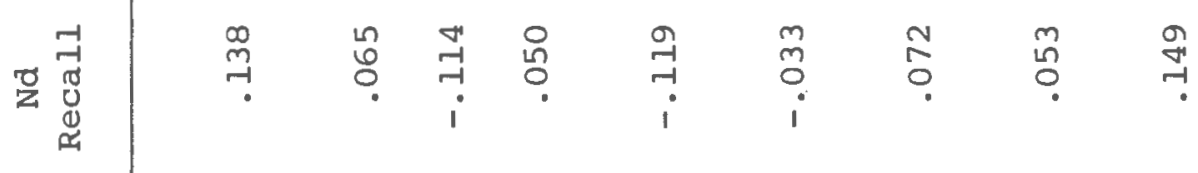

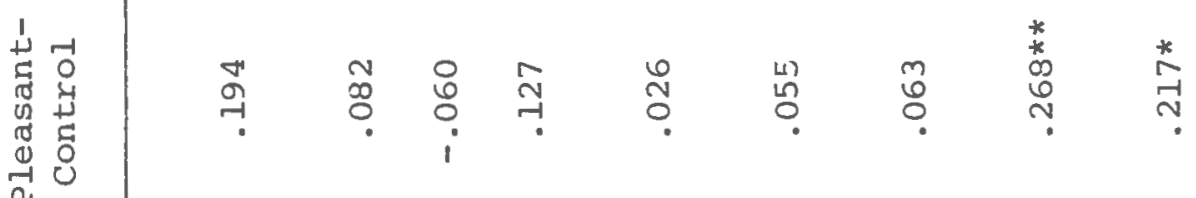

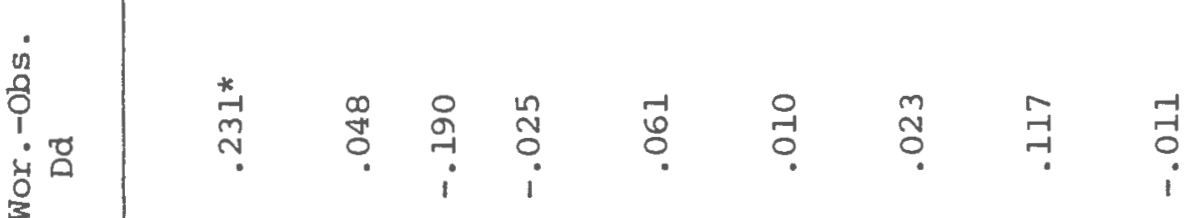

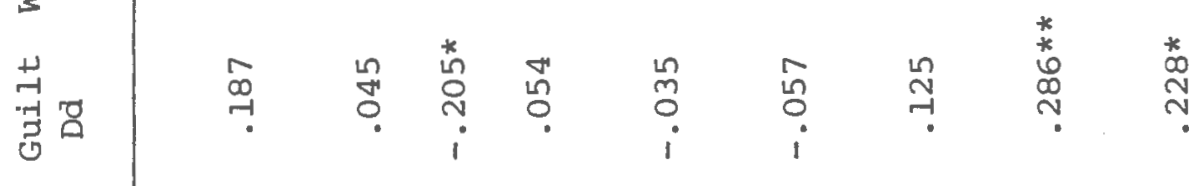

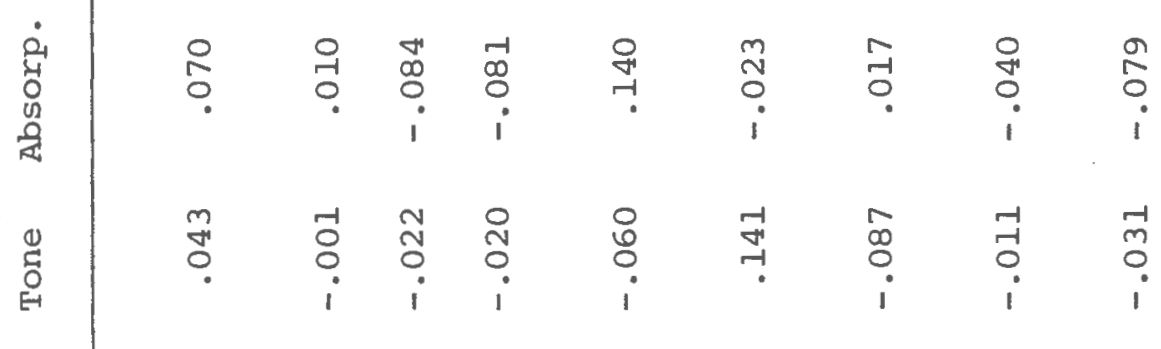

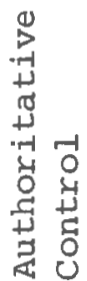
音

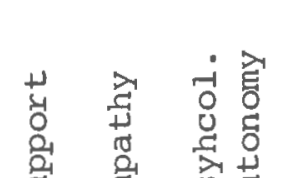

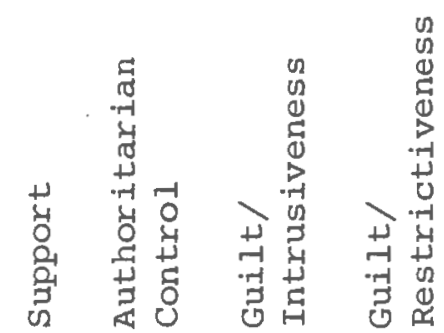




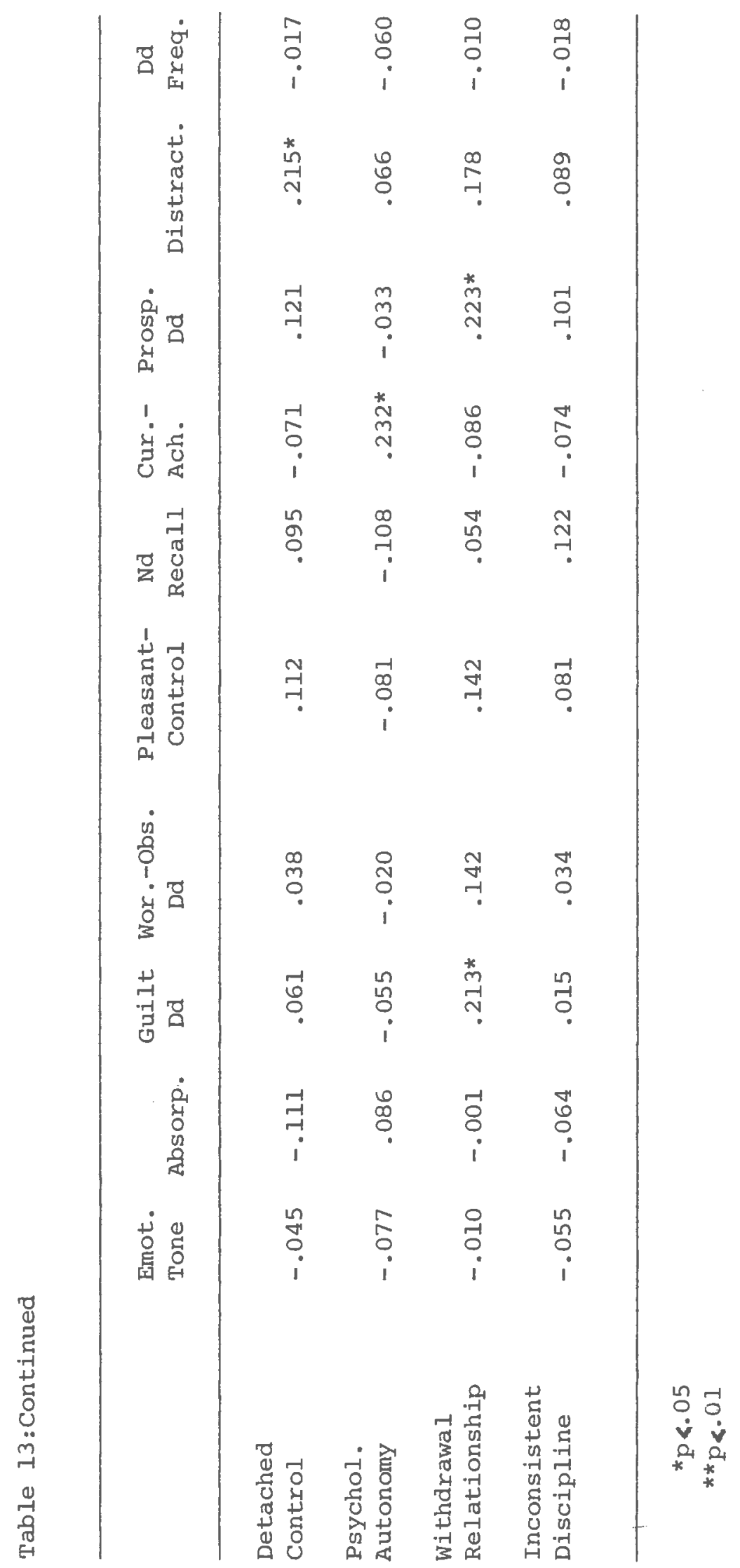




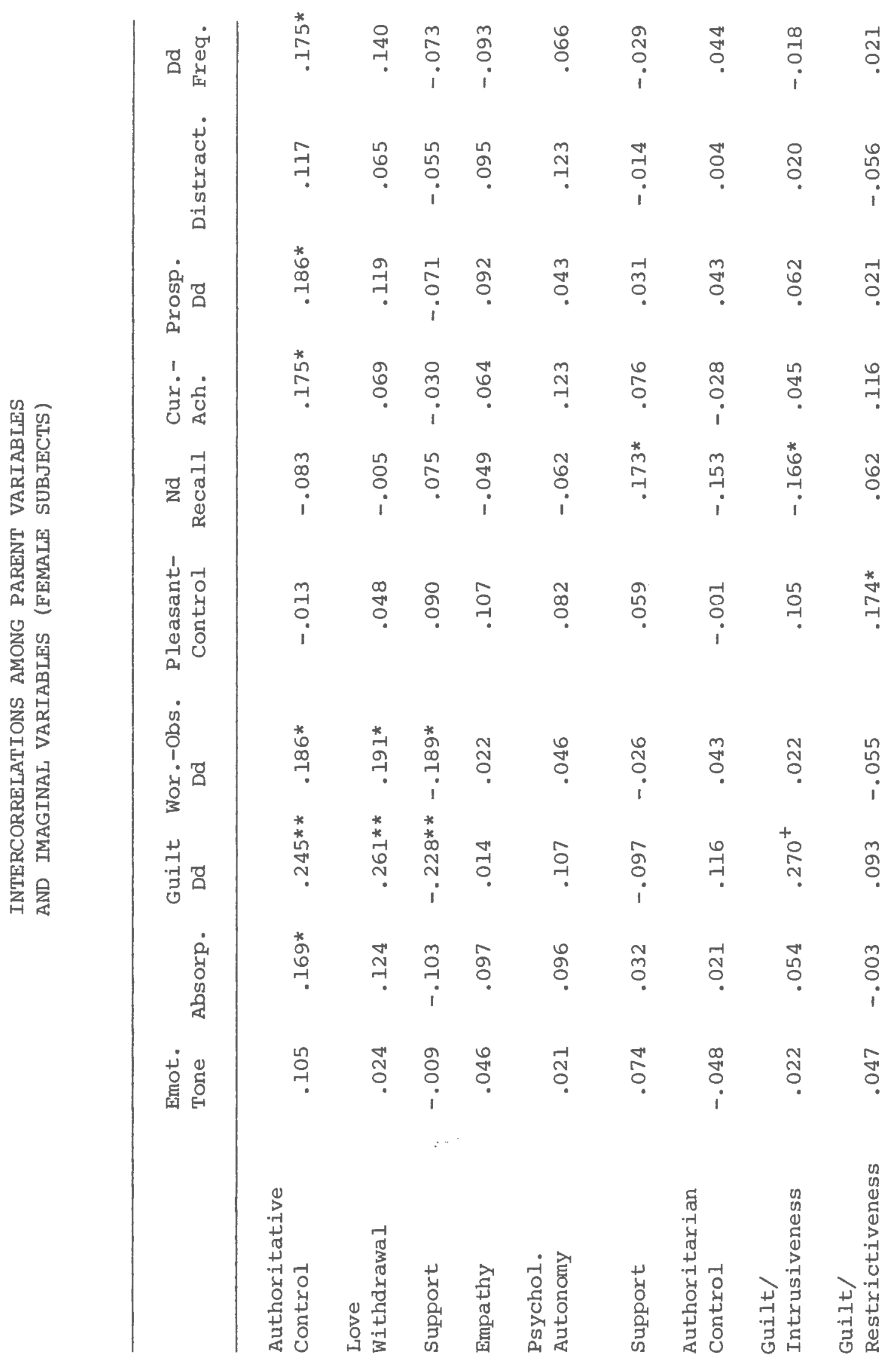




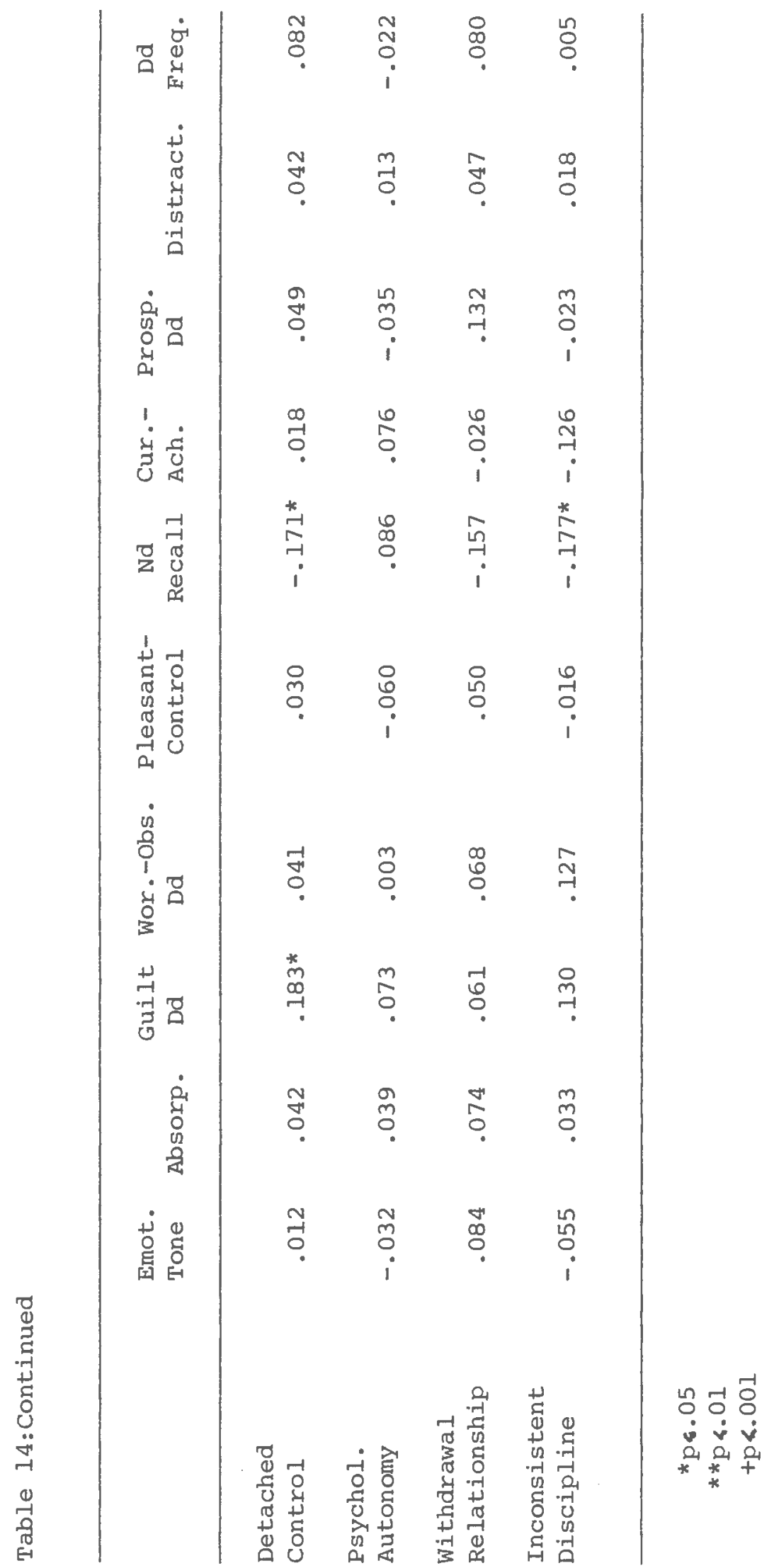


significant for the first variable, authoritative control $\left(R^{2}=.029, F=4.03, d f=1,137 ; p<.05\right)$. The addition of a second variable into the regression equation did not produce a significant incremental increase in the $\mathrm{R}^{2}$.

Guilt (parental) daydreams. An examination of regressions for this imaginal variable indicated significant correlations with the father variables for both males and females. For both sexes, there was a significant increment in $\mathrm{R}^{2}$ only through the first step. With regard to males, the first variable entered was support $\left(R^{2}=.042, F=3.85\right.$, $d f=1,88$; pe.05). By comparison, for females, the first father variable to be entered was control through love withdrawal $\left(R^{2}=.068, F=10.03\right.$, $\mathrm{df}=1,137 ; \mathrm{p}<.05)$.

The regression of guilt (parental) daydreams on the mother variables was similar to that for the father variables in that, for both sexes, there was no significant increment in $\mathrm{R}^{2}$ beyond the first step. For males, as well as females, the first variable entered was control through guilt/intrusiveness $\left(R^{2}=.082, F=7.82, d f=1,88\right.$; pe .05 and $R^{2}=.073, F=10.75, d f=1,137 ; p<.05$, respectively).

Worried-obsessive daydreams. For both sexes, the regression of this imaginal variable on the father variables, alone, was significant. Again, there was no significant incremental increase in $R^{2}$ beyond the first step. For males, the first variable to be entered was authoritative control $\left(\mathrm{R}^{2}=.054, \mathrm{~F}=4.98, \mathrm{df}=1,88 ; \mathrm{p}<.05\right)$ while for females this variable was control through love withdrawal $\left(R^{2}=.036, F=5.18, d f=1,137 ; p 4.05\right)$. 
Pleasant-controlled daydreams. In contrast to the above, the regression of pleasant-controlled daydreaming on the mother, but not the father, variables was significant for both sexes. In the male sample, the entry of control through guilt/intrusiveness resulted in an increment in $\mathrm{R}^{2}$ of $.072(\mathrm{~F}=6.80, \mathrm{df}=1,88 ; \mathrm{p}<.05)$. For females, the entry of control through guilt/restrictiveness provided an increase in $\mathrm{R}^{2}$ of $.030(\mathrm{~F}=4.28, \mathrm{df}=1,137 ; \mathrm{p}<.05)$. The entry of a second mother variable did not produce a significant incremental increase for either males or females.

Vividness of night dream recall. Examination of the regressions for night dream recall indicated that, for females alone, the entry of the first mother variable resulted in a significant increment in $\mathrm{R}^{2}$. The addition of variables beyond inconsistent discipline did not produce any further increments. The $\mathrm{R}^{2}$ at the first step was .031 $(F=4.42, d f=1,137 ; \mathrm{p}<.05)$.

Curiosity-achievement in daydreams. For females, the regression of curiosity-achievement in daydreams on the father variables was significant for the first variable, authoritative control $\left(R^{2}=.031\right.$, $\mathrm{F}=4.34, \mathrm{df}=1,137 ; \mathrm{p}<.05)$. By comparison, for males, the regression for mother variables resulted in a significant increment in $\mathrm{R}^{2}$ for the first step. The first step was for psychological autonomy, and the $\mathrm{R}^{2}$ at this step was $.054(\mathrm{~F}=5.01, \mathrm{df}=1,88 ; \mathrm{p}<.05)$.

Prospective daydreaming. The regressions of prospective daydreaming on the parent variables were similar to those for the preceding imaginal variable; that is a significant correlation with father variables resulted only for females, while a significant 
correlation with mother variables occurred only for males. In both instances only the first step resulted in a significant increment in $R^{2}$. For females, the first step was for the father variable authoritative control $\left(R^{2}=.035, F=4.93, d f=1,137 ; p<.05\right)$. The first step for males was the mother variable psychological control through guilt/intrusiveness $\left(\mathrm{R}^{2}=.063, \mathrm{~F}=5.89, \mathrm{df}=1,88 ; \mathrm{p}<.05\right)$.

Distractibility. For males alone there was a significant correlation between this imaginal variable and both the father and the mother variabies. With respect to the father the addition of variables into the regression equation beyond the first (authoritative control) did not produce a significant incremental increase in the $\mathrm{R}^{2}$ of .053 $(F=4.91, d f=1,88 ; p 4.05)$. Similarly, for the mother variables, only the entry of psychological control through guilt/intrusiveness resulted in a significant increment in $R^{2}\left(R^{2}=.049, F=4.49, d f=1,88\right.$; p <. 05). Frequency of daydreaming. For both sexes, the regression of frequency of daydreaming on the father variables was only significant for the first variable, authoritative control. The amount of variance accounted for by the father variable was somewhat larger for males $\left(R^{2}=.047, F=4.36, d f=1,88 ; p<.05\right)$ than for females $\left(R^{2}=.031, F=4.32\right.$, $\mathrm{df}=1,137 ; \mathrm{p}<.05)$

Summary of multiple regressions. The multiple regression analyses performed added little to the information already provided by the Pearson correlations. This was due to the fact that predictive power was not significantly enhanced by the addition of parent variables; 
that is, none of the regression analyses resulted in a significant increase in variance accounted for beyond the entry of the first variable. 


\section{DISCUSSION}

Given the rather large number of analyses presented in the Results chapter, each major section will be discussed separately. First, principal components analyses were employed to define the domain of parent-child interactions for the present sample. Relationships between the results obtained and previous research on the CR-PBI are discussed. Additional investigations of the dimensions of parent-child interaction are also presented in an effort to explain inconsistencies. Next, principal components analyses were used to define the domain of imaginal activity for the present sample. The results obtained are discussed in relation to previous analyses of the IPI, as well as theoretical conceptualizations of this domain. Finally, findings pertaining to the relationships between parent-child variables and imaginal variables are considered. The results of this study are discussed in relation to the present body of literature that relates to the antecedents of cognitive development, in general, and imaginal development, in particular. Implications for future research are considered.

\section{The Domain of Parent-Child Interactions}

As originally constructed, the Children's Report of Parental Behavior Inventory purports to measure eighteen general characteristics of parent-child interactions. Analyses of the scales representing these 
characteristics (e.g., Burger \& Armentrout, 1971; Cross, 1969; Schaefer, 1965b) have consistently indicated that the domain of parent-child interactions may be defined by a three-dinensional model. The first two dimensions of this model were bipolar and related to the extent of parental acceptance of the child and to the degree to which the parent controlled the child's behavior by direct means. The third dimension was unipolar and represented the extent to which the parent employed psychological pressure techniques to control the child. Findings further indicated that this model had equal validity for both mothers and fathers.

In the present study, item responses, rather than summated scale scores, were subjected to principal components analysis. The data derived from this analysis pertains to two interrelated questions:

1) To what extent can the a priori scales of the CR-PBI be supported?

2) To what extent is the three-dimensional model of parent-child interaction an arifact of the level of data analyzed?

With respect to the first question, the results of this investigation failed to support the present scoring of the CR-PBI. In general, the items comprising each of the 13 identified components were drawn in approximately equal numbers from between two and eight scales. There was only a single exception to this; the mother component labeled inconsistent discipline, which was comprised of five items, drew all but one of its items from the CR-PBI scale of the same name.

Given the above, it is not surprising that there were significant discrepancies between components identified in the present study and the model of parent-child interactions developed from the analysis of CR-PBI scales. Before considering these, however, it is important to briefly summarize the present findings. 
With regard to the analysis of the father response form five components were identified. Of these, the first three were well defined. Specifically, the first father component, labeled authoritative control, appeared to represent a general control dimension which coupled regulation of the child's behavior with a limited degree of meaningful interaction and flexibility. The second component represented a style of control in which the child is made to feel obligated to conform in order to win back the love and affection of a disapproving parent. The third component was bipolar and related to the extent to which the parent accepts or rejects the child. In contrast to the preceding components, the fourth and fifth ones were rather poorly defined. The former consisted of only five items and was not clearly distinguishable from the third component in that it also referred primarily to paternal support. The latter, also consisting of five items, alluded to a parenting style whereby the child is allowed independence through a laxness in rule enforcement.

In contrast to the results for the father, analysis of the mother response form revealed eight components. The first, like the third father component, contrasted parent-child interactions characterized by affection, security and sharing with those characterized by rejection and hostile detachment. The second mother component represented strict control coupled with coolness and unresponsiveness. The next two components were both poorly defined and alluded to psychological control through instilling guilt in the child. Like the first two components, labeled support and authoritarian control, the fifth component was rather well defined. It represented interactions marked by control, faultfinding, and detachment, and was, thus, labeled detached control. The 
remaining components identified in this analysis were all rather poorly defined and related to psychological autonomy, control through withdrawal from a relationship, and inconsistent discipline.

As is evident from this brief summary, there was only one major area of overlap between the present findings and the previously proposed model for parent-child interactions. Specifically, in all analyses the dimension of support, for both parents, appears to be represented as a continuum with one pole defined by the perception of the parent as affectionate, positively involved and accepting of individuation, and the other pole defined by rejection and hostile detachment. Such was not the case, however, for dimensions relating to parental control. In contrast to previous findings, direct and psychological styles of control were not represented as totally independent dimensions. Rather, such components as authoritative control (for the father) and authoritarian control (for the mother) combined rule-making with possessiveness, intrusiveness and the instilling of anxiety and guilt. Further, psychological control was not represented as a single, unified dimension. For the data relating to perceptions of the mother in particular, separate aspects of this style received individual representation. Finally, there was no dimension identified in the present analysis representing the extent of control exerted on the child by the parent. Instead, the regulation of behavior and the granting of autonomy either through laxness in rule enforcement or general permissiveness appeared as independent dimensions.

There is precedent in the literature for the type of findings obtained in the present study however. Interestingly, this is found 
exclusively in the results of investigations analyzing subjects' responses to individual inventory items. As noted in the Results chapter, two dimensions identified by this analysis bore such striking similarities to parenting styles reported by Baumrind (1968) that her labels were employed; that is, the components labeled authoritarian control and authoritative control. Beyond this, Baumrind's analyses indicated a third dimension, labeled Permissive, which was described in the following manner:

To behave in a nonpunitive, acceptant. . manner toward the child's impulses, desires, and actions. She makes few demands for household responsibility and orderly behavior. She allows the child to regulate his own activities as much as possible, avoids the exercise of control, and does not encourage him to obey externallydefined standards (Baumrind, 1968, p. 256).

As so defined, this parenting dimension closely corresponds to others labeled as psychological autonomy by Hower (1977) and the present author. Finally, in an analysis of selected CR-PBI items, Ellis, et al. (1976) reported on two dimensions relevant to this discussion. The first, represented a parenting style which, while not characterized by affection, was one in which parental disapproval was expressed by cutting off interaction with the child. The second dimension was represented by items relating to fault-finding, complaining, nonapproval, rejection, and attempts to control and change the child. In most respects, these dimensions are similar to components labeled in the present study as withdrawal from a relationship and detached control. 
Despite this limited support for the findings obtained in this investigation relating to the dimensions of parent-child interactions, they must obviously be considered tentative. Replication with broader samples is required, particularly in view of the fact that many of the identified components are poorly defined. Just as obviously, however, the results of studies reporting parenting dimensions based on the analysis of scale scores must, at this point, also be regarded as tentative.

Before concluding this section of the discussion, an additional set of findings must be given direct consideration. As has already been alluded to, the content of components for the father and the mother differed in several important respects. Largely, these dissimilarities appeared to be related to the fact that for the mother, but not for the father, attempts at control are perceived by the child as expressions of nonacceptance; that is, the controlling mother is viewed as being, to varying degrees, rejecting. One possible explanation for this relates to the characteristics that predominate the perception of both parents. On the basis of both the present findings and the literature on sex-role stereotypes (Bakan, 1966; Bem, 1976; Erikson, 1964; Parsons \& Bales, 1955) the central qualities in the perception of the mother are affectionate, compassionate, sympathetic, understanding, and warm. In contrast, the qualities which appear to characterize the perception of the father include aggressive, assertive, dominant, independent and forceful. Given the above, it follows that, for the father, the exercise of power would be both expected and accepted. For the mother, however, attempts at control occur within a different context and, consequently, may be 
seen to imply a lack of acceptance or trust. However, as with previously discussed findings, further research is required to both substantiate observed differences between parents and to investigate potential explanations, if confirmed.

\section{The Domain of Imaginal Activity}

The two stage analysis of the itens comprising the Imaginal Processes Inventory resulted in the identification of nine principal components. Of this number, three were rather well-defined and appeared to represent general dimensions of imaginal activity. The first, labeled emotional tone of daydreaming, was bipolar. The positive pole of this dimension related to daydreaming which is enjoyable, stimulating, fairly realistic, and is viewed by the individual as a productive aspect of his life. In contrast, the other pole represented a more generally negative approach to one's own fantasy activity, characterized by daydreams involving guilt, self-questioning and self-doubt. The second component was labeled absorption in daydreaming. For the individual scoring high on this dimension, daydreams would be experienced as both "real" and nonvolitional, and would elicit some type of emotional response. The third component was termed prospective daydreaming. As the label implies, this referred to vivid, future-oriented daydreams which serve the function of self-distraction and self-stimulation. The remaining six components were, in most instances, less clearly defined and appeared to represent limited dimensions of daydream content and structure. For example, components were identified which related to such aspects of daydream content as guilt, and curiosity and achievement. 
Further, such structural qualities as obsessiveness, control, and distractibility were represented in separate components. Finally, a component which referred to the vivianess of night dream recall was identified.

These findings are, again, directly relevant to the dual issues of scale and model validity. With respect to the former question, only one component, vividness of night dream recall, exhibited a high degree of correspondence to an original IPI scale. This component consisted of nine of the 12 items from the scale labeled Night Dreaming Frequency. The remaining eight components each drew at least $75 \%$ of their items from between four and 18 IPI scales. On the basis of this, it would appear safe to conclude that there was no support for the present scoring of the IPI.

With regard to the second issue, Singer $(1975,1978)$ contends, on the basis of factor-analytic sțuies of IPI scales, that imaginal activity is characterized by three distinct styles. The first, labeled Positivevivid, relates to the enjoyment of vivid and absorbing fantasies; the second, Guilty-Dysphoric, involves ideational activity that is ethically toned with much self-doubt and self-criticism; the third, MindwanderingDistractible, is generally characterized by fleeting, loosely connected fantasies. Further, it is contented (Giambra, 1974) that these patterns are highly stable across an extended age range.

The present findings, based on the analysis of item responses, generally failed to confirm Singer's model in several important respects. Perhaps the most apparent deviation related to the first component obtained. Contrary to Singer's conceptualization, it would seem that 
the so-called "positive" and "negative" approaches to fantasy activity are not independent modes. Rather, they appear to represent the poles of a continuum relating to the affective quality of such activity. At a more general level, the present findings diverge from those previously reported in that the identified components represented qualitative aspects of the imagining experience rather than discrete styles or patterns. One possible implication of this is that imagining may be more highly varied than previously considered. For example, according to Singer's conceptualization, imaginal activity which elicits positive reactions from the individual is also characterized as absorbing and future oriented. By comparison, the present data allow for both positively-and negatively-toned imaginings to vary in terms of both the extent of subjective involvement and the degree of prospectiveness.

While these findings were generally divergent from Singer's perspective on imaginal activity, there were certain consistencies with other theoretical and empirical conceptualizations appearing in the literature. Perhaps the strongest support is found for the dimension labeled absorption in daydreaming. As will be remembered from a previous chapter, Shor (1939) has formulated imagining as the fading of the "generalized reality-orientation." According to him, a core feature of this process is the amplification of receptivity to internal sources of stimulation concurrent with the receding from awareness of external events. As a consequence of this, experiences may take on special meanings and reality.

Along similar lines, Klinger (1978) has proposed five dimensions of thought. Most relevant to the discussion at this stage is his 
description of operant versus respondent thought. Klinger has operationalized fantasy and daydreaming as respondent thinking, and contrasted it with operant thinking in the following manner:

- . operant thinking appears to differ from respondent thinking in that it is accompanied by a sense of volition, is checked against feedback concerning its effects, is evaluated according to its effectiveness in advancing particular goals, and is protected from drift and distraction by the thinker's deliberately controlling his or her attention (Klinger, 1978, pg. 235).

Quite clearly, these implied qualities of respondent thought are in accord with those found to characterize the dimension of absorption in daydreaming.

Confirmation of this dimension is also found at the empirical level in the work of Tellegen and Atkinson (1974). Specifically, their analysis of questionnaire items believed to be related to hypnotizability revealed a major factor which was labeled "Openness to Absorbing and Self-Altering Experiences." This factor was interpreted as a disposition for "total" attention involving the full commitment of available representational resources to the experiencing of the attentional object. Moreover, Tellegen and Atkinson suggested that two phenomena might be inherently correlated with this process. First, the attentional object would be experienced as present and real due to an inability to consider such qualifying cognitions as "this is only my imagination" or "this is not really happening." Second, external events would tend not to be noticed owing to the full commitment of the representational system to the object of attention. 
While less extensive, theoretical support is also present for the identified component labeled prospective daydreaming. Specifically, the content of items with salient loadings on this component corresponds quite closely to Sarbin and Juhasz' (1970) description of the timebinding function of hypothetical instantiation. As will be remembered, this refers to the process of inhibiting overt behavior while the individual places himself in a wide variety of more or less hypothetical situations. This allows him to rehearse future acts and to examine and manipulate the specifics of present or past actions. While this function bears some semblance to thinking and remembering it differs in terms of the fact that the hypothetical situations need have no relationship to "reality."

There is little in the current literature which is directly relevant to the other components identified in this analysis. This is not particularly surprising, however, given their limited nature and their rather poor definition. Quite obviously, further investigation is required to substantiate and elaborate these dimensions. of particular interest would be data relating to the night dream recall dimension. While studies have examined possible thematic and structural continuities that transcend the arousal continuum (Starker, 1978), little has been done to assess the exact nature of the relationship between waking and sleeping fantasy activity. The present findings suggest that these two aspects of inner experience may represent independent cognitive processes. 


\section{Relationships Between Parent-Child Interactions and Imaginal Activity}

Analyses pertaining to the relationships between parent-child interaction variables and imaginal activity variables were rather disappointing. In most instances, relationships between these two sets of variables accounted for less than eight percent of the variance. Moreover, the results of multiple regression analyses indicated that predictive power was not substantially enhanced by the addition of variables to the predictor variable set. In that these analyses capitalize on chance variation in order to produce the highest possible correlation, it is possible that all relationships may be attributed to sample-specific covariation.

Given the above, no attempt will be made to interpret individual associations. Rather, the discussion will be limited to general consistencies among results from all analyses performed.

\section{Overall Relationships}

For both levels of analysis, parent variables relating to control were consistently and positively associated with both the frequency and qualitative aspects of imaginal activity. This applied to both direct and psychological styles of control. In contrast, parent variables regarding support tended to be unrelated. However, where significant correlations were obtained, they were typically negative.

Initially these findings appear to offer tentative support to Hilgard's (1970) conclusions regarding a positive association between the strictness of childhood discipline and imaginative involvement. On the other hand, they also appear to contradict the findings of a study 
conducted by Singer (1966) suggesting that the tendency toward imaginal activity is facilitated by a benign and nurturant parental figure. A closer examination of the relationships obtained does, however, provide some indirect support for Singer's conclusions. Specifically, of the seven parental control variables identified in the analysis of the CR-PBI, only four demonstrated repeated associations with various aspects of imaginal activity." Two of these were the father variables labeled authoritative control and control through love withdrawal, while the other two were the mother variables relating to control through guilt coupled with intrusiveness and restrictiveness. These may be distinguished from the other control variables (i.e., authoritarian control, detached control and control through withdrawal from a relationship) in that either a) the items constituting the variable specifically indicated love and/or support for the child, or b) the style of control presupposes the existence of an emotional attachment between parent and child. On the basis of this, it is possible to conclude that while nurturance or support is not a sufficient condition for facilitating the development of imaginal activity, it is a necessary condition. Phrased in a somewhat different manner, the present findings tentatively suggest that imagining is associated with parental control only when it is exercised within the context of emotional support.

Sex differences. At the outset, two hypotheses were presented regarding the sex of the parent and the interaction with the sex of the child. The first stated that the imaginal activity of the child would be related to the quality of interactions with both parents, and that neither the mother nor the father would show a clear preeminance. This 
hypothesis appears to be supported by the findings of this study. When considered across sex of subjects, the correlations between imaginal variables and mother and father variables were of approximately equal, albeit low, magnitude. Thus, the results of the present investigation are in accord with the growing body of literature indicating the equivalence in the importance of both parents' roles in child development.

The second hypothesis stated that when both the sex of the parent and the child is considered, imaginal activity would be most closely related to the quality of interaction with the same-sex parent. This was based primarily on a series of studies conducted by Radin (1972, 1973, 1974, 1976; Radin and Epstein, 1975 a, b) indicating that cognitive competence in boys (girls) was consistently related to the quality of paternal (matemal) behavior. The present findings failed to support this hypothesis. Specifically, while correlations were generally equivalent across all parent-child pairings, there was a slight tendency, particularly for females, for higher relationships with the opposite-sex parent.

A reexamination of the literature indicated some limited exceptions to the general rule of higher sensitivity to the behaviors of the samesex parent. For example, two studies suggest that fathers are more influential in the creativity of daughters and mothers, in the creativity of sons. The first, conducted by Long, Henderson and ziller (1967) found that children exhibiting a higher ability to find novel problem solutions appeared to model less closely after the same-sex parent. The second (Anastasi \& Schaefer, 1969) was based on the biographical inventories of high school students and indicated that mothers were more significant in 
their sons' creativity and fathers were more influential in their daughters'. Along somewhat different lines, Hilgard (1970) found that imaginative involvements associated with hypnotizability were more highly correlated to the identification with and the parental warmth of the opposite-sex parent. Finally, the initial conclusions regarding the preeminance of the mother in the development of imaginal activity, was based primarily on studies employing only male subjects (Bene, 1975; Singer \& Sugarman, 1955).

The discussion of the present findings cannot be concluded without considering the issue of the level of correlations obtained. The most readily apparent interpretation of these low level associations is that compared to other factors such as genetic heritage and societal influences, parent-child interactions play a relatively minor role in the development of imaginal activity. However, other possibilities present themselves in terms of alternative approaches to the study of parental influences. Each of these will be briefly considered in turn. 1. In the present study, subjects were required to rate each parent's behavior based on their perceptions of them at the age of 16 . It is quite possible that parental influence had its greatest impact at an earlier age, and that the nature of the parent-child interactions changed as a function of the child's age. There is at least some support for this from studies indicating a normative decline in parental control as the child gets older (Armentrout \& Burger, 1972; Jensen \& Buhanan, 1974). Thus, future studies of the relationship between parent-child interactions and imaginal activity might prove more productive by taking developmental trends into consideration. This could be accomplished 
through either the study of subjects falling into various age groupings or through a longitudinal study.

2. The quality of the parent-child interactions may only play a mediating role in the development of imaginal activity. Most learning theorists are in agreement that identification (modeling) is a crucial aspect of personality development. Further, several studies (e.g., Bandura \& Huston, 1961; Bandura \& Walters, 1959; Mussen \& Distler, 1959) indicate that the parent variables assessed in this investigation (i.e., support and control) facilitate identification by enhancing parental saliency. These same variables may, however, be only incidentally related to the imaginal characteristics of the parent. Thus, the role of the parent in imaginal development might be best assessed by directly considering the identification process. As Bronfenbrenner (1958) notes, such an investigation requires assessment of both motive and pattern. The former has already been discussed with regard to parental saliency. However, the notion of pattern needs to be briefly considered. According to Bronfenbrenner, absolute similarity is not a necessary consequence of modeling since the child's attempts at emulation may result in the exaggeration rather than the replication of parent characteristics. Thus, the correct measure of modeling would be an analogy in pattern such that corresponding features, while differing in magnitude, occupy the same relative position in the total configuration.

3. In the present study, the influence of each parent's behavior on imaginal activity was assessed independently. In a review of the literature, Biller (1974 b) cites evidence suggesting that the social and emotional development of the child is a function of both the absolute 
quality of each parent's behavior and the quality of one parent's behavior relative to the other's. Thus, future investigations might consider the imaginal activity of subjects whose parents exhibit either similar or differing patterns of interactions with the child (e.g., both parents high on the support dimension, both parents low, one parent high and the other low). Along somewhat different lines, it might also prove worthwhile to consider the nature of the parents' interactions with one another. A series of studies (reviewed by Biller, 1974 b) suggest that such aspects of interparental interaction as compatibility, domesticvalue consensus, and role tension have a significant impact on child development.

Assessment of these possibilities is beyond the scope of the present investigation. However, each warrants consideration in future research relating to the development of imaginal activity.

\section{Implications for Further Research}

In the preceding section, several alternative approaches to the investigation of parental influences on the development of imaginal activity were proposed. However, before conducting any further research in this area, it is necessary to abtain adequate measures of both parent-child interactions and imaginal activity. Analyses of both the CR-PBI and the IPI failed to replicate the original scales comprising each inventory. The majority of items from both the father and mother forms of the CR-PBI and the IPI loaded on three well-defined components. The remaining items loaded on a somewhat larger number of poorly-defined 
components. In only two instances did these components correspond to previously-defined scales.

Clearly, further work is necessary in the development of both these measures. The results from the present analyses can only be considered as a preliminary step in such a process. Further steps should take into account the following:

1. The major components for each inventory exhibited a high level of intercorrelation. This would suggest that these components were composed of both "pure" and "complex" items. Inspection of Tables 2, 3, and 10 indicates that "complex" items would be eliminated by retaining only the 10 to 15 highest loading items from each component.

2. A large proportion of the total variance from each analyis was left unaccounted for by the major components. Thus, there is a need to more clearly define the remaining components. This could be accomplished by the development of new inventory items reflecting the hypothesized content of each component; that is, items that should have major loadings on specified components and low loadings on others.

3. The results of the present analyses were based on data obtained from college "volunteers." At this point it is unclear as to how "volunteers" differ from "nonvolunteers" and as to how these differences might interact with the variables under investigation. However, demographic data presented earlier did suggest that the sample was biased in terms of race and religious affiliation. It is important to determine the impact of these and other variables on the component structure of the inventories under consideration. 
APPENDICES 
APPENDIX TABLE A

Scales and Sample Items of the Imaginal

Processes Inventory

Daydreaming Frequency . . . . . When I am not paying close attention (Df) to my job, a book, or TV, I tend to be daydreaming $(0 \%$ of my time - $50 \%$ of my time) lost in thought.

I lose myself in active daydreaming (infrequently--many different times during the day).

Night Dreaming Frequency . . . . I have a night dream (rarely or never-(Ndf) once a night).

I recall interesting or elaborate dreams (rarely or never--once a night).

Absorption in Daydreaming . . . . My daydreams seldom repeat themselves. (Abs) A daydream can completely change my mood.

Acceptance of Daydreaming . . . . I feel guilty about my daydreams. $(\mathrm{ACC})$

I find my daydreams are worthwhile and interesting to me.

Positive Reaction in Daydreaming . . I can be aroused and excited by a $(\mathrm{Pr})$ daydream.

My fantasies usually provide me with pleasant thoughts.

Frightened Reactions to Daydreams - My daydreams often contain depressing (Fr) events which upset me.

I never panic as a result of a daydream.

Visual Imagery in Daydreams . . . . I sometimes have a very clear, lifelike (Vi) picture of what I am imagining.

The scenes of my daydreams are never longer than brief flashes.

Auditory Images in Daydreams . . . When people speak in my daydreams, I (Ai) cannot really hear their voices. The sounds I hear in my daydreams are clear and distinct. 


\begin{abstract}
Problem Solving Daydreams . . . . My daydreams offer me useful clues to (Ps) tricky situations I face.

Daydreams do not have any practical significance for me. (Prs) current in my life.
I imagine myself in situations far

Present-Oriented Daydreams . . . . My daydreams always relate to events removed from my day-to-day affairs.
\end{abstract}

Future in Daydreams . . . . . Before going somewhere, I imagine the (Fut) scene and what I will be doing.

I do not think about what the future will be like.

Past in Daydreams . . . . . . I often daydream about event that (Pst) happened more than a year ago.

I never think at all about events or scenes of my early childhood.

Bizarre Improbably Daydreams . . . I often have thoughts about things (Bi) that could rarely occur in real life. My daydreams are rarely realistic.

Mind Wandering . . . . . . . . I am the kind of person whose thoughts (Mw) often wander.

I have difficulty in maintaining concentration for long periods of time.

Achievement-Oriented Daydreams . . . I daydream about accomplishing a dif(Ach) ficult task.

I daydream about being promoted to a better position.

Hallucinatory-Vividness of Daydreams . . . . . . . . Some of the voices in my thoughts are ( Hv) threatening of frightening.

My thoughts seem as real as events in my life.

Fear of Failure in Daydreams. (Ff)

In my daydreams, I fear meeting new responsibilities in life.

I imagine myself failing those I love.

Hostile Daydreams . . . . . . . I imagine myself physically hurting (Hos) someone I hate.

I picture myself telling off my parents. 


\begin{abstract}
Sexual Daydreams . . . . . . My sexual daydreams are very vivid and $(\mathrm{Sx})$ clear in my mind.

Whenever I am bored, I daydream about the opposite sex.
Heroic Daydreams . . . . . . . I daydream of becoming an important (Her) government official.
I daydream about saving a drowning child.
Guilt Daydreams . . . . . . . In my daydreams, I am caught after (Glt) stealing something very expensive. I often feel tortured by the images of the sins I have committed.
Curiosity: Interpersonal . . . . I often think about the lives of (Ci) famous people.
I have little or no interest in the private affairs of others.
Curiosity: Impersonal-Mechanical . I have always liked to take things $(\mathrm{Cm})$ apart to see what makes them work.
I find the arts more stimulating than the sciences.
Boredom . . . . . . . . Most of the things I do are not important or interesting.
I an seldom bored.
Mentation Rate.......... My mind is often blank. (Mr)
My thoughts often seem to race through my mind.
Distractibility . . . . . . My attention is seldom diverted by
(D) what others around me are doing. I am always glad to find an excuse to take me away from my work.

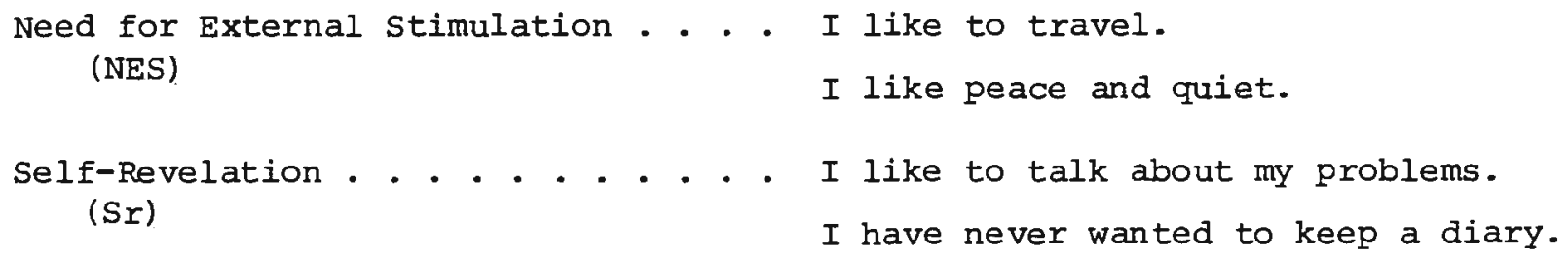


APPENDIX TABLE B

Scale and Sample Items of the Child's

Report of Parent Behavior Inventory

Acceptance of Individuation... . Likes me to choose my own way of (Ai) doing things. Gives me a choice when possible.

Acceptance . . . . . . . . . Sees my good points more than my (A) faults.

Likes me as I am.

Positive Involvement . . . . . Often praises me.

(Pi)

Is very interested in what I am learning.

Child-centeredness. . . . . Likes to talk with me and be with me (Cc) much of the time.

Makes me feel like the most important person in his(her) life.

Possessiveness . . . . . . . . Seems to regret my growing up and (Pos) spending more time away. Becomes very involved in my life.

Intrusiveness . . . . . . Wants to know exactly where $I$ am and (Int) what I am doing.

Keeps a careful check on me and my friends.

Control through Guilt . . . . . Feels I am not grateful when I don't (Cg) obey.

Tells me how much he(she) has suffered for me.

Hostile control......... Decides what friends I can go around (HC) with.

Always telling me how to behave.

Control through Instilling

Persistent Anxiety . . . . . . Worries how I'll turn out. $(\mathrm{Anx})$ 
Control through withdrawal of

Relationship

(W)

- Will not talk to me when I displease him(her).

Less friendly if I don't see things his (her) way.

Rejection ............ Isn't very patient with me.

$(\operatorname{Rej})$

Thinks my ideas are silly.

Hostile Detachment........ Doesn't talk with me much.

(Hd)

Doesn't think of me much.

Inconsistent Discipline... . . Sometimes allows me to do things he (she) says are wrong.

only keeps a rule when it suits him(her).

Nonenforcement . . . . . . . Doesn't pay much attention to my (Ne) misbehavior.

Seldom insists I do anything.

Extreme Automony ....... Doesn't tell me when to be home.

(Ea)

Lets me do anything I want.

Lax Discipline... . . . . . Can't say no.

(Id)

Excuses bad conduct.

Control... . . . . . . . Believes in having a lot of rules and

(C) sticking to them.

Insists I do exactly as I am told.

Enforcement . . . . . . . Is very strict with me.

(E)

Punishes me when I don't obey. 
APPENDIX TABLE C

Eigenvalues for the First Twenty-Five Components from the Principal Components Analyses of the

CR-PBI and the IPI

\begin{tabular}{|c|c|c|c|c|c|}
\hline Component & $\begin{array}{l}\text { CR-PBI } \\
\text { F.R.F. }\end{array}$ & $\begin{array}{l}\text { CR-PBI } \\
M . R \cdot F .\end{array}$ & $\begin{array}{c}\text { IPI Items } \\
1-172\end{array}$ & $\begin{array}{l}\text { IPI Items } \\
\text { 173-344 }\end{array}$ & $\begin{array}{c}\text { IPI } \\
\text { Combined }\end{array}$ \\
\hline 1 & 63.108 & 54.815 & 45.687 & 21.206 & 17.940 \\
\hline 2 & 25.474 & 12.395 & 10.694 & 13.926 & 13.092 \\
\hline 3 & 5.858 & 9.001 & 6.972 & 6.189 & 7.220 \\
\hline 4 & 4.662 & 7.284 & 4.965 & 4.907 & 6.551 \\
\hline 5 & 3.970 & 4.561 & 4.213 & 4.442 & 4.921 \\
\hline 6 & 3.290 & 4.427 & 4.105 & 4.079 & 4.744 \\
\hline 7 & 2.983 & 3.786 & 3.906 & 3.774 & 4.482 \\
\hline 8 & 2.591 & 3.326 & 3.500 & 3.571 & 3.887 \\
\hline 9 & 2.349 & 2.629 & 3.224 & 3.388 & 3.709 \\
\hline 10 & 2.313 & 2.426 & 2.595 & 3.034 & 3.455 \\
\hline 11 & 2.243 & 2.271 & 2.398 & 2.854 & 3.347 \\
\hline 12 & 2.005 & 2.151 & 2.251 & 2.623 & 3.178 \\
\hline 13 & 1.939 & 2.028 & 2.175 & 2.559 & 3.073 \\
\hline 14 & 1.778 & 2.002 & 2.068 & 2.488 & 2.933 \\
\hline 15 & 1.748 & 1.869 & 1.987 & 2.408 & 2.831 \\
\hline 16 & 1.682 & 1.820 & 1.920 & 2.339 & 2.706 \\
\hline 17 & 1.630 & 1.707 & 1.809 & 2.249 & 2.553 \\
\hline 18 & 1.601 & 1.621 & 1.790 & 2.158 & 2.529 \\
\hline 19 & 1.514 & 1.567 & 1.767 & 2.065 & 2.440 \\
\hline 20 & 1.459 & 1.497 & 1.705 & 2.018 & 2.315 \\
\hline 21 & 1.447 & 1.474 & 1.621 & 1.987 & 2.226 \\
\hline 22 & 1.407 & 1.448 & 1.582 & 1.937 & 2.118 \\
\hline 23 & 1.357 & 1.431 & 1.505 & 1.792 & 2.108 \\
\hline 24 & 1.327 & 1.419 & 1.460 & 1.734 & 2.079 \\
\hline 25 & 1.243 & 1.399 & 1.426 & 1.684 & 1.970 \\
\hline
\end{tabular}


REFERENCES 
REFERENCES

Ainsworth, M.S. The development of infant-mother attachment among the Ganda. In B.M. Foss (Ed.), Determinants of infant behavior II. London: Methuen, 1963.

Ainsworth, M.S. Infancy in Uganda: Infant care and the growth of love. Baltimore: Johns Hopkins Press, 1967.

Alkire, A.A. Social power and communication within families of disturbed and nondisturbed preadolescents. Journal of Personality and Social Psychology, 1969, 13, 335-349.

Ames, L.B. Children's stories. Genetic Psychology Monographs, 1966, 73, 337-396.

Anastasi, A. Psychological testing (4th ed.). New York: MacMillan, 1976.

Anastasi, A., \& Schaefer, C.E. Biographical correlates of artistic and literary creativity in adolescent girls, Journal of Applied Psychology, 1969, 53, 267-273.

Andersland, P.B. Parental rejection and adolescent academic achievement. Dissertation Abstracts, 1968, 28 (11-B), 4751.

Anderson, L.M. Personality characteristics of parents of neurotic, aggressive, and normal preadolescent boys. Journal of Consulting and Clinical Psychology, 1969, 33, 575-581.

Andrews, R.O., \& Christenson, H.T. Relationship of absence of a parent to courtship status: A repeat study. American Sociological Review, 1951, 16, 541-544.

Antrobus, J.S., Antrobus, Judith S., \& Singer, J.L. Experiments accompanying daydreaming, visual imagery, and thought suppression. Journal of Abnormal and Social Psychology, 1964, 69, 244-252.

Antrobus, J.S., Greenberg, S., \& Singer, J.L. Studies in the stream of consciousness: Experimental enhancement and suppression of spontaneous cognitive process. Perceptual and Motor Skills, 1966 , $23,399-417$.

Armentrout, J.A., \& Burger, G.K. Children's Reports of parental childrearing behavior at five grade levels. Developmental Psychology, $1972, \underline{7}, 44-48$. (a)

Armentrout, J.A., \& Burger, G.K. Factor analyses of college students' recall of parental child-rearing behaviors. Journal of Genetic Psychology, 1972, 121, 155-161. (b) 
As, A. Non-hypnotic experiences related to hypnotizability in male and female college students. Scandinavian Journal of Psychology, 1962, 3. $112-121$.

As, A., O'Hara, J.W., \& Mungar, N.P. The measurement of subjective experiences presumably related to hypnotic susceptibility. Scandinavian Journal of Psychology, 1962, $3,47-64$.

Ban, P., \& Lewis, M. Mothers and fathers, girls and boys: Attachment behavior in the year-old. Paper presented to a meeting of the Eastern Psychological Association, 1971.

Bakan, D. The duality of human existence. Chicago: Rand McNally, 1966.

Bandura, A. Social learning theory. Englewood Cliffs, N.W.: PrenticeHall, 1977.

Bandura, A., \& Huston, A.C. Identification as a process of incidental learning. Journal of Abnormal and Social Psychology, 1961, 63, 311-318.

Bandura, A., \& Walters, R.N. Adolescent aggression. New York: Ronald Press, 1959.

Barber, T.X. Suggested ('hypnotic') behavior: The trance state paradigm versus an alternative paradigm. In E. Fromm and R.E. Shor (Eds.), Hypnosis: Research developments and perspectives. Chicago: Aldine-Atherton, 1972 .

Barber, T.X., \& Ham, M.W. Hypnotic phenomena. Morristown, N.J.: General Learning Press, 1974.

Barber, T.X., Spanos, N.P., \& Chaves, J.F. "Hypnosis," imagination, and human potentialities. New York: Pergamon Press, 1974.

Barron, F. Threshold for the perception of human movement in inkblots. Journal of Consulting Psychology, 1955, 19, 33-38.

Baumrind, D. Authoritarian vs. authoritative parental control. Adolescence, $1968, \underline{3}, 255-272$.

Becker, W.C. Consequences of different kinds of parental discipline. In M.L. Hoffman and L.W. Hoffman (Eds.), Review of child development research I. New York: Russell Sage, $196 \overline{4}$.

Becker, W.C., Peterson, D.R., Hellmer, L.A., Shoemaker, D.J., \& Quay, H.C. Factors in parental behavior and personality as related to problem behavior in children. Journal of Consulting Psychology, 1959, 23, 107-118. 
Becker, W.C., Peterson, D.R., Luria, Z., Shoemaker, D.S. \& Hellmer, L.A. Relations of factors derived from parent interview ratings to behavior problems of five-year-olds. Child Development, 1962, 33, 509-535.

Bem, S.L. Probing the promise of Androgyny. In A.G. Kaplan and J.P. Bean (Eds.), Beyond sex-role stereotypes. Boston: Little, Brown, 1976.

Bene, E. An effect on Rorschach M responses of a boy's relationship with his mother. Journal of Personality Assessment, 1975, 39, 114-115.

Bijou, S.W., \& Baer, D.M. Child development I: A systematic and empirical theory. New York: Appleton-Century-Crofts, 1961.

Biller, H.B. A multiaspect investigation of masculine development in kindergarten-age boys. Genetic Psychology Monographs, 1968, 76 , 89-139.

Biller, H.B. Father-absence, maternal encouragement, and sex-role development in kindergarten-age boys. Child Development, 1969, 40, 539-546. (a)

Biller, Н.В. Father dominance and sex-role development in kindergartenage boys. Developmental Psychology, 1969, 1, 87-94. (b)

Biller, H.B. Father, child, and sex role. Lexington, Mass.: Heath, 1971.

Biller, H.B. Paternal and sex-role factors in cognitive and academic functioning. In J.K. Cole and R. Dienstbier (Eds.), Nebraska symposium on motivation. Lincoln: University of Nebraska Press, 1974. (a)

Biller, H.B. Paternal deprivation. Lexington, Mass.: Heath, 1974.

Biller, H.B. The father-infant relationship: Some naturalistic observations. Unpublished manuscript, University of Rhode Island, 1974. (c)

Biller, H.B., \& Bahm, R.M. Father absence, perceived maternal behavior, and masculinity of self-concept among junior high school boys. Developmental Psychology, 1971, 4, 1978-181.

Biller, H.B., \& Davids, A. Parent-child relations, personality development and psychopathology. In A. Davids (Ed.), Issues in abnormal child psychology, Belmont, Calif.: Brooks/Cole, 1973.

Biller, H.B., \& Zung, B. Perceived maternal control, anxiety and opposite sex-role preference among elementary school girls. Journal of Psychology, 1972, 81, 85-88. 
Blanchard, R.W., \& Biller, H.B. Father availability and academic performance among third-grade boys. Developmental Psychology, 1971, $\underline{4}, 301-305$.

Block, J. Lives through time. Berkeley: Bancroft Books, 1971.

Bowlby, J. Maternal care and mental health. Geneva: WHO, 1951.

Bowlby, J. Attachment and loss. Vol. 2. New York: Basic Books, 1973.

Bronfenbrenner, U. The study of identification through intexpersonal perception. In R. Tagiuri and L. Petrullo (Eds.), Person perception and interpersonal behavior. Stanford: Stanford University Press, 1958.

Bronson, W.C. Dimensions of ego and infantile identification. Journal of Personality, $1959, \underline{27}, 532-454$.

Burger, G.K., \& Armentrout, J.A. A factor analysis of fifth and sixth graders' reports of parental child-rearing behavior. Developmental Psychology, 1971, ㄴ, 483.

Busse, T.V. Child-rearing antecedents of flexible thinking. Developmental Psychology, 1969, 1 , 585-591.

Clarke-Stewart, K.A. Interactions between mothers and their young children: Characteristics and consequences. Unpublished doctoral dissertation, Yale University, 1972.

Cohen, L.J. \& Campos, J.J. Father, mother, and stranger as elicitors of attachment behaviors in infancy. Developmental Psychology, 1974, $10,146-154$.

Cooper, J.B., \& Lewis, J.H. Parent evaluation as related to social ideology and academic achievement. Journal of Genetic Psychology, $1962,101,135-143$.

Coopersmith, S. The antecedents of self-esteem. San Francisco: W.H. Freeman, 1967.

Cross, H.J. College students' memories of their parents: A factor analysis of the CR-PBI. Joumal of Consulting and Clinical Psychology, 1969, 33, 275-278.

Cross, H.J., \& Allen, J. Relationship between memories of parental behavior and academic achievement motivation. Proceedings, 77th Annual Convention of the American Psychological Association, 1969, 4, 285-286.

Datta, L.E., \& Parloff, M.B. Parent-child relationships and early scientific creativity. Proceedings of the 75th Annual Convention of the American Psychological Association, 1967, 2, 149-150. 
Deutsch, M., \& Brown, B. Social influences in Negro-white intelligence differences. Journal of Social Issues, 1964, 20, 24-35

Dyk, R.B., \& Witkin, H.A. Family experiences related to the development of differentiation in children. Child Development, 1965, 36 , $21-55$.

Dyl, A.S., \& Biller, H.B. Paternal absence, social class, and reading achievement. Unpublished study, University of Rhode Island, 1973.

Ellis, G.J., Thomas, D.L., \& Rollins, B.C. Measuring parental support: The interrelationships of three measures. Joumal of Marriage and the Family, 1976, 38, 713-72.2.

Erikson, E. Inner and outer space: Reflections on womanhood. In R.J. Lifton (Ed.), The woman in America. New York: Houghton Mifflin, 1964.

Fagot, B.I. Sex differences in toddler's behavior and parental reaction. Developmental Psychology, 1974, 10, 554-558.

Freud, S. An outline of psychoanalysis. New York: Norton, 1940.

Fusella, V. Blocking of an external signal through self-projected imagery: The role of inner-acceptant personality style and categories of imagery. Unpublished doctoral dissertation, City University of New York, 1972.

Gewirtz, J.I. Attachment, dependency, and a distinction in terms of stimulus control. In J.I. Gewirtz (Ed.), Attachment and dependency. Washington, D.C.: Winston, 1972.

Giambra, L. Daydreaming across the lifespan: Late adolescent to senior citizen. Aging and Human Development, 1974, ㄴ, 116-135.

Glueck, S., \& Glueck, E. Unravelling juvenile delinquency. New York: Commonwealth Fund, 1950.

Goode, W. Family disorganization. In R.K. Merton and R.A. Nisbet (Eds.), Contemporary social problems. New York: Harcourt, Brace, \& World, 1961.

Green, L., \& Parker, H. Parental influences upon adolescents' occupational choice: A test of an aspect of Roe's theory. Journal of Consulting Psychology, 1965, 12, 379, 383.

Grunebaum, M.G. , Hurwitz, I., Prentice, N.M., \& Sperry, B.M. Fathers of sons with primary neurotic learning inhibition. American Journal of Orthopsychiatry, 1962, 32, 462-473. 
Ham, M.W. Goal-directed fantasy, imaginative involvement, and the development of suggestibility. Unpublished masters thesis, University of Rhode Island, $1975^{\circ}$

Harlow, H.F. The development of affectional patterns in infant monkeys. In B.M. Foss (Ed.), Determinants of infant behavior $I$. London: Methuen, 1961.

Harlow, H.F., \& Zimmerman, R.R. Affectional responses in the infant monkey. Science, 1959, 130, 421 .

Harrington, D.M., Block, J.H., \& Block, J. Behavioral manifestations and parental correlates of intolerance of ambiguity in young children. Paper presented at meeting of the Society for Research in Child Development, 1975.

Hetherington, E.M. Effects of paternal absence on sex-typed behaviors in Negro and white preadolescent males. Journal of Personality and Social Psychology, 1966, 4, 87-91.

Hetherington, E.M. Effects of father-absence on personality development in adolescent daughters. Developmental Psychology, 1972, 7, 313-326.

Hilgard, J.R. Imaginative involvement: Some characteristics of the highly hypnotizable and non-hypnotizable. International Journal of Clinical and Experimental Hypnosis, 1974, 22, 138-156.

Holt, R.R. The nature of TAT stories as cognitive products: A psychoanalytic approach. In J. Kagan and G.S. Lesser (Eds.), Contemporary issues in thematic apperceptive methods. Springfield, IIl.: Thomas, 1961.

Holtzman, W.H. Holtzman Inkblot Technique. In A.I. Rabin (Ed.), Projective techniques in personality assessment. New York: Springer, 1968.

Honzik, M.P. Environmental correlates of mental growth: Prediction from the family setting at 21 months. Child Development, 1967, 38, 338-364.

Hower, J.T. The effects of parent-child relationships on the development of moral character. Unpublished doctoral dissertation, Rosemead, 1977.

Hurlock, E.B. Child development. New York: McGraw-Hill, 1964.

Jensen, I., \& Buhanan, K. Resistance to temptation following three types of motivational instructions among four-, six-, and eight-year-old female children. Journal of Genetic Psychology, 1974, 125, 51-59.

Jersild, A.T. Child psychology (3rd ed.). New York: Prentice-Hall, 1957. 
Jersild, A.T., Markey, F.V., \& Jersild, C.I. Children's fears, wishes, daydreams, likes, dislikes, pleasant and unpleasant memories. Child Development Monographs, 1933, No. 12 .

Johnson, M.A., \& Meadow, A. Parental identification among male schizophrenics. Journal of Personality, 1966, 34, 300-309.

Jordan, B.E., Rading, N., \& Epstein, A. Parental behavior and intellectual functioning in preschool boys and girls. Developmental Psychology, 1975, 11, 407-408.

Kagan, J., Freeman, M. Relations of childhood intelligence, maternal behaviors, and social class to behavior during adolescence. Child Development, 1963, 34, 899-911.

Katz, I. Socialization of academic motivation in minority group children. In D. Levine (Ed.), Nebraska Symposium on Motivation. Lincoln: University of Nebraska Press, 1967.

Kayton, R., \& Biller, н.В. Sex-role development and psychopathology in adult males. Journal of Consulting and Clinical Psychology, 1972, 38, 308-310.

Kimball, B. The Sentence Completion Technique in a study of scholastic under-achievement. Journal of Consulting Psychology, 1952, 16, 353-358.

Klinger, E. Structure and functions of fantasy. New York: Wiley, 1971.

Klinger, E. Modes of normal conscious flow. In K.S. Pope and J.L. Singer (Eds.), The Stream of Consciousness. New York: Plenum Press, 1978.

Kohlberg, L. A cognitive-developmental analysis of children's sex-role concepts and attitudes. In E.E. Maccoby (Ed.), The development of sex differences. Stanford: Stanford University Press, 1966.

Kotelchuck, M. The nature of the child's tie to his father. Unpublished doctoral dissertation, Harvard University, 1972.

Kotelchuck, M. The nature of the child's tie to his father. Paper presented to the Society for Research in Child Development, 1973.

Kotelchuck, M., Zelazo, P., Kagan, J., \& Spelke, E. Infant reaction to parental separations when left with familiar and unfamiliar adults. Journal of Genetic Psychology, 1975, 126, 255-262.

Lamb, M.E. Fathers: Forgotten contributors to child development. Human Development, $1975, \underline{18}, 245-266$. (a)

Lamb, M.E. Infant attachment to mothers: Interaction at eight-monthsof-age in the home and in the laboratory. Paper presented to the Eastern Psychological Association, 1975. (c) 
Lamb, M.E. Interaction between eight-month-old children and their fathers and mothers. In M.E. Lamb (Ed.), The role of the father in child development. New York: Wiley, 1976. (a)

Lamb, M.E. The role of the father: An overview. In M.E. Lamb (Ed.), The role of the father in child development. New York: Wiley, 1976. (b)

Landy, F., Rosenber, B.G., \& Sutton-Smith, B. The effect of limited father-absence on cognitive development. Child Development; 1969, $40,941-944$.

Lee-Teng, E. Trance-susceptibility, induction-susceptibility, and acquiescence as factors in hypnotic performance. Journal of Abnormal Psychology, 1965, 70, 383-389.

Lehman, H.C., \& Witty, P.A. The psychology of play activities. New York: Barnes, 1927.

Lessing, E.E., Zagorin, S.S., \& Nelson, D. WISC subtest and IQ score correlates of father absence. Journal of Genetic Psychology, 1970, $67,181-195$.

Lewis, M., \& Weinraub, M. Sex of parent $x$ sex of child: Socio-emotional development. In R. Richart, R. Friedman, and R. Vande Wiele (Eds.), Sex differences in behavior. New York: Wiley, 1974.

Lewis, M., Weinraub, M., \& Ban, P. Mothers and fathers, gixls and boys: Attachment behavior in the first two years of life. Educational Testing Service Research Bulletin, Princeton, N.J., 1972.

Long, B.H., Henderson, E.H. \& Ziller, R.C. Self-social sorrelates of originality in children. Journal of Genetic Psychology, 1967, 111, 47-54.

Lorr, M., \& Jenkins, R.L. Three factors in parent behavior. Journal of Consulting Psychology, 1953, 17, 306-308.

Lynn, D.B. The father: His role in child development. Monterey, Calif.: Brooks/Cole, 1974.

McClelland, D.C. The achieving society. Princeton: Van Nostrand, 1961.

Maccoby, E.E., and Masters, J.C. Attachment and dependency. In P.H. Mussen (Ed.), Carmichael's manual of child psychology, Vol. 2. (3rd ed.). New York: Wiley, 1970.

Mackinnon, D.W. The nature and nurture of creative talent. American Psychologist, 1962, 17, 484-495.

Margolies, P.J., \& Weintraub, S. The revised 56-item CR-PBI as a research instrument: Reliability and factor structure. Journal of Clinical Psychology, 1977, 33, 472-476. 
Markey, F.V. Imaginative behavior in preschool children. New York: Columbia University, 1935.

Meltzer, H. Children's attitudes to parents. American Journal of Orthopsychiatry, 1935, $\underline{5}, 244-265$.

Meltzoff, J., Singer, J.L., and Korchin, S.J. Motor inhibition and Rorschach movement responses: A test of sensori-tonic theory. Journal of Personality, 1953, 21, 400-410.

Meskin, B., and Singer, J.L. Reflective thought and laterality of eye movements. Journal of Personality and Social Psychology, $1974,30,64-71$.

Mishler, E.G., and Waxler, N.E. Interaction in families. New York: Wiley, 1968.

Moulton, R.w., Burnstein, E., Liberty, P.G., and Altucher, N. Patterning of parental affection and disciplinary dominance as a determinant of guilt and sex typing. Journal of Personality and Social Psychology, 1966, $\underline{4}, 356-363$.

Mower, O.H. Learning theory and personality dynamics. New York: Ronald Press, 1950.

Mussen, P.H. Some antecedents and consequences of masculine sex-typing in adolescent boys. Psychological Monographs, 1961, 75, No. 2 .

Mussen, P.H., \& Distler, L. Masculinity, identification, and father-son relationships. Journal of Abnormal and Social Psychology, 1959, 59, 350-356.

Mussen, P.H., Young, H.B., Gaddini, R., and Morante, L. The influence of father-son relationships on adolescent personality and attitudes. Journal of Child Psychology and Psychiatry, 1963, 4, 3-16.

Mutimer, D., Loughlin, L., and Powell, M. Some differences in the family relationships of achieving and under-achieving readers. Journal of Genetic. Psychology, 1966, 109; 67-74.

Newson, J., and Newson, E. Patterns of infant care in an urban community. London: Pelican, 1965.

Newson, J., and Newson, E. Four years old in an urban community. London: Allen \& Unwin, 1968.

Nie, N.H., Hull, C.H., Jenkins, J.G., Steinbrenner, K., and Bent, D.H. Statistical package for the social sciences (2nd ed.). New York: MCGraw-Hill, 1975. 
Norman, C.D. The interpersonal values of parents of achieving and nonachieving gifted children. Journal of Psychology, 1966, 64, 49-57.

Parke, R.D., and O'Leary, S. Father-mother-infant interaction in the newborn period: Some findings, some observations, and some unresolved issues. In K.F. Riegel and J. Meachum (Eds.), The developing individual in a changing world, Vol. 2. The Hague: Moulton, 1976.

Parke, R.D., and O'Leary, S.E., and West, S. Mother-father-newborn interactions: Effects of maternal medication, labor and sex of infant. Proceedings of the American Psychological Association, $1972,85-86$.

Parke, R.D., and Sawin, D.B. The father's role in infancy: A re-evaluation. Family Coordinator, 1976, 25, 365-371.

Parsons, T. Social structure and the development of personality: Freud's contribution to the integration of psychology and sociology. Psychiatry, 1958, 21, 321-340.

Parsons, T., \& Bales, R.F. Family, socialization and interaction process. New York: Free Press, 1955.

Pederson, F.A., and Robson, K.S. Father participation in infancy. American Journal of Orthopsychiatry, 1969, 39, 466-472.

Piaget, J. Play, dreams, and imitation in childhood. 1945 New York: Norton, 1962 .

Piety, K.R. Patterns of parent perceptions among neuropsychiatric patients and normal controls. Journal of Clinical Psychology, 1967, $23,428-433$.

Pitcher, E.G., and Prelinger, F. Children tell stories: An analysis of fantasy. New York: International Universities, 1963.

Radin, N. Father-child interaction and the intellectual functioning of four-year old boys. Developmental Psychology, 1972, 6, 353-361.

Radin, N. Observed paternal behaviors as antecedents of intellectual functioning in young boys. Developmental Psychology, 1973, 8, 369-376.

Radin, N. Observed maternal behavior with four-year old boys and girls in lower-class families. Child Development, 1974, 45, 1126-1131.

Radin, N. The role of the father in cognitive, academic, and intellectual development. In M.E. Lamb (Ed.), The role of the father in child development. New York: Wiley, 1976. 
Radin, N., and Epstein, A.S. Observed paternal behavior and the intellectual functioning of preschool boys and girls: Paper presented to the Society for Research in Child Development, 1975. (a)

Radin, N., and Epstein, A.S. Observed paternal behavior with preschool children: Final report. Ann. Arbor: University of Michigan, School of Social Work, 1975. (b)

Rebelsky, F., and Hanks, C. Fathers' verbal interaction with infants in the first three months of life. Child Development, 1971, 42, 63-68.

Renson, G.H., Schaefer, E.S., and Levy, B.I. Cross-national validity of a spherical conceptual model of parent behavior. Child Development. $1968,39,1229-1235$.

Roe, A. Early determinants of vocational choice. Journal of Counseling Psychology, 1963, 4, 212-217.

Roe, A., and Siegelman, M.A. Parent-child relations questionnaire. Child Development, 1963, 34, 355-369.

Rorschach, H. Psychodiagnostics: A diagnostic test based on perception. Berne: Huber, 1942 .

Ross, G., Kagan, J., Zelazo, P., and Kotelchuck, M. Separation protest in infants in home and laboratory. Developmental Psychology, 1975, 11, 256-257.

Sanford, R.N., Adkins, M.M., Miller, R.B., and Cobb, E. Physique, personality, and scholarship. Monographs of the Society for Research in Child Development, 1943, 8, No. 1 .

Santrock, J.W. Relation of type and onset of father-absence to cognitive development. Child Development, 1972, 43, 455-469.

Sarason, S.B. Dreams and Thematic Apperception Test stories. Journal of Abnormal and Social Psychology, 1944, 39, 486-492.

Sarbin, T.R., and Coe, W.C. Hypnosis: A social psychological analysis of influence communication. New York: Holt, Rinehart \& Winston, 1972 .

Sarbin, T.R., and Juhasz, J.B. Toward a theory of imagination. Journal of Personality, 1970, 38, 52-76.

Schaefer, E.S. Converging conceptual models for maternal behavior and for child behavior. In J.C. Glidewell (Ed.), Parental attitudes and child behavior. Springfield, Ill.: Thomas, 1961 .

Schaefer, E.S. A configurational analysis of children's reports of parent behavior. Journal of Consulting Psychology, 1965, 29, 552-557. (a) 
Schaefer, E.S. Children's reports of parental behavior: An inventory. Child Development, 1965, 36, 413-424. (b)

Schaefer, E.S., and Bayley, N. Validity and consistency of motherinfant observations, adolescent maternal interviews, and adult retrospective reports of maternal behavior. Proceedings of the 75 th Annual Convention of the American Psychological Association, $1967,2,147-148$.

Schaefer, E.S., Bell, R.Q., and Bayley, N. Development of a maternal behavior research instrument. Journal of Genetic Psychology, 1959, 95, 83-104.

Schaffer, H.R., and Emerson, P.E. The development of social attachments in infancy. Monographs of the Society for Research in Child Development, 1964, 29, No. 94 .

Schludermann, E., and Schludermann, S. Replicability of factors in Children's Report of Parent Behavior (CR-PBI). Journal of Psychology, 1970, 76, 239-249.

Schludermann, S., \& Schludermann, E. Adolescent perception of parent behavior (CR-PBI) in Hutterite communal society. Journal of Psychology, 1971, 79, 29-39.

Schutz, A. On multiple realities. In M. Natanson (Ed.), Collected papers. I: The problem of social reality. The Hague: Martinus Nijhoff, 1967.

Sears, R.R. Identification as a form of behavior development. In D.B. Harris (Ed.), The concept of development. Minneapolis: University of Minnesota Press, 1957.

Sears, R.R. Relation of early socialization experiences to self-concepts and gender role in middle childhood. Child Development, 1970, 41, 267-289.

Sears, R.R., Maccoby, E.E., and Levin, H. Patterns of child rearing. Evanston, Ill.: Row Peterson, 1957.

Sears, R.R., Whiting, J.W.M., Nowlis, V., and Sears, P.S. Some childrearing antecedents of aggression and dependency in young children. Genetic Psychology Monographs, 1953, 47, 135-236.

Seder, J.A. The origin of differences in extent of independence in children: Developmental factors in perceptual field dependence. Unpublished bachelor's thesis, Radcliffe College, 1957.

Segal, B., and Singer, J.L. Daydream patterns, personality traits, and drug usage in college freshman. Manuscript in preparation, 1974. 
Segal, S.J. The Perky effect: Changes in reality judgments with changing methods of inquiry. Psychonomic Science, 1968, 12, 393-394.

Segal, S.J. Imagery and reality: Can they be distinguished? In W. Keup (Ed.), Origin and mechanisms of hallucinations. New York: Plenum, 1970.

Segal, S.J. (Ed.) The adaptive functions of imagery. New York: Academic Press, 1971.

Segal, S.J., and Fusella, V. Effects of imaging on signal-to-noise ratio, with varying signal conditions. British Journal of Psychology, 1969, 60, 459-464.

Segal, S.J., and Glicksman, M. Relaxation and the Perky effect: The influence of body position on judgements of imagery. American Journal of Psychology, 1967, 80, 257-262.

Segal, S.J., and Gordon, P.E. The Perky effect revisited: Blocking of visual signals by imagery. Perceptual and Motor Skills, 1969, 28, 791-797.

Segal, S.J., and Nathan, S. The Perky effect: Incorporation of an external stimulus into an imagery experience under placebo and control conditions. Perceptual and Motor Skills, 1964, 18, 385-395.

Shatin, I. Rorschach adjustment and the Thematic Apperception Test. Journal of Projective Techniques, 1953, 17, 92-101.

Shor, R.E. Hypnosis and the concept of the generalized realityorientation. American Journal of Psychotherapy, 1959, 13, 582-602.

Shor, R.E. Three dimensions of hypnotic depth. International Journal of Clinical and Experimental Hypnosis, $1962,10,23-38$.

Shor, R.E. The three factor theory of hypnosis as applied to the book reading fantasy and to the concept of suggestion. International Journal of Clinical and Experimental Hypnosis, 1970, 18, 89-98.

Shor, R.E., Orne, M.T., and O'Connell, D.N. Validation and crossvalidation of the scale of self-reported personal experiences which predicts hypnotizability. Journal of Psychology, 1962, 53, 55-75.

Siegelman, M. Evaluation of Bronfenbrenner's questionnaire for children concerning parent behavior. Child Development, 1965, 36, 163-174.

Singer, J.I. The experience type: Some behavioral correlates and theoretical implications. In M.A. Rickers-Ovsiankina (Ed.), Rorschach psychology. New York: Wiley, 1960. 
Singer, J.L. Imagination and waiting ability in young children. Journal of Personality, 1961, 29, 396-413.

Singer, J.L. Daydreaming. New York: Random House, 1966.

Singer, J.L. The inner world of daydreaming. New York: Harper \& Row, 1975.

Singer, J.L. Experimental studies of daydreaming and the stream of thought. In K.S. Pope and J.L. Singer (Eds.), The stream of consciousness. New York: Plenum Press, 1978.

Singer, J.L., and Antrobus, J.S. A factor-analytic study of day-dreaming and conceptually related cognitive and personality variables. Perceptual and Motor Skills, 1963, 17, 187-209.

Singer, J.I., and Antrobus, J. Visual signal detection as a function of simultaneous speech. Journal of Experimental Psychology, 1964, 68, 603-610.

Singer, J.L., and Antrobus, J.S. Signal performance by subjects differing in predisposition to daydreaming. Journal of Consulting Psychology, 1967, 31, 498-491.

Singer, J.L., and Antrobus, J.S. Dimensions of daydreaming: A factor analysis of imaginal processes and personality scales. NIMH Progress Report, 1970. (Mimeo)

Singer, J.L., and Antrobus, J.S. Daydreaming, imaginal processes, and personality: A normative study. In P.W. Sheehan (Ed.), The function and nature of imagery, New York, Academic Press, 1972.

Singer, J.L., and Herman, J. Motor and fantasy correlates of Rorschach human movement responses. Journal of Consulting Psychology, 1954, 18, $325-331$.

Singer, J.L., and McCraven, V. Patterns of daydreaming in American subcultural groups. International Journal of Social Psychiatry, 1962, 8, 272-282.

Singer, J.L., Meltzoff, J., and Goldman, G.D. Rorschach movement responses following motor inhibition and hyperactivity. Journal of Consulting Psychology, 1952, 16, 359-364.

Singer, J.L., and Opler, M.K. Contrasting patterns of fantasy and motility in Irish and Italian schizophrenics. Journal of Abnormal and Social Psychology, 1956, 53, 42-47.

Singer, J.L., and Sugarman, D. Some Thematic Apperception Test correlates of Rorschach Human Movement Responses. Journal of Consulting Psychology, 1955, 19, 117-119. 
Slater, P. Paternal behavior and the personality of the child. Journal of Genetic Psychology, 1962, 101, 53-68.

Smith, T.L. The psychology of daydreams. American Journal of Psychology, 1904, 15, 465-488.

Solomon, D. The generality of children's achievement-related behavior. Journal of Genetic Psychology, 1969, 114, 109-125.

Spanos, N.P. Hypnosis: A sociological and phenomenological perspective. Unpublished doctoral dissertation, Boston University, 1973.

Spanos, N.P., and McPeake, J.D. Involvement in everyday imaginative activities, attitudes toward hypnosis, and hypnotic suggestibility. Journal of Personality and Social Psychology, 1975, 31, 594-598. (a)

Spanos, N.P., and McPeake, J.D. The interaction of attitudes toward hypnosis and involvement in everyday imaginative activities on hypnotic suggestibility. American Journal of Clinical Hypnosis, $1975, \underline{17}, 247-252$. (b)

Spelke, E., Zelazo, P., Kagan, J., and Kotelchuck, M. Father interaction and separation protest. Developmental Psychology, 1973, 9, 83-90.

Starker, S. Daydreaming styles and nocturnal dreaming. Journal of Abnormal Psychology, 1974, 83, 52-55.

Starker, S. Dreams and waking fantasy. In K.S. Pope and J.L. Singer (Eds.), The stream of consciousness. New York: Plenum Press, 1978.

Stolz, L.M., et al. Father relations of war-born children. Stanford: Stanford University Press, 1954.

Symonds, P.S. The psychology of parent-child relationships. New York: Appleton-century, 1939.

Teahan, J.E. Parental attitudes and college success. Journal of Educational Psychology, 1963, 54, 104-109.

Tellegen, A., and Atkinson, G. Openness to absorbing and self-altering experiences ("absorption"), a trait related to hypnotic susceptibility. Journal of Abnormal Psychology, 1974, 83, 268-277.

Thurstone, L.L. Multiple factor analysis. Chicago: University of Chicago Press, 1947 .

Velicer, W.F. Determining the number of components from the matrix of partial correlations. Psychometrika, 1976, 41, 321-327.

Veroff, J., Atkinson, J., Field, S., and Gurin, G. The use of thematic apperception to assess motivation in a nationwide interview study. Psychological Monographs, 1960, 74, No. 499. 
Weisberg, P.S., and Springer, K.J. Environment factors in creative function: A study of gifted children. Archives of General Psychiatry, 1961, $\underline{5}, 554-564$.

Weisskopf, E.A. A transcendence index as proposed measure in the Thematic Apperception Test. Journal of Psychology, 1950, 29, $379-390$.

Werner, H. Motion and motion perception: A study on vicarious perception. Journal of Psychology, 1945, 19, 317-327.

Werts, C.E. Social class and initial career choice of college freshman. Sociology of Education, 1966, 39, 74-85.

Winnicott, D.W. The maturational process and the facilitating environment. London: Hogarth, 1965.

Witkin, H.A. The problem of individuality in development. In B. Kaplan and S. Wapner (Eds.), Perspectives in psychological theory. New York: International Universities Press, 1960.

Yarrow, M.R. The measurement of children's attitudes and values. In P.H. Mussen (Ed.), Handbook of research methods in child development. New York: Wiley, 1960. 